LEANDRO MARINO TAKAZONO ORBOLATO

\title{
ANÁLISE DO COMPORTAMENTO SISMICO DAS PARTES INTERNAS DE UM EQUIPAMENTO DE PROTEÇÃO AMBIENTAL
}

\author{
Dissertação a ser apresentado na Escola \\ Politécnica da Universidade de São Paulo para \\ obtenção do título de Mestre em Engenharia.
}




\section{ANÁLISE DO COMPORTAMENTO SISMICO DAS PARTES INTERNAS DE UM EQUIPAMENTO DE PROTEÇÃO AMBIENTAL}

Dissertação a ser apresentado na Escola Politécnica da Universidade de São Paulo para obtenção do título de Mestre em Engenharia.

Área de concentração:

Engenharia de Estruturas

Orientador:

Prof. Dr. Reyolando Manoel Lopes

Rebello da Fonseca Brasil

São Paulo

2012 
Este exemplar foi revisado e alterado em relação à versão original, sob responsabilidade única do autor $\mathrm{e}$ com a anuência de seu orientador.

São Paulo, 03 de dezembro de 2012.

Assinatura do autor

Assinatura do orientador

\section{FICHA CATALOGRÁFICA}

Orbolato, Leandro Marino Takazono

Análise do comportamento sísmico das partes internas de um equipamento de proteção ambiental / L.M.T. Orbolato. -ed.rev. -- São Paulo, 2012.

p.

Dissertação (Mestrado) - Escola Politécnica da Universidade de São Paulo. Departamento de Engenharia de Estruturas e Geotécnica.

1.Sistemas não lineares I.Universidade de São Paulo.

Escola Politécnica. Departamento de Engenharia de Estruturas e Geotécnica Il.t. 


\section{AGRADECIMENTOS}

Ao professor Reyolando pela orientação e pelo constante estímulo durante todo o trabalho.

A meus pais e a minha irmã pelo suporte e incentivo durante os meus estudos.

A minha namorada Ana Claudia pela paciência, apoio e carinho nos momentos difíceis.

Ao amigo João Arthur pelos comentários valiosos, e a todos que colaboraram direta ou indiretamente na execução deste trabalho. 


\section{RESUMO}

Neste trabalho o comportamento sísmico das partes internas de um equipamento de proteção ambiental é estudado. O equipamento, um precipitador eletrostático, é composto basicamente de uma grande caixa de metal elevada, que contem eletrodos positivos e negativos responsáveis pela coleta de material particulado no fluxo de gases industriais. Esses componentes se comportam como pêndulos. No modelo foram considerados os deslocamentos sísmicos horizontais em duas direções ortogonais. De especial interesse está o fato de os eletrodos terem a liberdade de oscilar no plano de uma direção, mas não no seu plano perpendicular. Serão analisados quatro modelos com um, dois, três graus de liberdade, e um com três graus de liberdade linearizado. $O$ modelo mais completo considera como graus de liberdade e coordenadas generalizadas os dois deslocamentos horizontais, e o deslocamento angular do pendulo. Foi adotada a formulação Lagrangeana para derivar as equações de movimento do modelo. As equações diferenciais do movimento de segunda ordem obtidas apresentam um comportamento não linear. Os movimentos sísmicos, que são estocásticos por natureza, serão simulados por meio de um registro sísmico existente, arbitrariamente escolhido.

A obtenção dos parâmetros do modelo a ser estudado é de especial interesse para a melhor previsão do comportamento do equipamento quando solicitado a esforços sísmicos.

A integração numérica do modelo matemático é efetuada, sendo posteriormente realizados comparativos entre as respostas dos modelos, quando submetidos tanto a vibração livre, como a um sismo real já registrado, arbitrário. 


\section{ABSTRACT}

In this work, the seismic behavior of the internal parts of an environmental control equipment is studied. The equipment, an electrostatic precipitator, is basic composed of an elevated large steel box, containing positive and negative electrodes that capture powdered material of industrial effluent gases. These internal components behave essentially as pendula. In the mathematical model seismic motions in two orthogonal directions are considered. It is interesting to realize that the pendular electrodes are free to swing in one plane but not in the other plane. Four increasingly complex nonlinear models are analyzed, with one, two and three degrees of freedom, as well as one 3-degree-of-freedom linearized model. The generalized coordinates of the most complete model are the two horizontal displacements of the top mass and the angular motion of the pendulum. Lagrange's formulation is used to derive the equations of motion of the models. These are second order nonlinear ordinary differential equations. The base seismic motions, that are stochastic in nature, are replaced by a arbitrarily chosen existing seismic record.

The models parameters are carefully chosen to a good prediction of the equipment under seismic support excitation.

Numerical integration of the mathematical model is performed, and comparisons are made of the several models response submitted to free vibrations and to an existing seismic record.

Keywords: Dynamics (analysis). Earthquakes. Structures (analysis). Steel Structures. 


\section{SUMÁRIO}

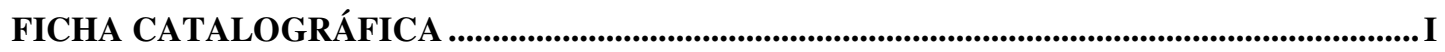

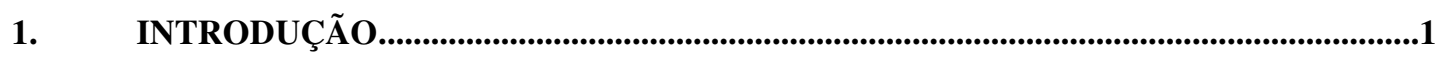

2. O PROBLEMA DE ENGENHARIA ..........................................................................2

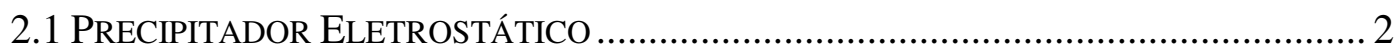

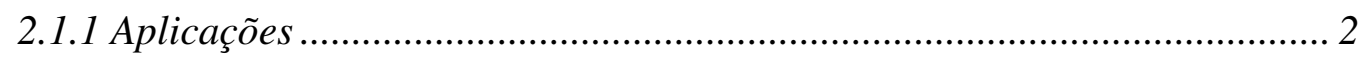

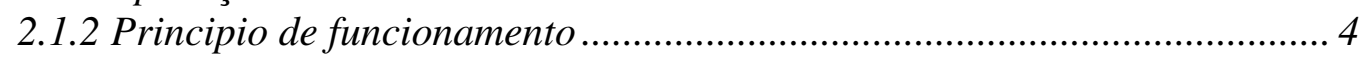

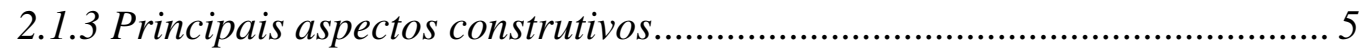

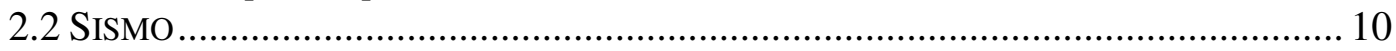

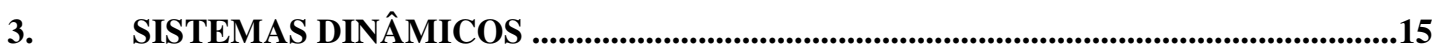

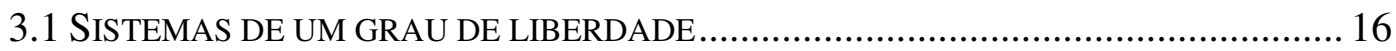

3.1.1 Excitação de suporte - Um grau de liberdade .......................................... 17

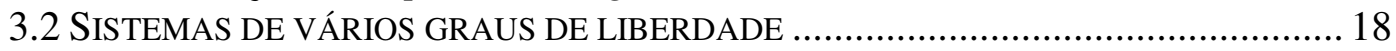

3.2.1 Excitação de suporte - Vários graus de liberdade ................................ 19

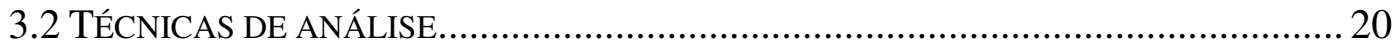

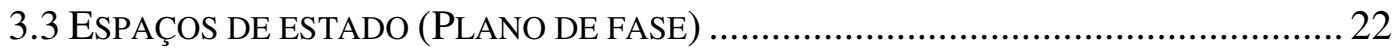

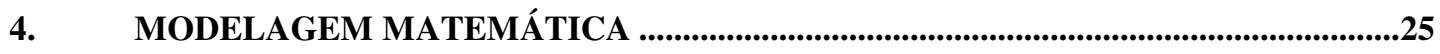

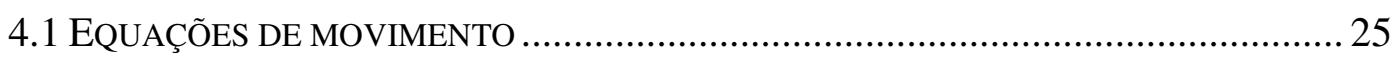

4.1.1 Sistema de 1 grau de liberdade ............................................................... 26

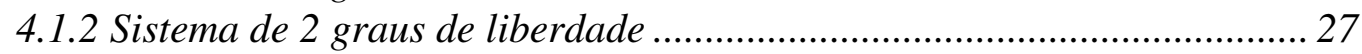

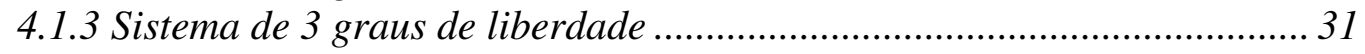

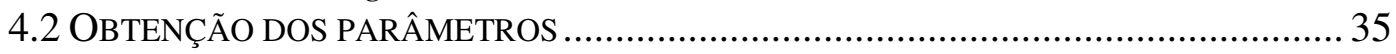

5. RESPOSTA DOS SISTEMAS A ENTRADAS INICIAIS NÃO NULAS ...........................38

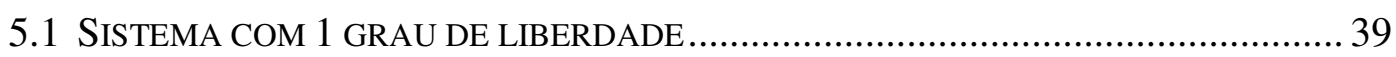

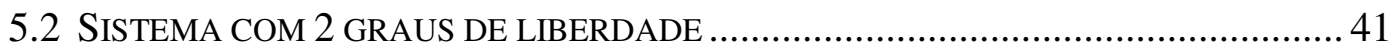

5.3 SISTEMA COM 3 GRAUS DE LIBERDADE................................................... 45

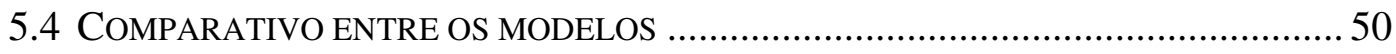

6. RESPOSTAS DOS SISTEMAS A UM TERREMOTO REAL .......................................52

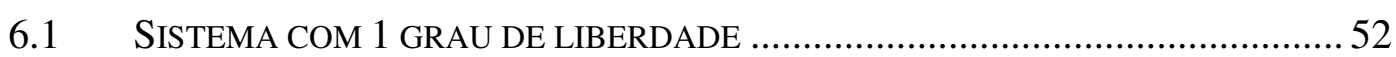

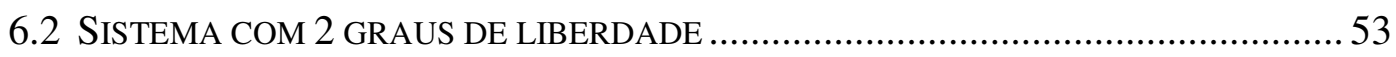

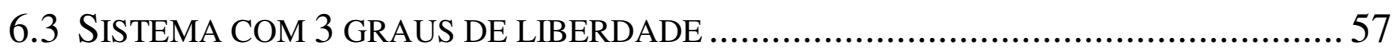

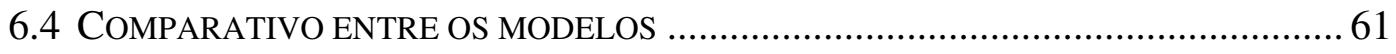

7. COMPARATIVO DOS SISTEMAS DE TRÊS GRAUS DE LIBERDADE NÃO

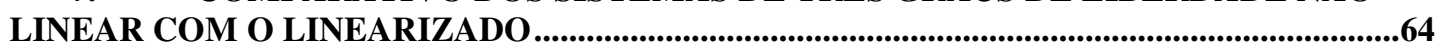

8. VERIFICAÇÃO DO ESTADO LIMITE DE SERVIÇO DO PRECIPITADOR..............67

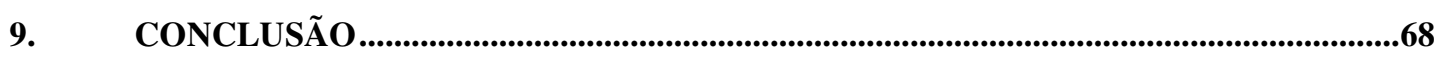

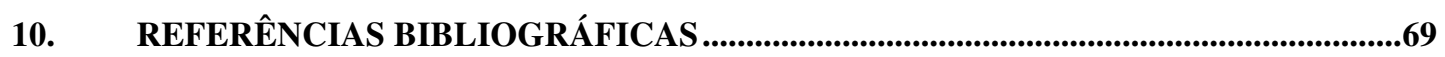




\section{ÍNDICE DE FIGURAS}

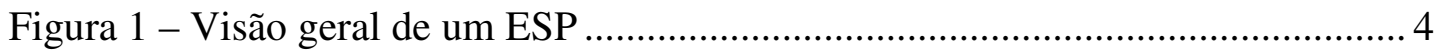

Figura 2 - Principio de coleta de partículas em um ESP .......................................... 5

Figura 3 - Arranjo geral de um Precipitador Eletrostático. ...................................... 5

Figura 4 - Placas perfuradas no duto de entrada - ESP .............................................. 6

Figura 5 - Exemplo de carcaça de um precipitador eletrostático ................................ 7

Figura 6 - Rótula esférica entre a estrutura de suporte do ESP e da sua carcaça........ 7

Figura 7- Exemplo de uma tremonha piramidal....................................................... 8

Figura 8 - Vários tipos de eletrodos do sistema de emissão................................... 8

Figura 9 - Quadro rígido do sistema de emissão ...................................................... 9

Figura 10 - Sistema de emissão (amarelo) e Sistema de coleta (Azul). ...................... 9

Figura 11 - Sistema de batimento das placas coletoras de um ESP ......................... 10

Figura 12 - Continuidade entre a costa leste da America do sul com a costa oeste da

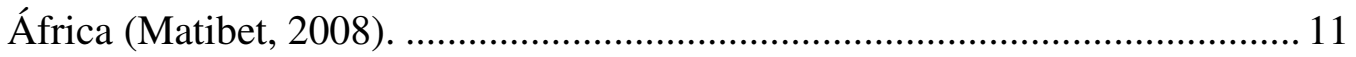

Figura 13 - Placas tectônicas (Hyndman, 2009).................................................... 11

Figura 14 - Teoria da recuperação elástica (Datta, 2010). ...................................... 12

Figura 15 - Propagação de ondas na superfície terrestre devido a efeitos de sismo

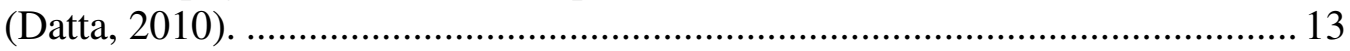

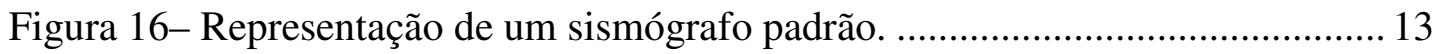

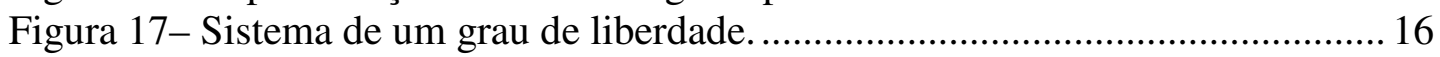

Figura 18- Sistema de um grau de liberdade - Excitação de suporte........................ 17

Figura 19- Plano de fase................................................................................. 24

Figura 20 - Modelo com 1 grau de liberdade ....................................................... 26

Figura 21 - Sistema com 2 graus de liberdade .................................................... 27

Figura 22- Sistema com 2 graus de liberdade - Plano xz ...................................... 28

Figura 23 - Sistema com 3 graus de liberdade .................................................. 31

Figura 24 - Vistas laterais do sistema com 3 graus de liberdade................................ 33

Figura 25 - Modelo tridimensional de um ESP ..................................................... 36 


\section{ÍNDICE DE GRÁFICOS}

Gráfico 1- Componente norte-sul horizontal do movimento de aceleração do solo, sismo El Centro, Califórnia, maio de 1940 (Chopra, 1980). ............................. 14

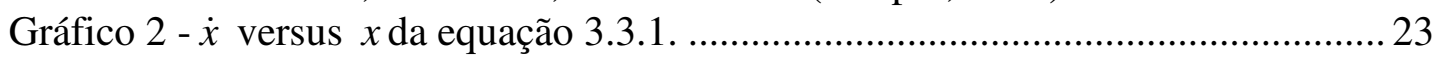

Gráfico 3 - Solução qualitativa da equação 3.3.1................................................... 24

Gráfico 4 - Deslocamento de $\mathrm{q}_{3}$ em função do tempo - sistema com 1 grau de

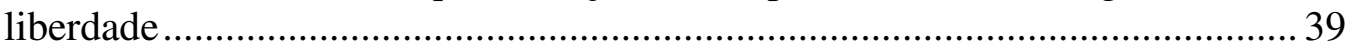

Gráfico 5- Velocidade de $\mathrm{q}_{3}$ em função do tempo - sistema com 1 grau de liberdade

Gráfico 6- Velocidade angular $q_{3}$ em função da sua posição - sistema com 1 grau de liberdade

Gráfico 7 - Posição de $q_{1}$ em função do tempo - sistema com 2 graus de liberdade 41

Gráfico 8 - Velocidade de $\mathrm{q}_{1}$ em função do tempo - sistema com 2 graus de liberdade

Gráfico 9 - Ângulo de $\mathrm{q}_{3}$ em função do tempo - sistema com 2 graus de liberdade 42

Gráfico 10 - Velocidade angular de $\mathrm{q}_{3}$ em função do tempo - sistema com 2 graus de liberdade

Gráfico 11 - Velocidade de q1 em função da posição de $\mathrm{q}_{1}$ - sistema com 2 graus de liberdade

Gráfico 12 - velocidade de $\mathrm{q}_{3}$ em função da sua posição- sistema com 2 graus de liberdade

Gráfico 13 - Posição de $\mathrm{q}_{1}$ em função do tempo - sistema com 3 graus de liberdade

Gráfico 14 - velocidade de $\mathrm{q}_{1}$ em função do tempo - sistema com 3 graus de liberdade

Gráfico 15 - posição de $\mathrm{q}_{2}$ em função do tempo - sistema com 3 graus de liberdade

Gráfico 16 - velocidade de $\mathrm{q}_{2}$ em função do tempo - sistema com 3 graus de liberdade

Gráfico 17 - ângulo de $\mathrm{q}_{3}$ em função do tempo - sistema com 3 graus de liberdade 47

Gráfico 18 - velocidade de $\mathrm{q}_{3}$ em função do tempo - sistema com 3 graus de liberdade

Gráfico 19 - velocidade de $\mathrm{q}_{1}$ em função de sua posição - sistema com 3 graus de liberdade

Gráfico 20 - plano de fase de $\mathrm{q}_{2}$ - sistema com 3 graus de liberdade ...................... 49

Gráfico 21 - plano de fase de $\mathrm{q}_{3}$ - sistema com 3 graus de liberdade ........................ 49

Gráfico 22 - comparativo de $\mathrm{q}_{3}$ para 1,2 e 3 graus de liberdade ..............................50

Gráfico 23 - comparativo de $\mathrm{q}_{1}$ para 2 e 3 graus de liberdade - entradas iniciais..... 50

Gráfico 24 - comparativo do plano de fase de $\mathrm{q}_{3}$ para 1, 2 e 3 graus de liberdade entradas iniciais

Gráfico 25 - comparativo do plano de fase de $\mathrm{q}_{1}$ para 2 e 3 graus de liberdade -

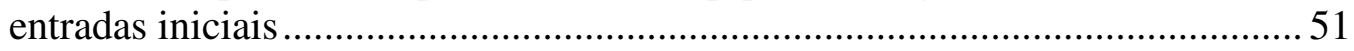

Gráfico 26 - ângulo de $\mathrm{q}_{3}$ em função do tempo - sistema com 1 grau de liberdade entrada sísmica.

Gráfico 27 - plano de fase de $\mathrm{q}_{3}$ - sistema com 1 grau de liberdade - entrada sismica 
Gráfico 28 - posição de $\mathrm{q}_{1}$ em função do tempo - sistema com 2 graus de liberdade entrada sísmica.

Gráfico 29 - velocidade de $\mathrm{q}_{1}$ em função do tempo - sistema com 1 grau de liberdade - entrada sísmica....

Gráfico 30 - ângulo de $\mathrm{q}_{3}$ em função do tempo - sistema com 2 graus de liberdade entrada sísmica.

Gráfico 31 - velocidade angular de $\mathrm{q}_{3}$ em função do tempo - sistema com 2 graus de

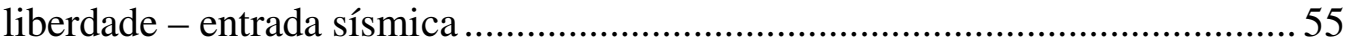

Gráfico 32 - plano de fase de $\mathrm{q}_{1}$ - sistema com 2 graus de liberdade - entrada sísmica.

Gráfico 33 - plano de fase de $\mathrm{q}_{3}$ - sistema com 2 graus de liberdade - entrada sísmica.

Gráfico 34 - posição de $\mathrm{q}_{1}$ em função do tempo - sistema com 3 graus de liberdade entrada sísmica.

Gráfico 35 - velocidade de $\mathrm{q}_{1}$ em função do tempo - sistema com 3 graus de liberdade - entrada sismica .....

Gráfico 36 - posição de $\mathrm{q}_{2}$ em função do tempo - sistema com 3 graus de liberdade entrada sísmica

Gráfico 37 - velocidade de $\mathrm{q}_{2}$ em função do tempo - sistema com 3 graus de liberdade - entrada sísmica

Gráfico 38 - ângulo de $\mathrm{q}_{3}$ em função do tempo - sistema com 3 graus de liberdade entrada sísmica.

Gráfico 39 - velocidade angular de $\mathrm{q}_{3}$ em função do tempo - sistema com 3 graus de liberdade - entrada sísmica

Gráfico 40 - plano de fase de $\mathrm{q}_{1}$ - sistema com 3 graus de liberdade - entrada sísmica.

Gráfico 41 - plano de fase de $\mathrm{q}_{2}$ - sistema com 3 graus de liberdade - entrada sísmica

Gráfico 42 - plano de fase de $\mathrm{q}_{3}$ - sistema com 3 graus de liberdade - entrada sísmica

Gráfico 43 - comparativo de $\mathrm{q}_{3}$ sistemas com 1, 2 e 3 graus de liberdade - entrada

Gráfico 44 - comparativo de q1 - sistemas com 2 e 3 graus de liberdade - entrada

Gráfico 45 - comparativo do plano de fase de $\mathrm{q}_{3}$ - sistemas com 1,2 e 3 graus de liberdade - entrada sismica. liberdade - entrada sismica

Gráfico 47 - comparativo de $\mathrm{q}_{1}$ - modelo com 3 graus de liberdade - não linear e linear.

Gráfico 48- comparativo de $\mathrm{q}_{2}$ - modelo com 3 graus de liberdade - não linear e linear.

Gráfico 49- comparativo de $\mathrm{q}_{3}$ - modelos com 3 graus de liberdade - não linear e linear.

Gráfico 50 - comparativo do plano de fase de $\mathrm{q}_{3}$ - modelos com 3 graus de liberdade - não linear e linear.

Gráfico 51- comparativo do plano de fase de $\mathrm{q}_{1}$ - modelos com 3 graus de liberdade - não linear e linear. 


\section{INTRODUÇÃO}

Neste trabalho registram-se os estudos realizados sobre modelos de resposta sísmica de um equipamento de proteção ambiental.

A análise do comportamento sísmico em estruturas vem se tornando cada vez mais comum no ambiente nacional dado o grande número de empresas multinacionais presente no país que são responsáveis por projetos em toda a América Latina, região onde o cálculo do sismo se faz necessário. Vale lembrar também a recente criação da norma de sismo brasileira NBR 15421:2006, utilizada no país principalmente para estruturas especiais como barragens e usinas nucleares.

A principal motivação desse trabalho surgiu pelo fato do equipamento em questão, um precipitador eletrostático, possuir um sistema de emissão e de coleta energizados isolados, e, por estarem suspensos e próximos, o contato entre eles durante uma atividade sísmica levaria a um curto circuito catastrófico dado a tensão de mais de 10000 Volts do sistema, o que tiraria o equipamento de funcionamento e interromperia o processo produtivo. É desejável, assim, uma previsão do seu comportamento dinâmico frente a oscilações para que isso não ocorra.

Pretende-se nesse trabalho desenvolver um modelo matemático desse Precipitador Eletrostático e efetuar uma análise transiente do seu comportamento sísmico através da simulação do modelo frente a históricos de aceleração já registrados, para a verificação do seu estado limite último de serviço. 


\section{O PROBLEMA DE ENGENHARIA}

\subsection{Precipitador Eletrostático}

O Precipitador Eletrostático (ESP) é composto basicamente de uma grande caixa de metal elevada contendo eletrodos positivos e negativos suspensos, que produzem o efeito de captura de materiais em suspensão no fluxo de gases industriais. Essas partes suspensas se comportam como pêndulos e são diretamente afetadas pelos movimentos sísmicos. No modelo estudado foram considerados os deslocamentos horizontais como geralmente é feito. De especial interesse está o fato dos eletrodos serem livres para se deslocar em uma direção, mas não na sua direção perpendicular. Em um dos modelos considera-se o precipitador rígido e em outros dois ele é representado por uma barra flexível, em todos os casos com um pendulo rotulado na sua parte superior.

As não linearidades surgem da consideração de largos deslocamentos do mecanismo pendular, como comentado em Nayfeh e Mook (1979). Um estudo completo sobre o comportamento de estruturas sob o efeito sísmico pode ser encontrado em Clough e Penzien (1993).

\subsubsection{Aplicações}

Os Precipitadores Eletrostáticos são equipamentos utilizados para coletar particulado de fontes industriais. Segundo a "American Conference of Industrial Hygienists", Thomas, et al (2009), temos dois tipos principais de precipitadores, o de estágio simples de coleta "Cottrell" que opera com voltagens de 40000 a 75000 Volts (Alta Voltagem - DC), e o tipo "Penny" de dois estágios de coleta, que opera entre 11000 e 15000 Volts (Baixa Voltagem - DC).

Sua utilização é feita por vários motivos, como:

-Recuperação de material coletado do processo para uso ou venda 
-Remoção de materiais abrasivos que podem desgastar ventiladores/dutos

-Reduzir a emissão de partículas na atmosfera evitando impactos ambientais e doenças em seres humanos

Historicamente, a maior utilização de ESPs tem sido feita na remoção de partículas suspensas no ar geradas pela queima de combustíveis fósseis como carvão e óleo como podemos verificar em Porle, Kjell, et al (2007).

Também são usados em caldeiras de biomassa, além de processos na indústria de cimento, de papel e celulose, e em indústrias de aço. 


\subsubsection{Principio de funcionamento}

Os gases gerados em caldeiras, incineradores, etc, são levados ao ESP por uma rede de dutos. O ESP é composto por uma grande caixa fechada de metal que possui varias linhas de eletrodos de alta voltagem (eletrodos de emissão), e também possui eletrodos aterrados (placas coletoras). Com essa grande diferença de voltagem entre esses dois sistemas, um forte campo elétrico é criado entre os eletrodos, ionizando assim as partículas presentes no fluxo de gás, e gerando uma efeito denominado "corona" nas placas coletoras (conforme figura 1 e 2), com isso essas partículas migram para as placas coletoras, aderindo a sua superfície.

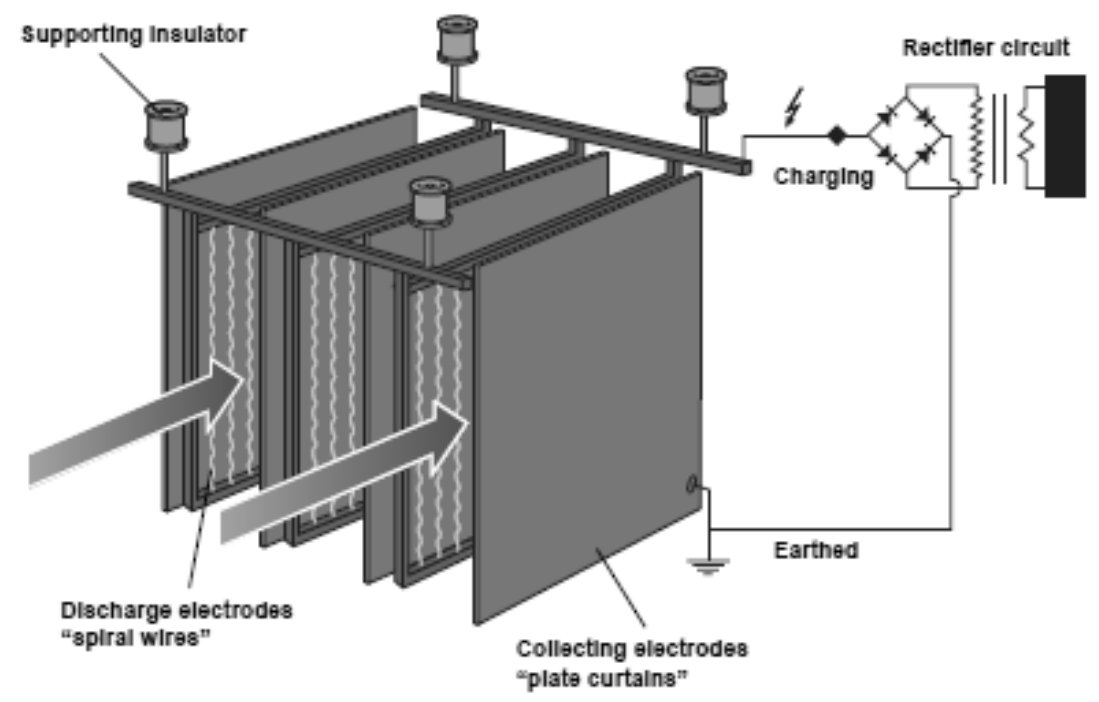

Figura 1 - Visão geral de um ESP

Com esse processo de deposição são formadas varias camadas de pó aderidas às placas coletoras, essas camadas têm de ser retiradas frequentemente para que novas partículas possam se alocar. 


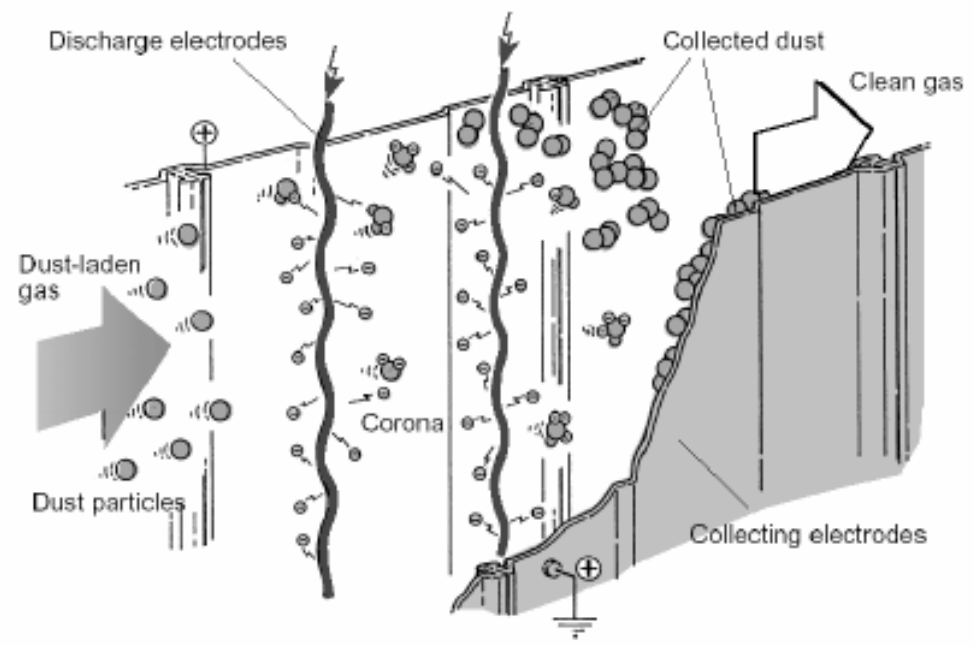

Figura 2 - Principio de coleta de partículas em um ESP

O processo de limpeza das placas coletoras é feito geralmente por martelos que limpam as placas coletoras pelo impacto, (ver tópico 2.1.3.8).

\subsubsection{Principais aspectos construtivos}

\subsubsection{Rede de dutos e arranjo geral}

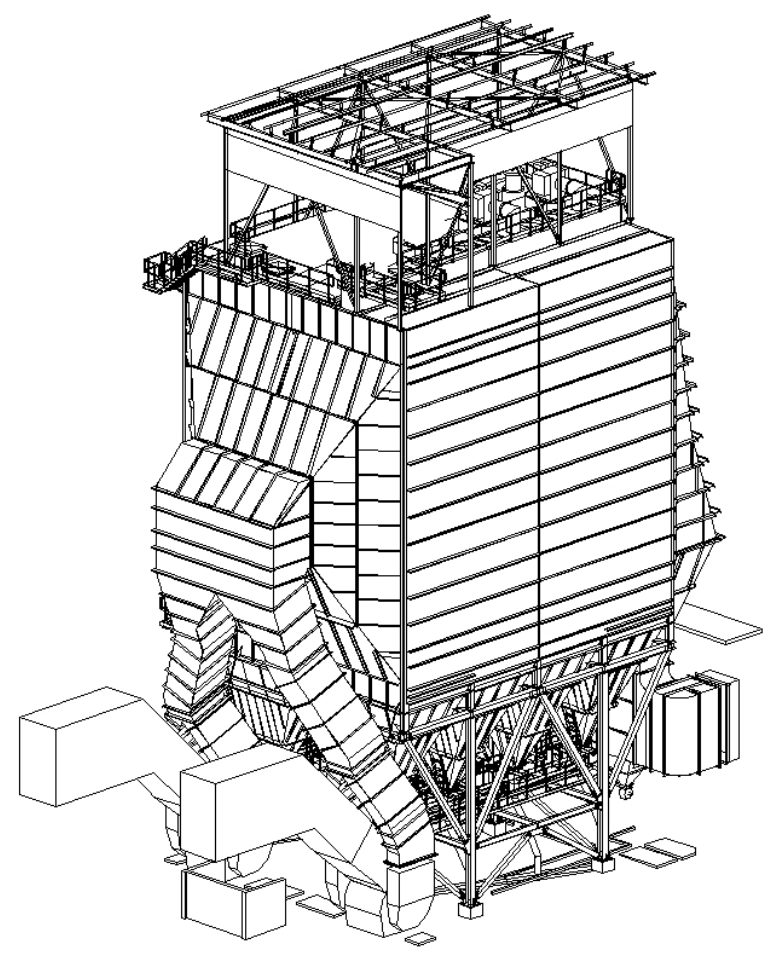

Figura 3 - Arranjo geral de um Precipitador Eletrostático. 


\subsubsection{Duto de entrada}

O duto de entrada tem como função reduzir a velocidade dos gases para 0.75 a $1.5 \mathrm{~m} / \mathrm{s}$ e melhorar a sua distribuição para se atingir uma coleta mais eficiente do particulado. Para isso temos a presença de placas perfuradas, conforme figura 4.

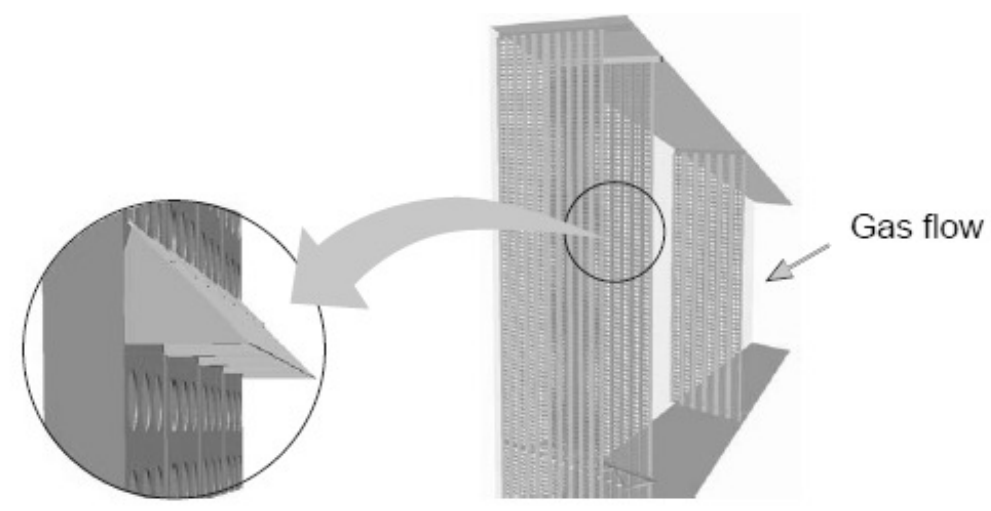

Figura 4 - Placas perfuradas no duto de entrada - ESP.

\subsubsection{Carcaça}

A carcaça do ESP é feita por painéis de aço soldados reforçados por vigas, as cargas do teto são distribuídos as paredes laterais pela viga de teto (Roof Beam).

O seu desenho é feito levando em conta as deflexões laterais e não a resistência do material como geralmente é feito em estruturas de aço, gerando uma estrutura bem rígida para permitir que os sistemas internos de emissão e coleta permaneçam alinhados durante a operação. 


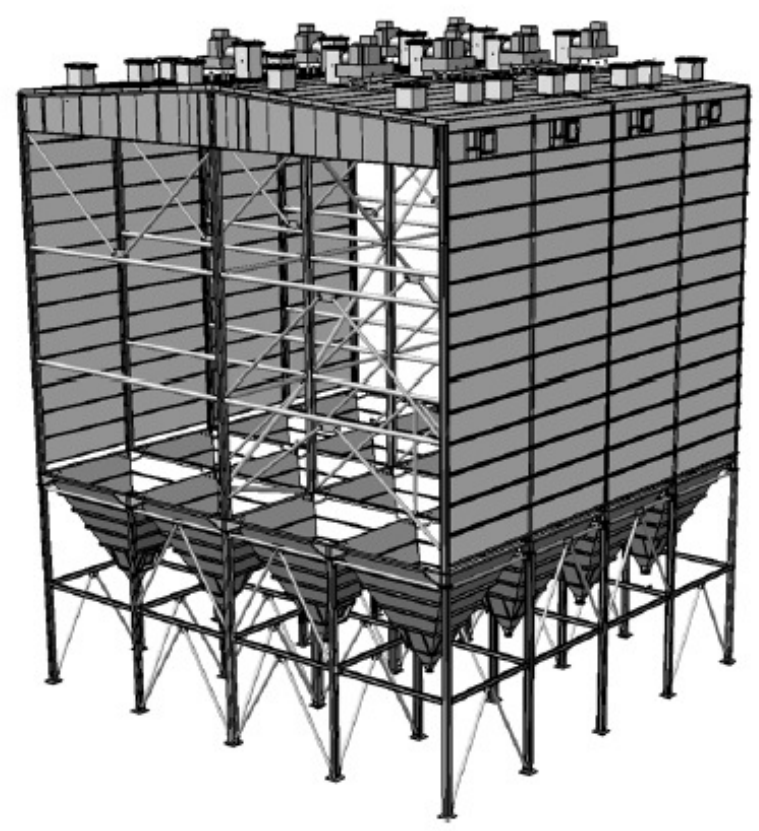

Figura 5 - Exemplo de carcaça de um precipitador eletrostático

\subsubsection{Rótulas}

As rótulas são utilizadas em ESPs que trabalham em alta temperatura (100 a 400 graus Celsius), para impedir que tensões excessivas sejam geradas devido a expansão térmica da carcaça do equipamento. Por esse motivo são adicionadas rótulas guiadas ou livres conforme figura 6 .

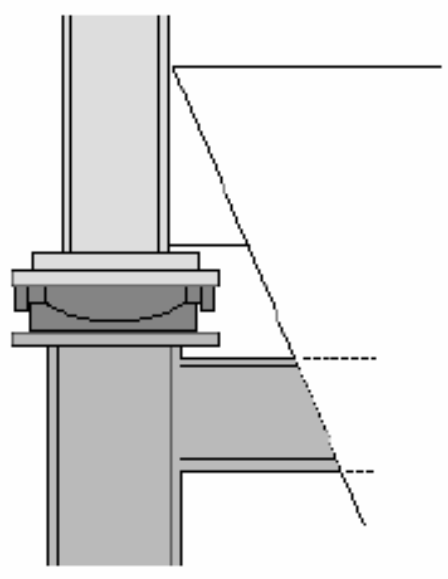

Figura 6 - Rótula esférica entre a estrutura de suporte do ESP e da sua carcaça. 


\subsubsection{5 - Tremonhas}

O pó coletado no precipitador, liberado pelo batimento dos sistemas de emissão e coleta caem por gravidade e são coletados nas tremonhas, ver figura 7.

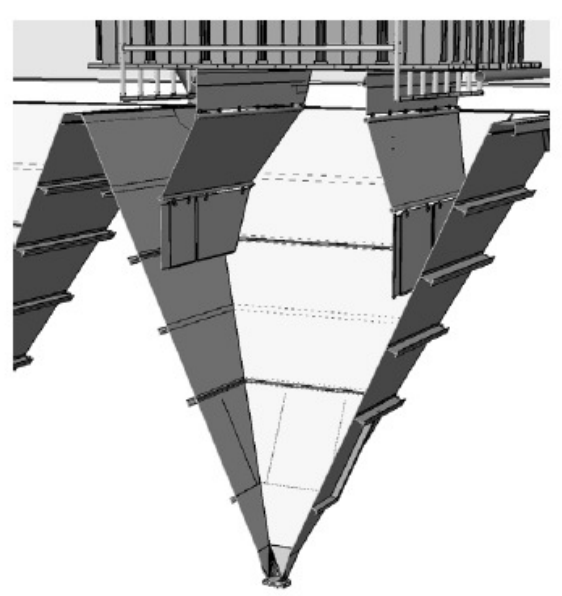

Figura 7- Exemplo de uma tremonha piramidal.

\subsubsection{Sistema de Emissão}

O objetivo do sistema de emissão é agir como a fonte para a geração do efeito corona, necessário para o carregamento elétrico das partículas em suspensão no fluxo de gás. Os eletrodos são distribuídos simetricamente no campo elétrico. Vários tipos de eletrodos são utilizados, alguns podem ser visualizados na figura 8 .

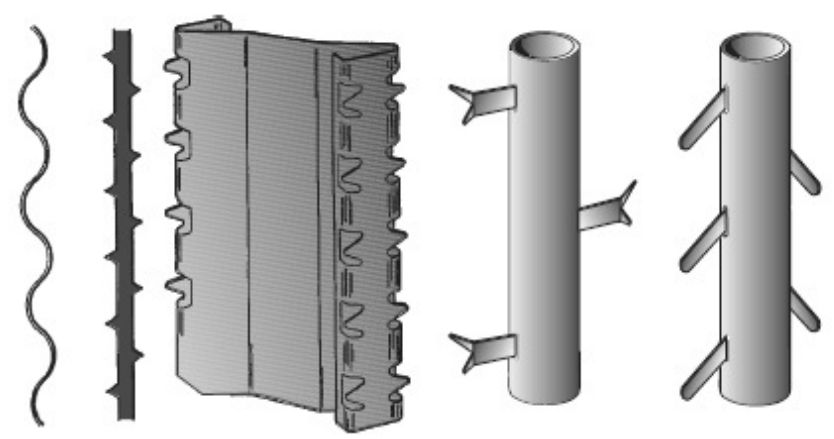

Figura 8 - Vários tipos de eletrodos do sistema de emissão 
O quadro de eletrodos, conforme figura 9 representa o sistema de emissão, ele é composto por um quadro rígido onde são dispostos os eletrodos, esse sistema está isolado da carcaça pelos suportes isoladores (suportes cerâmicos, ver figuras 9 e 10), e não podem se mover para não gerar descargas de energia (sparkings) ou curto circuito.

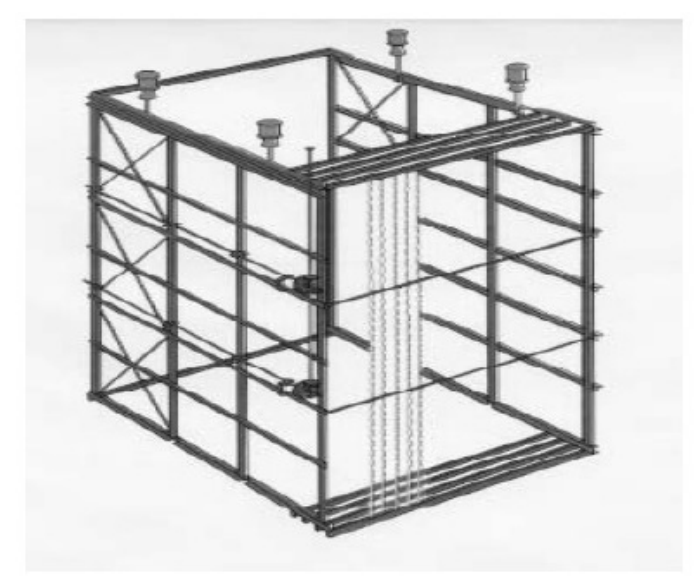

Figura 9 - Quadro rígido do sistema de emissão

\subsubsection{Sistema de Coleta}

É no sistema de coleta que o pó ionizado se adere, ele é composto por um conjunto de placas denominadas placas coletoras, que são aterradas e possuem um sistema de batimento conforme tópico 2.1.3.8. O sistema de coleta pode ser visualizado na figura 10 .

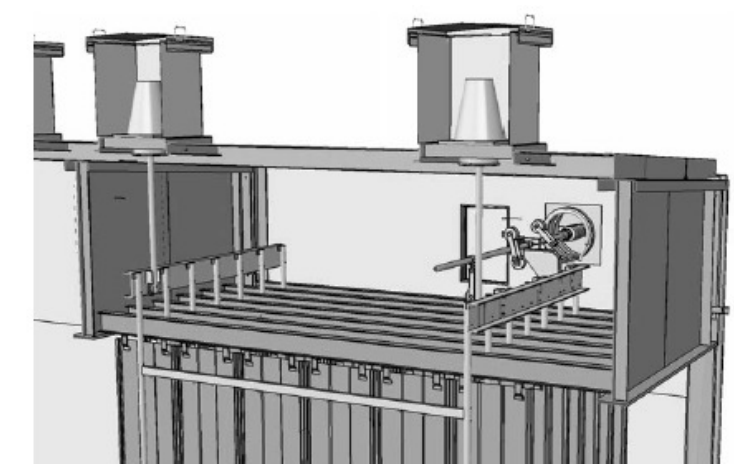

Figura 10 - Sistema de emissão (amarelo) e Sistema de coleta (Azul). 


\subsubsection{Sistema de Batimento}

Após a coleta do material particulado nas placas, ele deve ser removido periodicamente para que o ESP continue a funcionar adequadamente. A limpeza das placas é feita pelo batimento das placas coletoras por martelos, geralmente na região inferior das placas, conforme Cooper (2002). O sistema pode ser visto na figura 11.

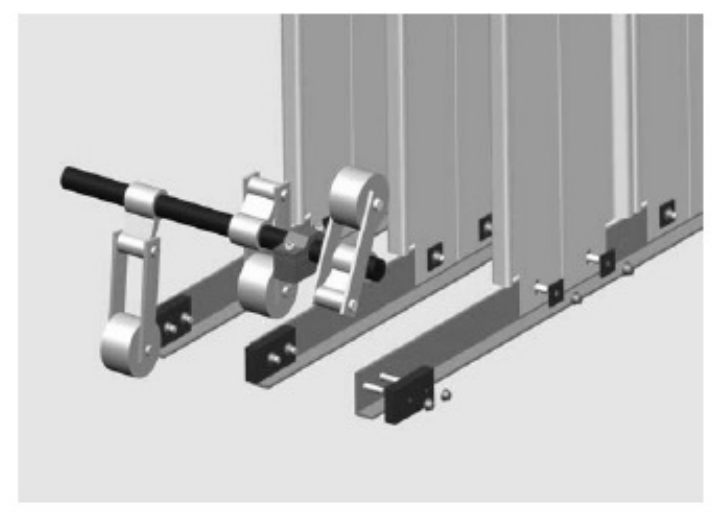

Figura 11 - Sistema de batimento das placas coletoras de um ESP

\subsection{Sismo}

Um terremoto é um movimento repentino e transiente da superfície da terra. De acordo com os geólogos a terra vem sofrendo terremotos por milhões de anos, bem antes da existência dos seres humanos (Datta, 2010).

Acredita-se que os continentes já foram uma única massa chamada de "Pangea", e que elas se separam ao longo de milhões de anos até alcançar a forma atual, uma das provas desse fenômeno é a possível continuidade entre a costa leste da America do sul com a costa oeste da África, conforme figura 12. 


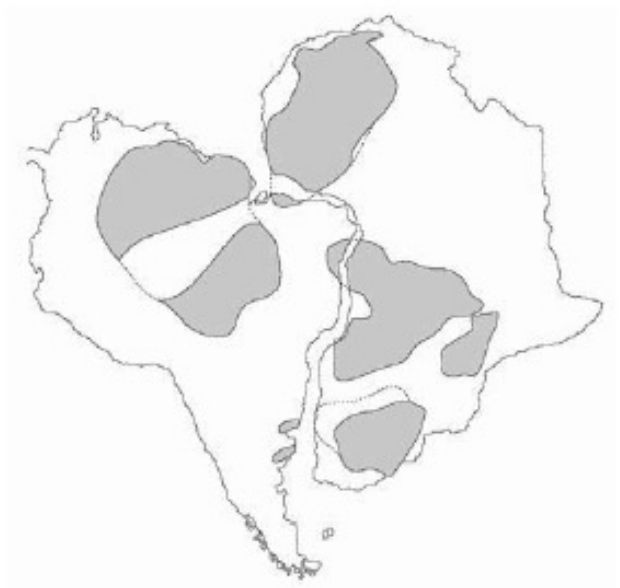

Figura 12 - Continuidade entre a costa leste da America do sul com a costa oeste da África (Matibet, 2008).

Em virtude dessa teoria, a superfície do nosso planeta não é continua. Ela é quebrada em doze grandes pedaços (ver figura 13) chamados de placas tectônicas, que se movem em media 11 centímetros por ano (Hyndman, 2009)

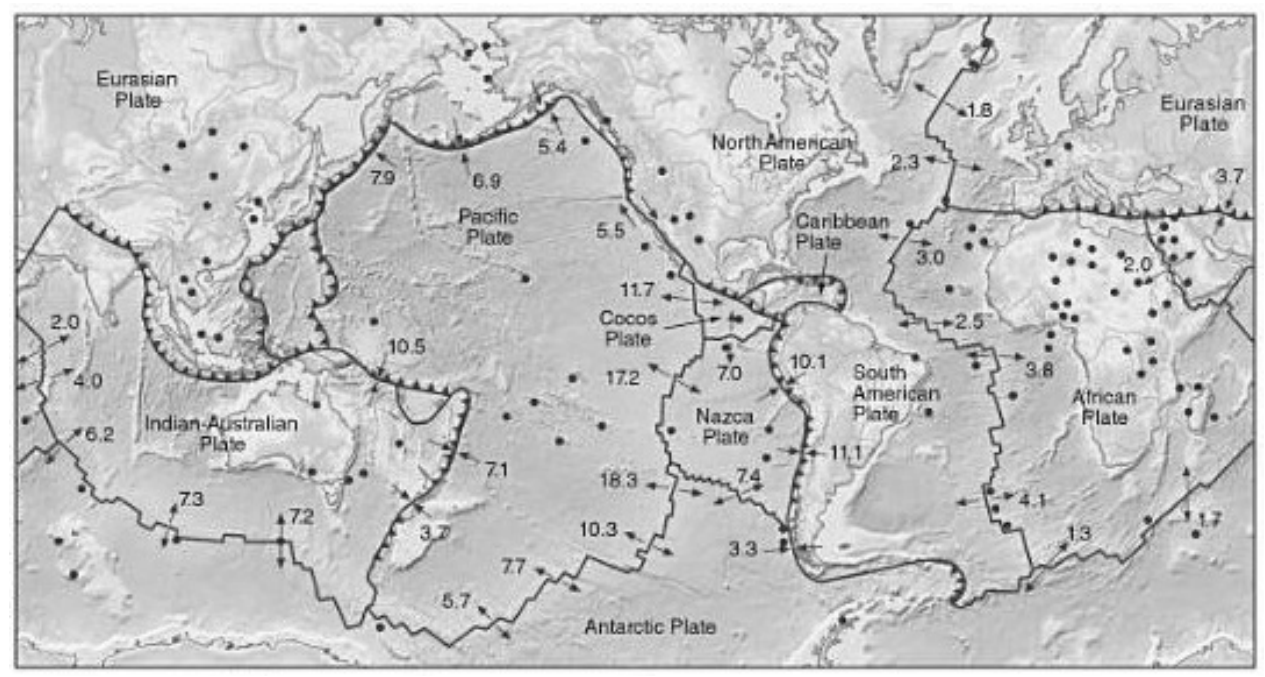

Figura 13 - Placas tectônicas (Hyndman, 2009)

Devido a esses movimentos relativos entre as placas, temos um acumulo de tensão nas bordas das placas e dentro delas. Quando essa energia elástica atinge seu valor limite por uma região fraca ou de falhas, um 
movimento repentino ocorre liberando toda essa energia. Essa ação gera ondas elásticas que se propagam pela superfície da terra.

Pode-se resumir esse processo em algumas etapas:

-Processo lento de acumulo de tensões

-Deformação gerada pelo acumulo de tensões

-Propagação das ondas geradas pela energia liberada

$\mathrm{Na}$ figura 14, pode-se visualizar o esquema de um processo de acumulo de tensões e sua posterior deformação, e na figura 15, a propagação de uma onda gerada por um terremoto.

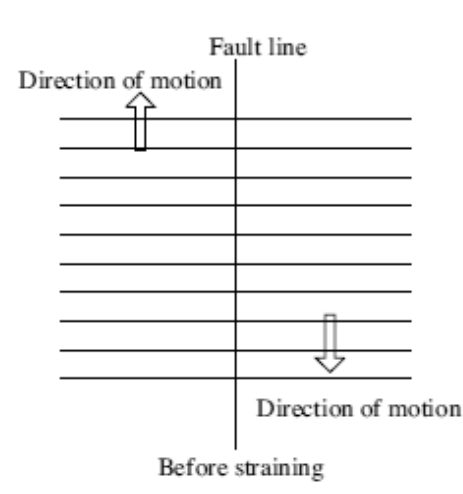

(a)

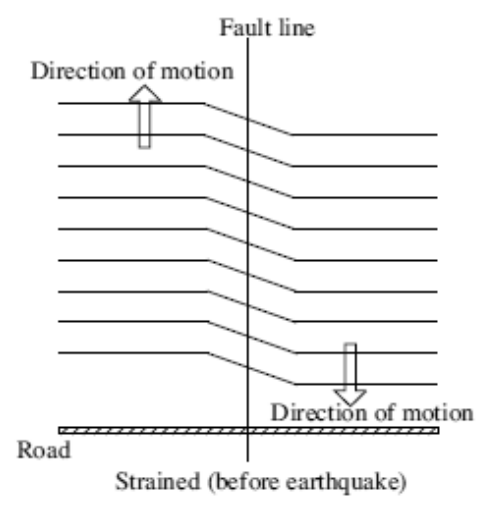

(b)

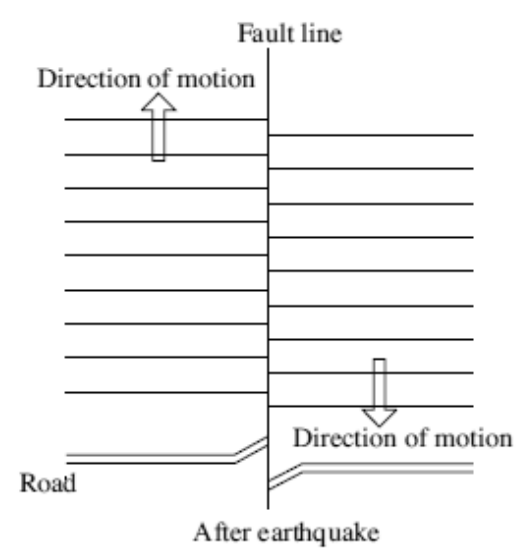

(c)

Figura 14 - Teoria da recuperação elástica (Datta, 2010). 

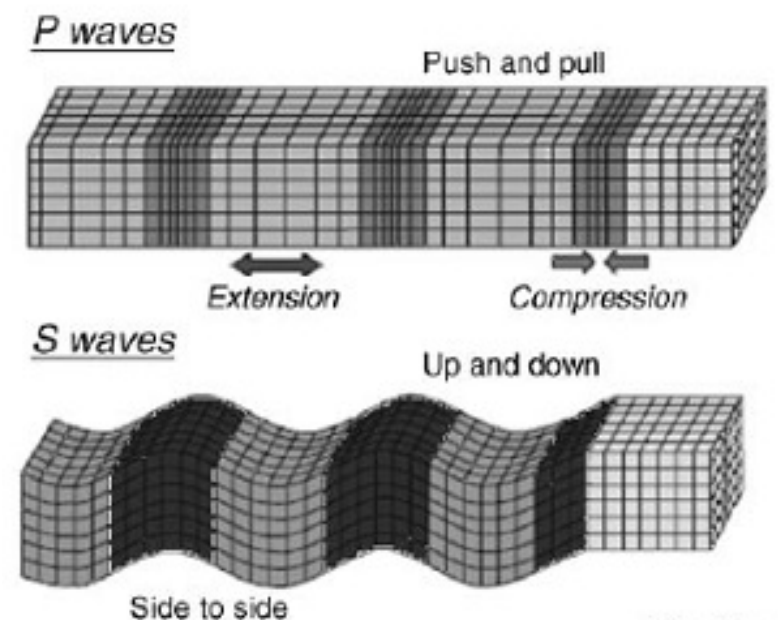

Side to side

Direction of

energy transmission

Figura 15 - Propagação de ondas na superfície terrestre devido a efeitos de sismo (Datta, 2010).

Esses movimentos são registrados por aparelhos denominados sismógrafos que se baseiam no movimento diferencial entre uma massa livre, que tende a permanecer em repouso, e uma estrutura de suporte fixada ao solo. Registra-se, assim, o movimento do solo, que é convertido matematicamente para se obter o movimento absoluto.

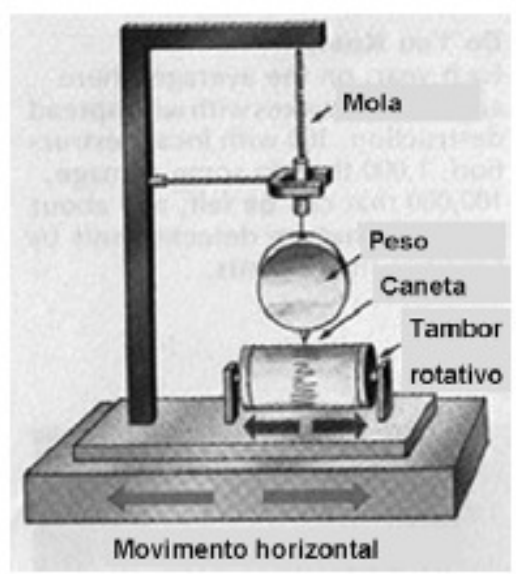

Figura 16- Representação de um sismógrafo padrão.

Um dos primeiros registros completos de sismo ocorreu na Califórnia em 1940 quando do terremoto denominado "El Centro". Ele pode ser visto no gráfico 1. Esses dados se tornaram conhecidos em todo o mundo e vem sendo utilizados como uma referencia para calculo de sismos por pelo 
menos 40 anos. As características desse registro são picos de aceleração de $3,3 \mathrm{~m} / \mathrm{s}^{2}$, velocidades de movimento de $0,37 \mathrm{~m} / \mathrm{s}$.
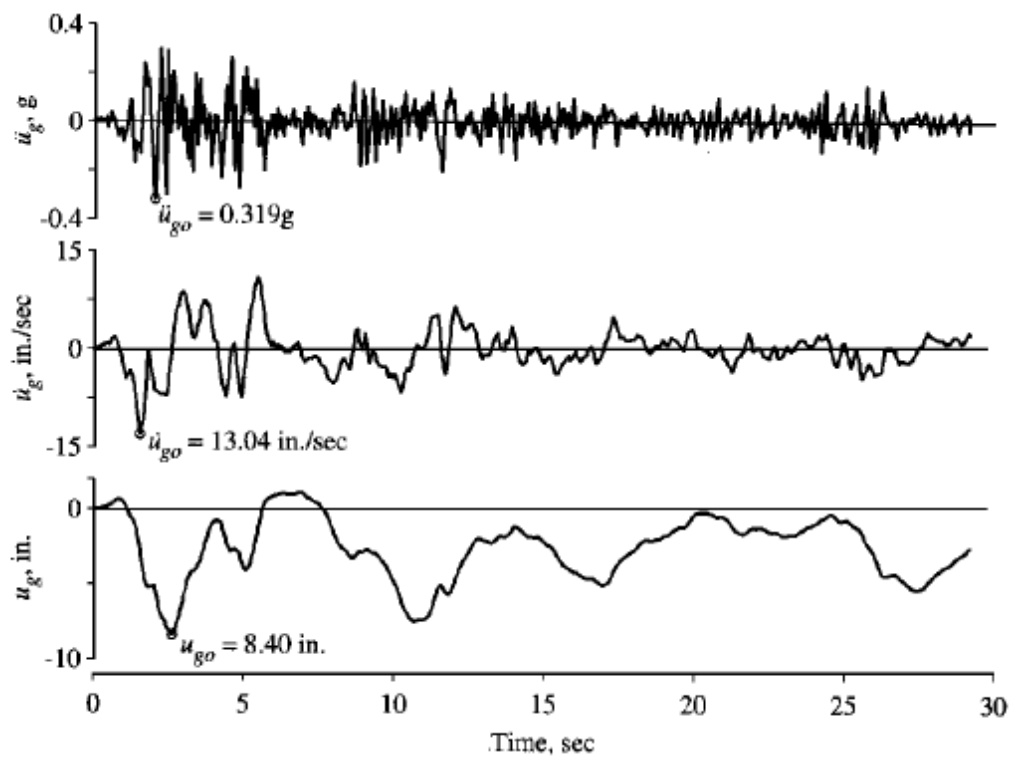

Gráfico 1- Componente norte-sul horizontal do movimento de aceleração do solo, sismo El Centro, Califórnia, maio de 1940 (Chopra, 1980).

Uma visão geral dos códigos de sismos de alguns países da América Latina pode ser encontrada em Brasil, 2007. 


\section{SISTEMAS DINÂMICOS}

Define-se por sistema um conjunto de objetos agrupados por uma interdependência ou interação (Perko, 2000), de modo que existam relações de causa e feito nos fenômenos que ocorrem com os elementos desse conjunto.

Os sistemas são ditos dinâmicos quando uma ou mais de suas grandezas variam no tempo.

Sendo um sistema dinâmico uma aplicação $\phi C^{1} R x S \rightarrow S$ onde $S$ é um conjunto aberto do espaço Euclidiano, escrevendo $\phi_{t}: S \rightarrow S$ satisfaz:

(a) $\phi_{0}: S \rightarrow S$ é a identidade

(b) A composição $\phi_{t} \circ \phi_{s}=\phi_{t+s}$ para todo t, $s \in R$.

A definição implica que a aplicação $\phi_{t}: S \rightarrow S$ é $C^{1}$ para cada t em uma inversa $C^{1}, \phi_{-t}$ (com s=-t em (b)).

Seja $A$ um operador em um espaço vetorial $E$, seja $E=S$ e $\phi: R x S \rightarrow S$ definida por $\phi(t, x)=e^{t A} x$. Então $\phi_{t}: S \rightarrow S$ pode ser representado por $\phi_{t}=e^{t A}$. Sendo assim, $\phi_{0}=e^{0}$ é o operador identidade, e desde que $e^{(t+s) A}=e^{t A}$, definimos um sistema dinâmico em $E$.

Representa-se, assim, um exemplo de sistema dinâmico pela equação diferencial $\frac{d x}{d t}=A x$ em $E$. Um sistema dinâmico $\phi_{t}$ em $S$ é, geralmente, dado por uma equação diferencial.

Reescrevendo em termos convencionais, seja $\phi_{t}: S \rightarrow S$ um sistema dinâmico e $x \in S$, seja $x(t)=\phi_{t}(x)$, e $f: S \rightarrow E$ :

$$
f(x)=\frac{d}{d t} \phi_{t}(x)
$$

Reescrevendo (3.0.1) como

$$
\dot{x}=f(x)
$$


assim, $x(t)$ ou $\phi_{t}(x)$ são soluções satisfazendo a condição inicial $x(0)=x_{0}$.

A equação (3.0.2) é chamada de equação autônoma por não depender do tempo explicitamente. Equações não autônomas são da forma $\dot{x}=f(t, x)$.

Nesse trabalho analisaremos sistemas dinâmicos contínuos, onde $t \in R_{+}$. Em sistemas contínuos sua evolução é descrita por uma ou mais equações diferencias que dependem do tempo.

\subsection{Sistemas de um grau de liberdade}

O movimento de um sistema de um grau de liberdade é descrito por uma equação diferencial ordinária de segunda ordem que é sua equação de movimento (eq 3.1.1)
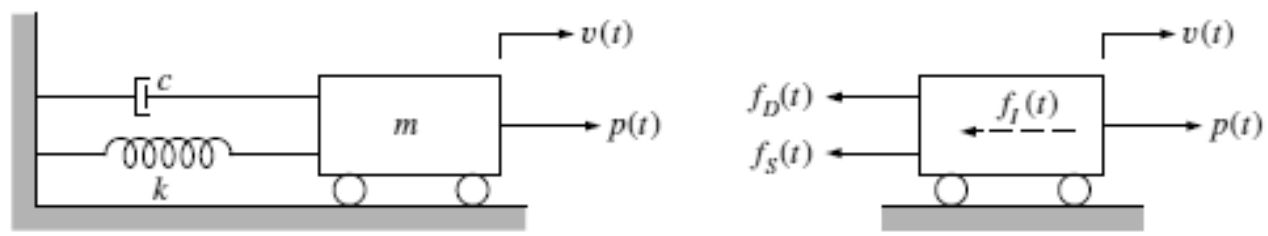

Figura 17- Sistema de um grau de liberdade.

$$
m \ddot{v}(t)+c \dot{v}(t)+k v(t)=p(t)
$$

A equação do movimento acima representa o equilíbrio das forças segundo o principio de d'Alembert, e pode ser reescrito como:

$$
f_{I}(t)+f_{D}(t)+f_{S}(t)=p(t)
$$

onde: 


$$
\begin{aligned}
& f_{I}(t)=\text { Força resistente de Inércia } \\
& f_{D}(t)=\text { Força resistente de Amortecimento } \\
& f_{S}(t)=\text { Força resistente Elástica } \\
& p(t)=\text { Força externa } \\
& m=\text { Massa } \\
& c=\text { coeficiente de amortecimento } \\
& k=\text { coeficiente de rigidez }
\end{aligned}
$$

\subsubsection{Excitação de suporte - Um grau de liberdade}

Pelas suas características, os esforços sísmicos são considerados como uma excitação dos suportes de uma estrutura. Dessa forma, não há a aplicação de um esforço externo $p(t)$, mas sim um movimento da base, com deslocamentos $v_{g}(t)$, com velocidade $\dot{v}_{g}(t)$ e aceleração $\ddot{v}_{g}(t)$.

Considerando um piso rígido onde a base sofre um deslocamento horizontal $v_{g}(t)$ e sendo $v^{t}(t)$ o deslocamento total da massa em relação a referencia fixada, tem-se:

$$
v^{t}(t)=v(t)+v_{g}(t)
$$
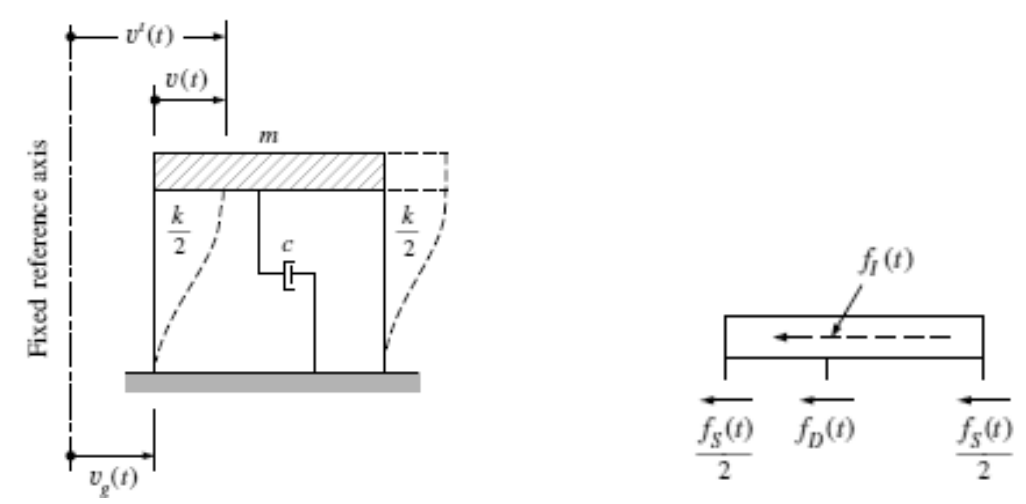

Figura 18- Sistema de um grau de liberdade - Excitação de suporte. 
ou seja:

$$
m \ddot{v}(t)+m \ddot{v}_{g}(t)+c \dot{v}(t)+k v(t)=0
$$

equação que pode ser convenientemente escrita como:

$$
m \ddot{v}(t)+c \dot{v}(t)+k v(t)=-m \ddot{v}_{g}(t)
$$

Dessa forma, comparando as equações tem-se que a expressão que rege o movimento de um sistema sujeito a excitação de suporte é a mesma do caso sob ação de um esforço externo de valor $-m \ddot{v}_{g}(t)$.

\subsection{Sistemas de vários graus de liberdade}

Segundo Clough e Penzien (1993), o movimento de um sistema de vários graus de liberdade é governado por equações diferenciais ordinárias, tantas quanto o número de graus de liberdade (GDL) da estrutura. Essas equações estão acopladas e, portanto, devem ser resolvidas simultaneamente para que se possa obter a resposta do sistema.

Em qualquer instante de tempo, a configuração deformada pode ser especificada pelos deslocamentos $v_{1}$ até $v_{N}$, onde $\mathrm{N}$ é o numero de GDL. $\mathrm{O}$ conjunto das equações de movimento pode ser escrito em forma matricial

$$
M \ddot{v}(t)+C \dot{v}(t)+K v(t)=p(t)
$$

Onde:

$$
\begin{aligned}
& v(t)=\text { Vetor dos deslocamentos } \\
& \dot{v}(t)=\text { Vetor das velocidades } \\
& \ddot{v}(t)=\text { Vetor das acelerações } \\
& p(t)=\text { Vetor dos carregamentos } \\
& M=\text { Matriz de massa }
\end{aligned}
$$




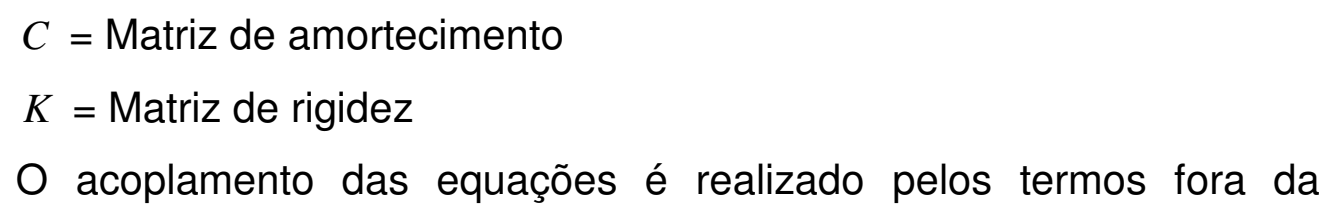
diagonal principal nas matrizes.

\subsubsection{Excitação de suporte - Vários graus de liberdade}

A excitação de suporte é dado pelo movimento da base, e é definida por funções escalares de deslocamento $v_{g}(t)$, velocidade $\dot{v}_{g}(t)$ e aceleração $\ddot{v}_{g}(t)$. A resposta relativa da estrutura é definida pelos deslocamentos $v_{j}(t)$.

Os deslocamentos totais na direção da excitação são dados pela soma de um componente de movimento de corpo rígido, igual para todos os graus de liberdade, e o deslocamento em relação à base, conforme equação 3.2.1.1.

$$
v_{j}^{t}(t)=v_{g}(t)+v_{j}(t)
$$

Analogamente ao sistema de um grau de liberdade, chegamos à equação do movimento:

$$
M \ddot{v}(t)+C \dot{v}(t)+K v(t)=-M i \ddot{v}_{g}(t)
$$

onde

$i=$ vetor que define a direção de aplicação da excitação de suporte

$v(t)=$ Vetor dos deslocamentos relativos

$\dot{v}(t)=$ Vetor das velocidades relativas

$\ddot{v}(t)=$ Vetor das acelerações relativas

$\ddot{v}_{g}(t)=$ função escalar que define a direção de aplicação da excitação de suporte

$M=$ Matriz de massa 


$$
\begin{aligned}
& C=\text { Matriz de amortecimento } \\
& K=\text { Matriz de rigidez }
\end{aligned}
$$

O comportamento em vibração livre pode ser encontrado em Morcelli (2010), Ferreira (2007) e Beltrami (1987).

\subsection{Técnicas de análise}

O estudo de sistemas lineares é de grande interesse, pois diversos fenômenos da natureza são modelados através deles. Além disso, por meio de métodos de linearização, conseguimos estudar sistemas não lineares pelo seu sistema linear associado (Monteiro, 2006)

Uma técnica de análise de uma equação diferencial de ordem $\mathrm{n}$ é a sua representação por meio de um sistema de $n$ equações de primeira ordem através da definição de novas variáveis.

Tendo em mãos a equação diferencial linear de ordem n:

$$
a_{0}(t) \frac{d^{n} x(t)}{d t^{n}}+a_{1}(t) \frac{d^{n-1} x(t)}{d t^{n-1}}+\ldots+a_{n-1}(t) \frac{d x(t)}{d t}+a_{n}(t) x(t)-F(t)=0
$$

Tomando $x_{1}(t) \equiv x(t)$, ela pode ser reescrita como:

$$
\begin{gathered}
\frac{d x_{1}(t)}{d t}=x_{2}(t) \\
\frac{d x_{2}(t)}{d t}=x_{3}(t) \\
\frac{d x_{n-1}(t)}{d t}=x_{n}(t) \\
\frac{d x_{n}(t)}{d t}=\frac{F(t)}{a_{0}(t)}-\frac{a_{n}(t)}{a_{0}(t)} x_{1}(t)-\frac{a_{n-1}(t)}{a_{0}(t)} x_{2}(t)-\ldots-\frac{a_{1}(t)}{a_{0}(t)} x_{n}(t)
\end{gathered}
$$

$\mathrm{O}$ estado de um sistema em um instante t é especificado pelos valores das variáveis de estado $x_{j}(t) \quad(j=1,2, \ldots, n)$ nesse instante. Percebe- 
se assim que o estado de um sistema em um dado momento de sua historia passada, constitui toda a informação necessária para determinar sua evolução futura em um problema de condição inicial. Percebe-se, também, que a escolha das variáveis de estado não é única.

Há algumas vantagens de se escrever uma equação diferencial de ordem $n$ como $n$ equações diferenciais de primeira ordem. A principal vantagem de se trabalhar dessa forma é que estão bem desenvolvidas as técnicas de análise para esses sistemas. Existem três técnicas para se analisar um sistema dinâmico, a seguir detalhadas.

- Técnica analítica: integram-se analiticamente as equações, determinando a solução em termos de uma formulação fechada (solução nem sempre possível, pois quase nunca a integração analítica e factível).

- Técnica numérica: integram-se numericamente as equações, calculando-se valores para as variáveis dependentes $x(t)=(x 1(t), x 2(t), \ldots$, $x n(t))$ em pontos pré selecionados da variável independente $t$. A desvantagem desse método é que a solução calculada é aproximada e só é válida para a situação calculada, ou seja, vale apenas para aqueles valores de condições iniciais e de parâmetros usados na integração. Quando algum desses valores é alterado, e necessário integrar novamente as equações do sistema.

- Técnica qualitativa: através de representações geométricas relativamente simples, pode-se analisar a evolução do sistema. Essa técnica usa a descrição das variáveis de estado, e seus resultados são representados no espaço de estados, também chamado de espaço de fases, tema que será discutido no próximo tópico. A desvantagem dessa técnica é que parte da informação quantitativa é perdida, como o comportamento transiente do sistema.

É importante notar que o que foi dito acima neste item vale para sistemas lineares e não lineares. Em sistemas fracamente não lineares uma técnica alternativa à solução analítica são os métodos de perturbações como o de múltiplas escalas, que podem ser encontrados em Mazzilli (2002). 


\subsection{Espaços de estado (Plano de fase)}

Em sistemas não lineares dificilmente encontra-se uma solução exata, e mesmo quando encontradas são geralmente de difícil interpretação. Por isso, o uso de fotos e gráficos é geralmente útil para sua análise (Strogatz, 2000).

Considere-se a equação diferencial não linear:

$$
\dot{x}=\operatorname{sen}(x)
$$

Separando as variáveis e então integrando

$$
d t=\frac{d x}{\operatorname{sen}(x)}
$$

O que implica em

$$
\begin{aligned}
& t=\int \csc x d x \\
& =-\ln \left|\frac{\csc x_{0}+\cot x_{0}}{\csc x+\cot x}\right|+C
\end{aligned}
$$

Para avaliar a constante $\mathrm{C}$ usam-se as condições inicias $x=x_{0}$ em $t=0$. Então $C=\ln \left|\csc x_{0}+\cot x_{0}\right|$. Tem-se assim a solução:

$$
t=\left|\frac{\csc x_{0}+\cot x_{0}}{\csc x+\cot x}\right|
$$

Ou seja, nesse caso em particular, tem-se uma solução exata, mas de difícil compreensão. Pelo método gráfico essa analise se torna bem mais simples.

Tomando $t$ como $o$ tempo e $x$ como a posição imaginária do movimento da partícula por uma linha e $\dot{x}$ como a velocidade da partícula, então a equação diferencial $\dot{x}=\operatorname{sen}(x)$ representa um campo vetorial na linha, ele mostra a velocidade vetorial $\dot{x}$ em função do deslocamento $x$.

Plotando o gráfico $\dot{x}$ versus $x$, e desenhando as flechas no eixo $x$ para indicar a velocidade correspondente do vetor para cada $x$ tem-se 0 gráfico 2. 


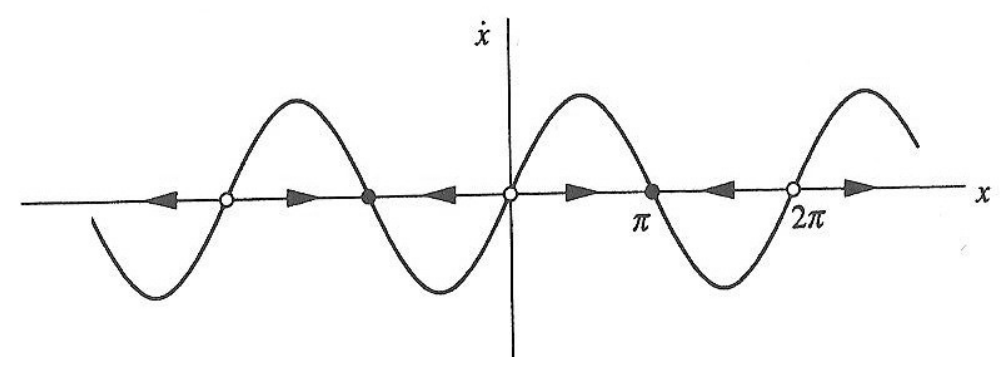

Gráfico $2-\dot{x}$ versus $x$ da equação 3.3.1.

Dessa forma a análise das soluções da equação diferencial fica bem mais simples.

Pode-se perceber dois tipos de pontos fixos (onde $\dot{x}=0$ ), os pontos pretos preenchidos representam pontos fixos estáveis (também chamados de atratores), e os pontos não preenchidos representam pontos fixos instáveis (também conhecidos como repelidores).

No gráfico 2, analisando uma partícula que se inicia em $x_{0}=\frac{\pi}{4}$ se move para a direita rapidamente até $\operatorname{cruzar} x=\frac{\pi}{2}$, onde $\operatorname{sen}(x)$ alcança sua máxima velocidade, posteriormente ela reduz sua velocidade e se aproxima do ponto fixo estável $x=\pi$.

A forma qualitativa da solução da equação 3.3.1 para algumas condições iniciais pode ser encontrada no gráfico 3. 


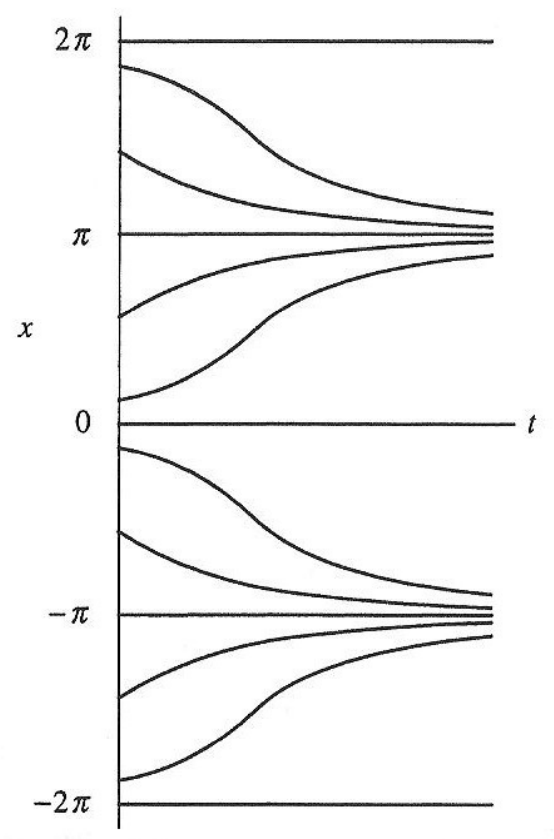

Gráfico 3 - Solução qualitativa da equação 3.3.1

Esse conceito pode ser estendido para sistemas de duas dimensões, considerando o sistema da forma:

$$
\begin{aligned}
& \dot{x}_{1}=f_{1}\left(x_{1}, x_{2}\right) \\
& \dot{x}_{2}=f_{2}\left(x_{1}, x_{2}\right)
\end{aligned}
$$

Esse sistema pode ser escrito de forma mais compacta na notação vetorial como:

$$
\dot{x}=f(x)
$$

Onde $x=\left(x_{1}, x_{2}\right)$ e $f(x)=\left(f_{1}(x), f_{2}(x)\right)$. Assim, $x$ representa um ponto no plano de fase e $\dot{x}$ a velocidade do vetor nesse ponto. Representa-se um plano de fase genérico na figura 17.

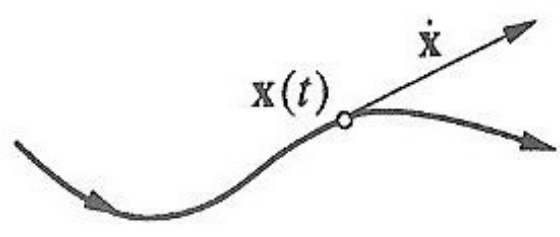

Figura 19- Plano de fase. 


\section{MODELAGEM MATEMÁTICA}

\subsection{Equações de movimento}

As equações diferenciais de movimento de um sistema dinâmico governam o comportamento do mesmo. Como os sistemas estudados neste trabalho possuem até três graus de liberdade, temos até três equações diferenciais de segunda ordem. Para encontrá-las, usam-se as equações de Euler-Lagrange do cálculo variacional, com base no que foi estudado em Ogata (1987):

$$
\begin{gathered}
\frac{d}{d t}\left(\frac{\partial L}{\partial \dot{q}_{i}}\right)-\frac{\partial L}{\partial q_{i}}=N i \\
\text { onde } \frac{\partial L}{\partial \dot{q}_{i}}=\frac{\partial T}{\partial \dot{q}_{i}} \\
\frac{\partial L}{\partial q_{i}}=\frac{\partial T}{\partial q_{i}}-\frac{\partial V}{\partial q_{i}} \\
\frac{d}{d t}\left(\frac{\partial T}{\partial \dot{q}_{i}}\right)-\frac{\partial T}{\partial q_{i}}+\frac{\partial V}{\partial q_{i}}=N i ; \mathrm{i}=1,2,3 \ldots
\end{gathered}
$$

Este capítulo apresentará os sistemas dinâmicos estudados. Outros modelos podem sem encontrados em Savi (2006) e Mazilli (2002). 


\subsubsection{Sistema de 1 grau de liberdade}

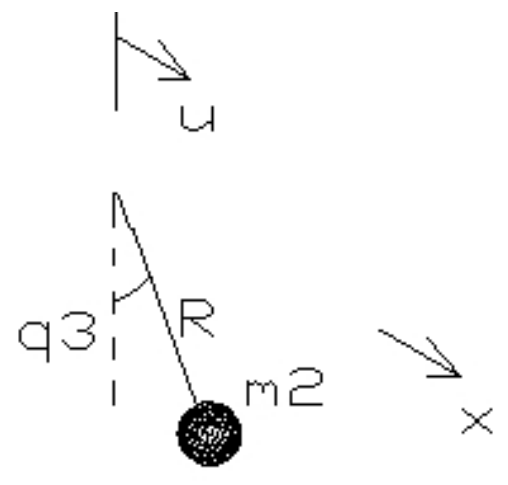

Figura 20 - Modelo com 1 grau de liberdade

O modelo da figura 20 consiste em um pêndulo pinado, sob excitação de suporte $u$, na direção de $x$. O ângulo do deslocamento do pendulo é a coordenada generalizada do sistema. Tem-se a energia cinética:

$$
T=\frac{1}{2}\left[m_{2}\left(\dot{x}_{2}^{2}+\dot{z}_{2}^{2}\right)\right]
$$

que em termos das coordenadas generalizadas é

$$
\begin{aligned}
& T=\frac{1}{2}\left[m_{2}\left(\dot{u}^{2}+\dot{q}_{3}^{2} R^{2}+2 \dot{u} \dot{q}_{3} R \cos \left(q_{3}\right)\right)\right] \\
& U=0
\end{aligned}
$$

Agora, considera-se o trabalho das forças conservativas, no caso o peso do pêndulo:

$$
W=-m_{2} g R\left(1-\cos \left(q_{3}\right)\right)
$$

A energia potencial total é dada por 
$V=U-W$

A força não conservativa é dada pelo amortecimento viscoso adotado:

$N=-c_{3} \dot{q}_{3}$

$\mathrm{Na}$ seqüência, as equações de Lagrange 4.1.4 são aplicadas, resultando na equação de movimento, com termos quadráticos:

$$
\ddot{q}_{3}=\frac{\left(-m_{2} \ddot{u} R \cos \left(q_{3}\right)-m_{2} g R \operatorname{sen}\left(q_{3}\right)-c_{3} \dot{q}_{3}\right)}{m_{2} R^{2}}
$$

\subsubsection{Sistema de 2 graus de liberdade}

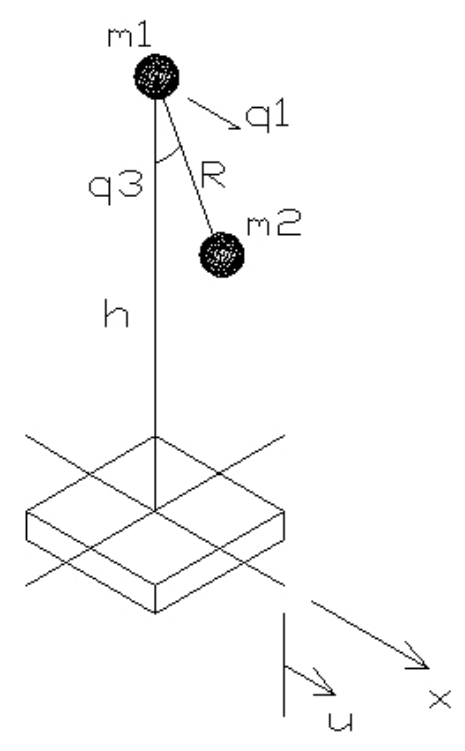

Figura 21 - Sistema com 2 graus de liberdade

Nesse sistema, consideramos um pendulo pinado na extremidade superior de uma barra elástica engastada na base, que sofre deslocamento sísmico $u$, na direção de $x$, e uma massa no topo. O movimento horizontal dessa massa em $x$ e o ângulo do pendulo são as coordenadas generalizadas adotadas. 
Os deslocamentos que ocorrem ao longo da barra flexível são interpolados por um polinômio cúbico. Definem-se como coordenadas generalizadas os termos $q_{1}$ e $q_{3}$. O deslocamento horizontal é dado por $x$, e as massas $m_{1}$ como sendo a massa do equipamento e $m_{2}$ a massa das placas coletoras.

\section{Plane $x z$}

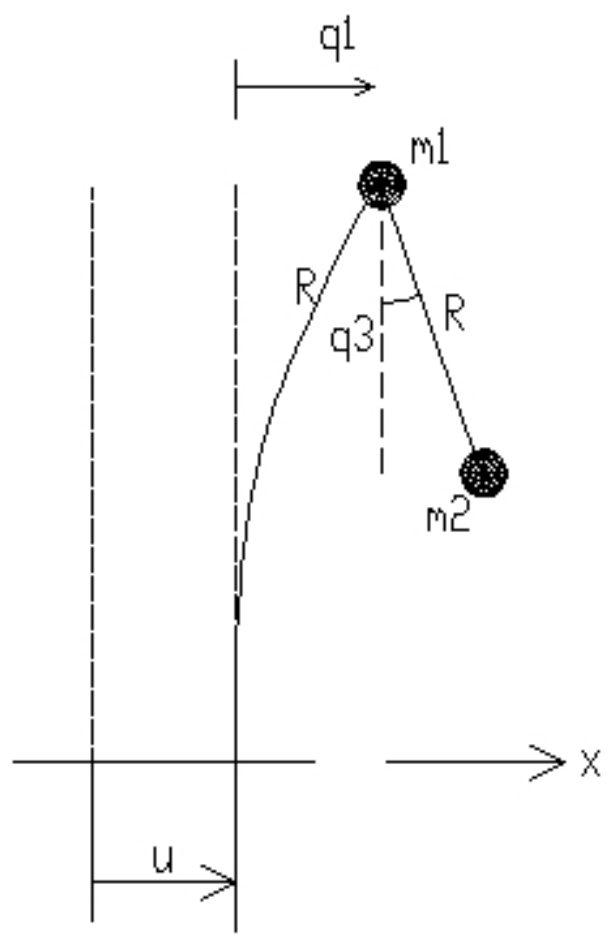

Figura 22- Sistema com 2 graus de liberdade - Plano xz

No cálculo da energia potencial do sistema o encurtamento das colunas devido ao movimento de balanço da barra foi desconsiderado.

Os deslocamentos da barra e do pendulo são dados por:

$$
\begin{aligned}
& x_{1}=q_{1} \\
& \theta_{1}=q_{3}
\end{aligned}
$$


A função $\varphi$, a função de forma, um polinômio cúbico, é dado por: $\phi(z)=-\frac{z^{3}}{2 h^{3}}+\frac{3 z^{2}}{2 h^{2}}$

A energia cinética é

$T=\frac{1}{2}\left[\dot{q}_{1}^{2}\left(m_{1}+m_{2}\right)+\dot{q}_{3}^{2} R^{2} m_{2}+2 \ddot{u} \dot{q}_{1}\left(m_{1}+m_{2}\right)+2 m_{2}\left(\dot{u}+\dot{q}_{1}\right) \dot{q}_{3} R \cos q_{3}+\dot{u}^{2}\left(m_{1}+m_{2}\right)\right]$

E a energia de deformação é

$U=\frac{1}{2}\left[k_{1} q_{1}^{2}\right]$

O trabalho das forças conservativas é dado pelo peso do pêndulo:

$W=-m_{2} g R\left(1-\cos \left(q_{3}\right)\right)$

A energia potencial total é dada por

$V=U-W$

Aplicando Lagrange, tem-se:

$$
\begin{aligned}
& \ddot{q}_{1}=\frac{G_{1} m_{2} R^{2}-G_{3} m_{2} R \cos \left(q_{3}\right)}{\Delta} \\
& \ddot{q}_{3}=\frac{G_{3}\left(m_{1}+m_{2}\right)-G_{1} m_{2} R \cos \left(q_{3}\right)}{\Delta}
\end{aligned}
$$


onde

$$
\begin{aligned}
& G_{1}=m_{2} \dot{q}_{3}^{2} R \operatorname{sen}\left(q_{3}\right)-k_{1} q_{1}-c_{1} \dot{q}_{1}-\ddot{u}\left(m_{1}+m_{2}\right) \\
& G_{3}=\left(-m_{2} \ddot{u} R \cos \left(q_{3}\right)-m_{2} g R \operatorname{sen}\left(q_{3}\right)-c_{3} \dot{q}_{3}\right) \\
& \Delta=\left(m_{1}+m_{2}\right)\left(m_{2} R \cos \left(q_{3}\right)\right)-\left(m_{2} R \cos \left(q_{3}\right)\right)^{2}
\end{aligned}
$$




\subsubsection{Sistema de 3 graus de liberdade}

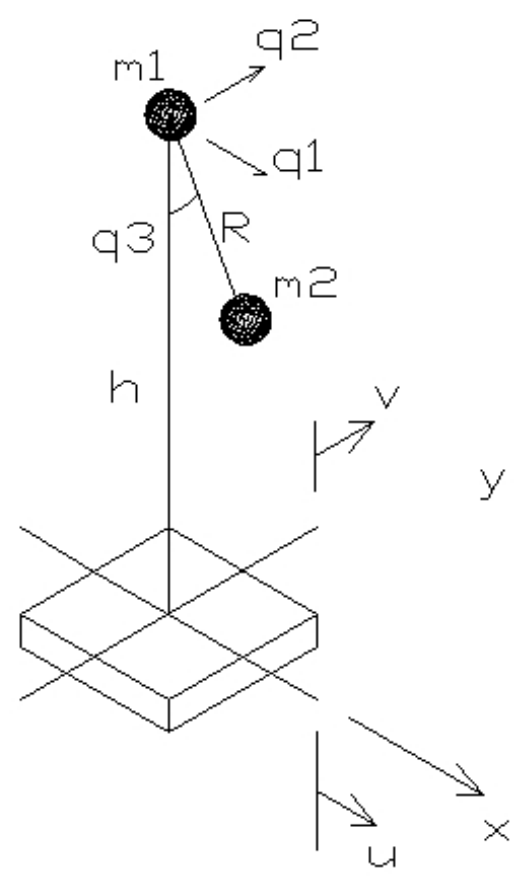

Figura 23 - Sistema com 3 graus de liberdade

O modelo da figura 23 considera uma barra com um pendulo pinado na sua extremidade superior. Os dois movimentos horizontais nesse nível superior e o ângulo de deslocamento do pendulo são as coordenadas generalizadas adotadas. A base sofre deslocamentos sísmicos $u$ e $v$ nas direções de $x$ e $y$. Outros deslocamentos que ocorrem ao longo da barra flexível são computados utilizando um polinômio de forma cúbica. Definemse, assim, como coordenadas generalizadas os termos $q_{1}, q_{2} \mathrm{e} q_{3}$. Consideram-se coordenadas $x, y$ e $z$ para cada massa, $m_{1}$ como sendo a massa do equipamento e $m_{2}$ a massa das placas coletoras.

No calculo da energia potencial do sistema o encurtamento das colunas devido à flexão da barra foi desconsiderado.

Os deslocamentos da barra e do pendulo são dados por: 


$$
\begin{aligned}
& x_{1}=q_{1} \\
& y_{1}=q_{2} \\
& \theta_{1}=q_{3}
\end{aligned}
$$

A função de forma $\varphi$, um polinômio cúbico, é dado por: $\phi(z)=-\frac{z^{3}}{2 h^{3}}+\frac{3 z^{2}}{2 h^{2}}$

A energia cinética é $T=\frac{1}{2}\left[m_{1}\left(\dot{x}_{1}^{2}+\dot{y}_{1}^{2}\right)+m_{2}\left(\dot{x}_{2}^{2}+\dot{y}_{2}{ }^{2}+\dot{z}_{2}^{2}\right)\right]$

A partir das definições dadas pela equação presente em 4.1.3.1, obtêm-se:

$$
T=\frac{1}{2}\left[\begin{array}{l}
\dot{q}_{1}^{2}\left(m_{1}+m_{2}\right)+\dot{q}_{2}^{2}\left(m_{1}+m_{2} \alpha^{2}\right)+\dot{q}_{3}^{2} R^{2} m_{2}+2 \dot{q}_{3} R \cos \left(q_{3}\right) m_{2}\left(\dot{q}_{1}+\dot{u}\right) \\
+2 \dot{u} \dot{q}_{1}\left(m_{1}+m_{2}\right)+2 \dot{v}_{1}\left(m_{1}+m_{2} \alpha\right)+\dot{u}^{2}\left(m_{1}+m_{2}\right)+\dot{v}^{2}\left(m_{1}+m_{2}\right)
\end{array}\right]
$$

A energia de deformação, considerando a rigidez em ambas as direções $x$ e $y$ da barra de altura h é:

$U=\frac{1}{2}\left[k_{1} q_{1}^{2}+k_{2} q_{2}^{2}\right]$

O trabalho das forças conservativas é devido ao peso do pêndulo:

$W=-m_{2} g R\left(1-\cos \left(q_{3}\right)\right)$

A energia potencial total é dada por

$$
V=U-W
$$


Plane yz

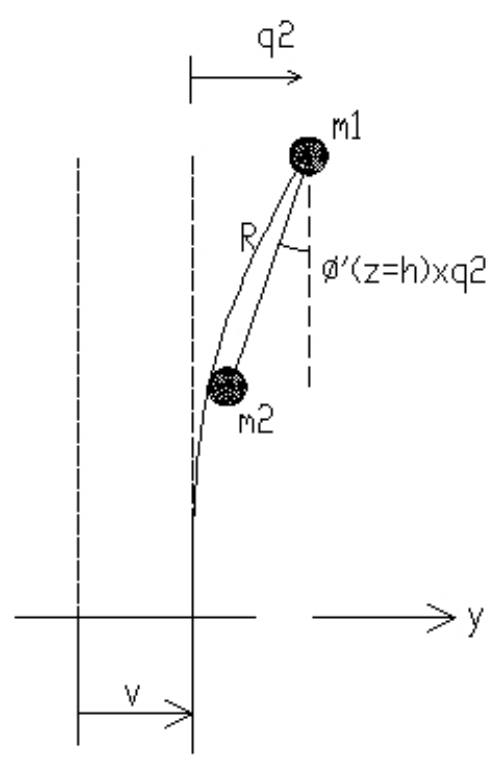

Plane $x z$

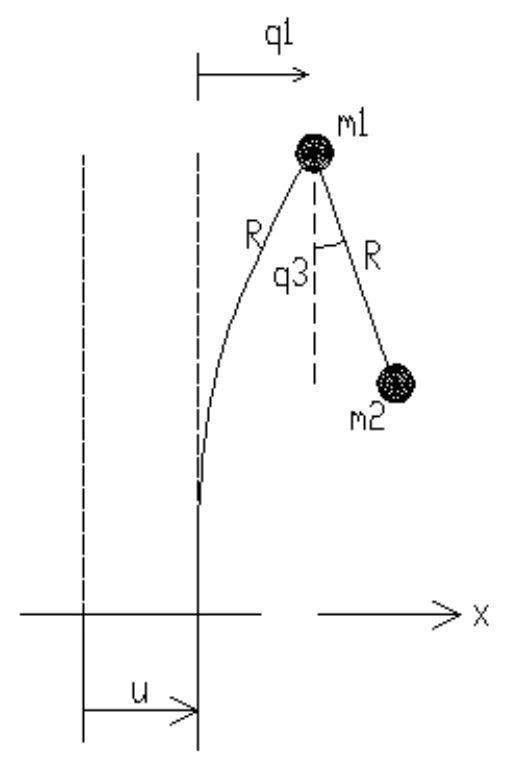

Figura 24 - Vistas laterais do sistema com 3 graus de liberdade

Na seqüência, as equações de Lagrange são aplicadas. Os únicos termos de força não conservativos $N_{i}$ são devidos ao amortecimento viscoso linear, representado pelos coeficientes $c_{1}$ e $c_{2}$. As equações de movimento, finalmente são:

$$
\begin{aligned}
& \ddot{q}_{1}=\frac{G_{1}\left(m_{1}+m_{2} \alpha^{2}\right) m_{2} R^{2}-G_{3}\left(m_{1}+m_{2} \alpha^{2}\right)\left(m_{2} R \cos \left(q_{3}\right)\right)}{\Delta} \\
& \ddot{q}_{2}=\frac{G_{2}\left[\left(m_{1}+m_{2}\right) m_{2} R^{2}-\left(m_{2} R \cos \left(q_{3}\right)\right)^{2}\right]}{\Delta} \\
& \ddot{q}_{3}=\frac{G_{3}\left(m_{1}+m_{2}\right)\left(m_{1}+m_{2} \alpha^{2}\right)-G_{1}\left(m_{1}+m_{2} \alpha^{2}\right)\left(m_{2} R \cos \left(q_{3}\right)\right)}{\Delta}
\end{aligned}
$$

onde 


$$
\begin{aligned}
& \alpha=\left(1-\frac{R}{2 h^{2}}\right) \\
& G_{1}=m_{2} \dot{q}_{3}^{2} R \operatorname{sen}\left(q_{3}\right)-k_{1} q_{1}-c_{1} \dot{q}_{1}-\ddot{u}\left(m_{1}+m_{2}\right) \\
& G_{2}=-k_{2} q_{2}-c_{2} \dot{q}_{2}-\ddot{v}\left(m_{1}+m_{2} \alpha\right) \\
& G_{3}=\left(-m_{2} \ddot{u} R \cos \left(q_{3}\right)-m_{2} g R \operatorname{sen}\left(q_{3}\right)-c_{3} \dot{q}_{3}\right) \\
& \Delta=\left(m_{1}+m_{2}\right)\left(m_{1}+m_{2} \alpha^{2}\right) m_{2} R^{2}-\left(m_{1}+m_{2} \alpha^{2}\right)\left(m_{2} R \cos \left(q_{3}\right)\right)^{2}
\end{aligned}
$$




\subsection{Obtenção dos parâmetros}

A obtenção dos parâmetros de massa, rigidez e amortecimento para serem utilizados nos modelos é de extrema importância. Eles podem ser obtidos através do estudo de modelos matemáticos, numéricos e experimentais. Neste trabalho, utilizam-se um modelo computacional em elementos finitos e fórmulas matemáticas.

\subsubsection{Massa}

Os valores de massa foram tomados tendo como base um modelo de elementos finitos de um equipamento real instalado na America Latina, construído pela empresa "Alstom".

\subsubsection{Rigidez}

Para a obtenção da rigidez do equipamento em estudo, foi utilizado um modelo de elementos finitos, simulado no programa "Staad Pro", do fabricante Bentley. O modelo pode ser visualizado na figura 25. 


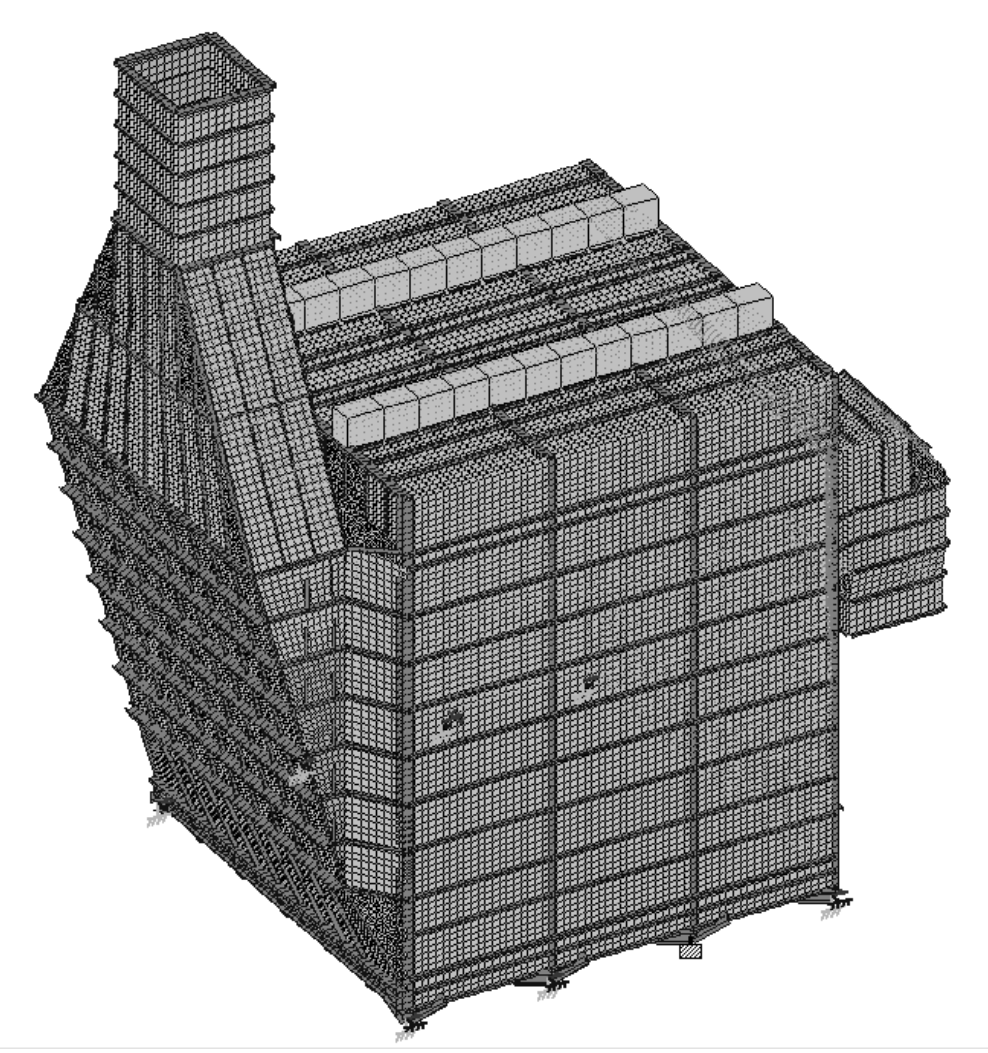

Figura 25 - Modelo tridimensional de um ESP

O método baseou-se em aplicar uma força constante no topo do equipamento e verificar qual o deslocamento obtido. Por meio da relação linear $F=k x$ foi possível obter os valores de $k$ aproximados para as direções $x$ e $y$.

\subsubsection{Amortecimento}

Segundo Clough and Penzien (1993), Rayleigh formulou uma matriz de amortecimento resultante de uma combinação linear entre as matrizes de rigidez e de massa:

$$
C=\alpha M+\beta K
$$

sendo $\alpha$ e $\beta$ constantes.

A razão de amortecimento do i-'esimo modo de vibração e dada por: 


$$
\zeta_{i}=\frac{\alpha+\beta \omega_{i}^{2}}{2 \omega_{i}}
$$

onde $\omega_{i}$ é a freqüência natural do i-ésimo modo de vibração.

As constantes $\alpha$ e $\beta$ podem ser determinadas a partir das razões de amortecimento $\zeta_{i}$ e $\zeta_{j}$ conhecidas para o i-ésimo e j-ésimo modos de vibração, respectivamente, através do seguinte sistema de equações lineares:

$$
\frac{1}{2}\left[\begin{array}{cc}
1 / \omega_{i} & \omega_{i} \\
1 / \omega_{j} & \omega_{j}
\end{array}\right]\left(\begin{array}{l}
\alpha \\
\beta
\end{array}\right)=\left(\begin{array}{c}
\zeta_{i} \\
\zeta_{j}
\end{array}\right)
$$

Se ambos os modos tem a mesma razão de amortecimento ( $\zeta_{i}=\zeta_{j}=\zeta$ ), então os valores de $\alpha$ e $\beta$ são dados por:

$$
\alpha=\zeta \frac{2 \omega_{i} \omega_{j}}{\omega_{i}+\omega_{j}} \text { e } \beta=\zeta \frac{2}{\omega_{i}+\omega_{j}}
$$

Para o pendulo, adotou-se coeficiente de amortecimento determinado por

$$
c_{3}=2 m_{2} \zeta \omega
$$

sendo

$$
\omega=\sqrt{\frac{g}{R}} .
$$

No caso do amortecimento da carcaça de um ESP, do modelo calculado no programa "Staad Pro", obtêm-se as frequências $\omega_{1}=4,3$ e $\omega_{2}=6,8$, e adota-se $\zeta=0,05$, resultando $\alpha=0,26$ e $\beta=0,01$.

O parâmetro $\zeta$ foi adotado considerando normas internacionais como a de sismo chilena NCh2369 (ARZE, 2003). 


\section{RESPOSTA DOS SISTEMAS A ENTRADAS INICIAIS NÃO NULAS}

Os modelos matemáticos descritos na seção anterior foram simulados em MATLAB 7.0 (Haselman e Littlefield (2003)), retornando os resultados que serão apresentados e discutidos nesta seção.

Para a simulação dos sistemas utilizou-se a função ode45, que se utiliza do algoritmo de Runge-Kutta de quarta e quinta ordem para integração numérica. Os parâmetros utilizados foram obtidos conforme o capitulo 4.2, e os seus resultados indicam o comportamento do sistema.

Os parâmetros utilizados nas simulações são (todos em SI):

$$
\begin{aligned}
& \mathrm{m}_{1}=150000 ; \\
& \mathrm{m}_{2}=50000 ; \\
& \mathrm{R}=5 ; \\
& \mathrm{h}=10 ; \\
& \mathrm{k}_{1}=956922 ; \\
& \mathrm{k}_{2}=1540000 ; \\
& \mathrm{c}_{1}=48569 ; \\
& \mathrm{c}_{2}=28440 ; \\
& \mathrm{C}_{3}=7003 ;
\end{aligned}
$$

valores iniciais:

$q_{1}=0$;

$\mathrm{q}^{\prime}{ }_{1}=0$;

$\mathrm{q}_{2}=0.01$;

$\mathrm{q}_{2}=0$;

$\mathrm{q}_{3}=0.01$;

$\mathrm{q}_{3}{ }_{3}=0$; 


\subsection{Sistema com 1 grau de liberdade}

O comportamento de vibração livre a partir de condições iniciais não nulas é aqui estudado. De acordo com os gráficos de resposta, percebemos que todos os valores decaem assintoticamente para a posição nula.

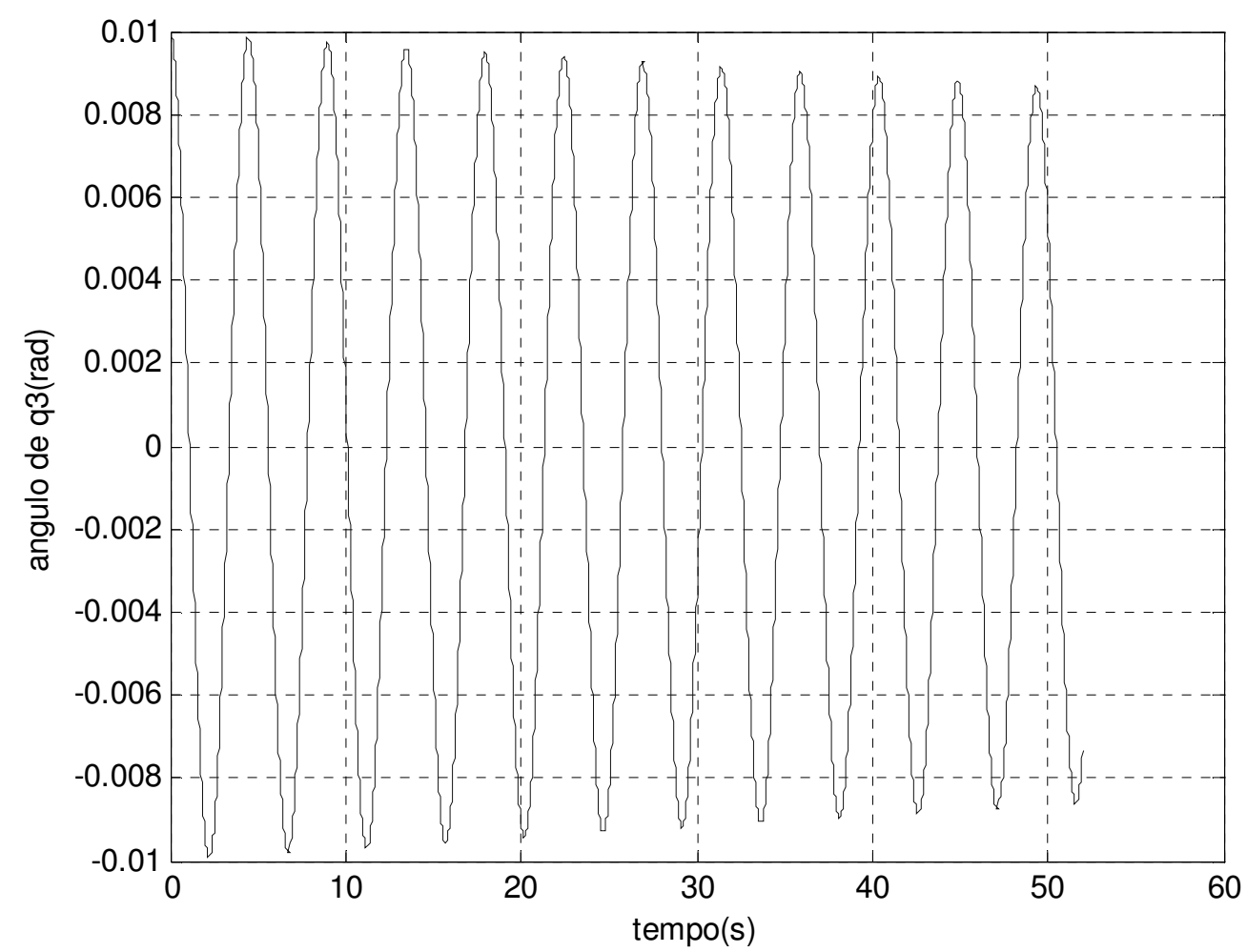

Gráfico 4 - Deslocamento de $q_{3}$ em função do tempo - sistema com 1 grau de liberdade 


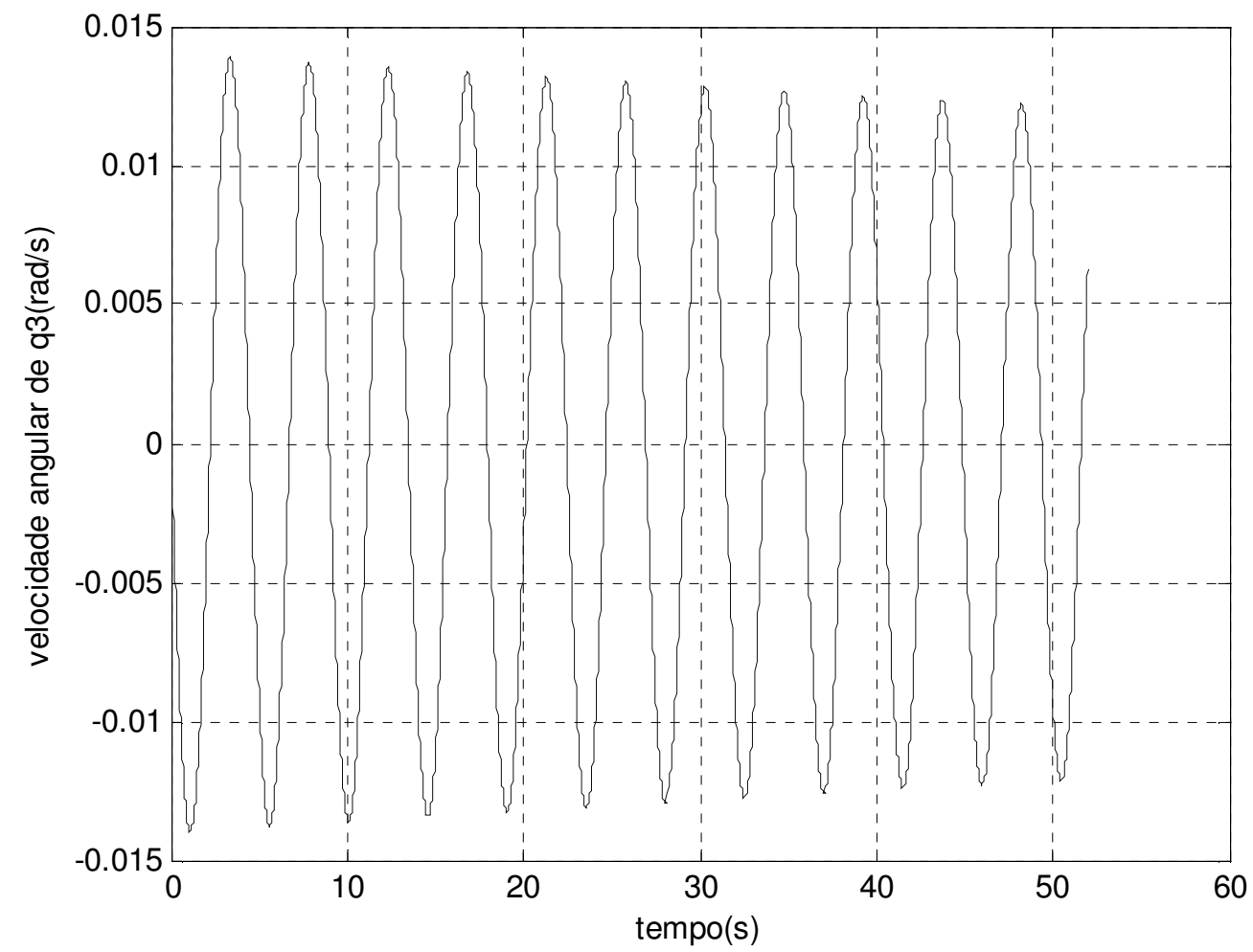

Gráfico 5- Velocidade de $q_{3}$ em função do tempo - sistema com 1 grau de liberdade

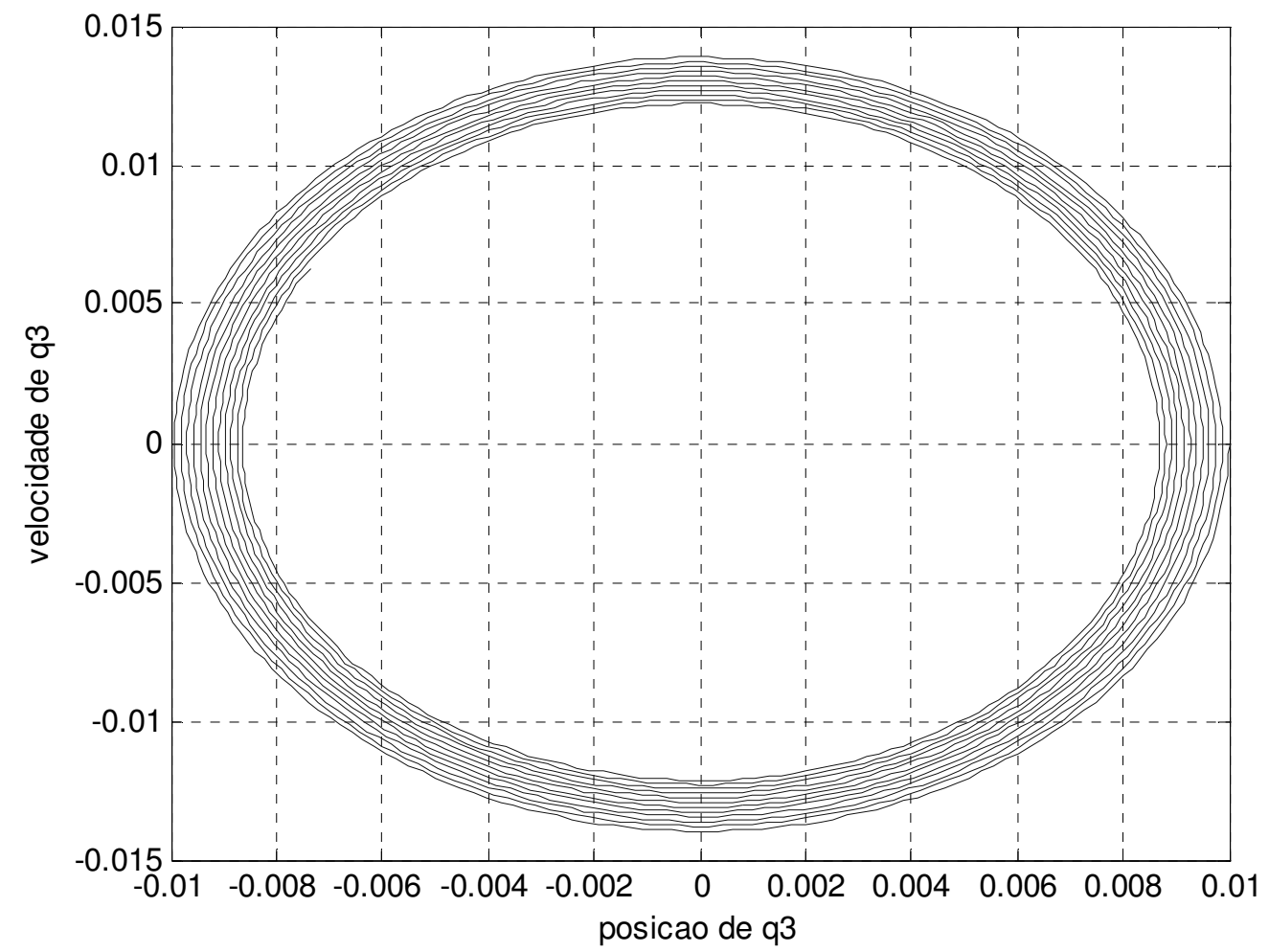

Gráfico 6- Velocidade angular $q_{3}$ em função da sua posição - sistema com 1 grau de liberdade 


\subsection{Sistema com 2 graus de liberdade}

Neste sistema considera-se como condição inicial um deslocamento em q3 igual ao do sistema anterior com 1 grau de liberdade.

Devido ao amortecimento as coordenadas tendem a posição de equilíbrio igual à zero.

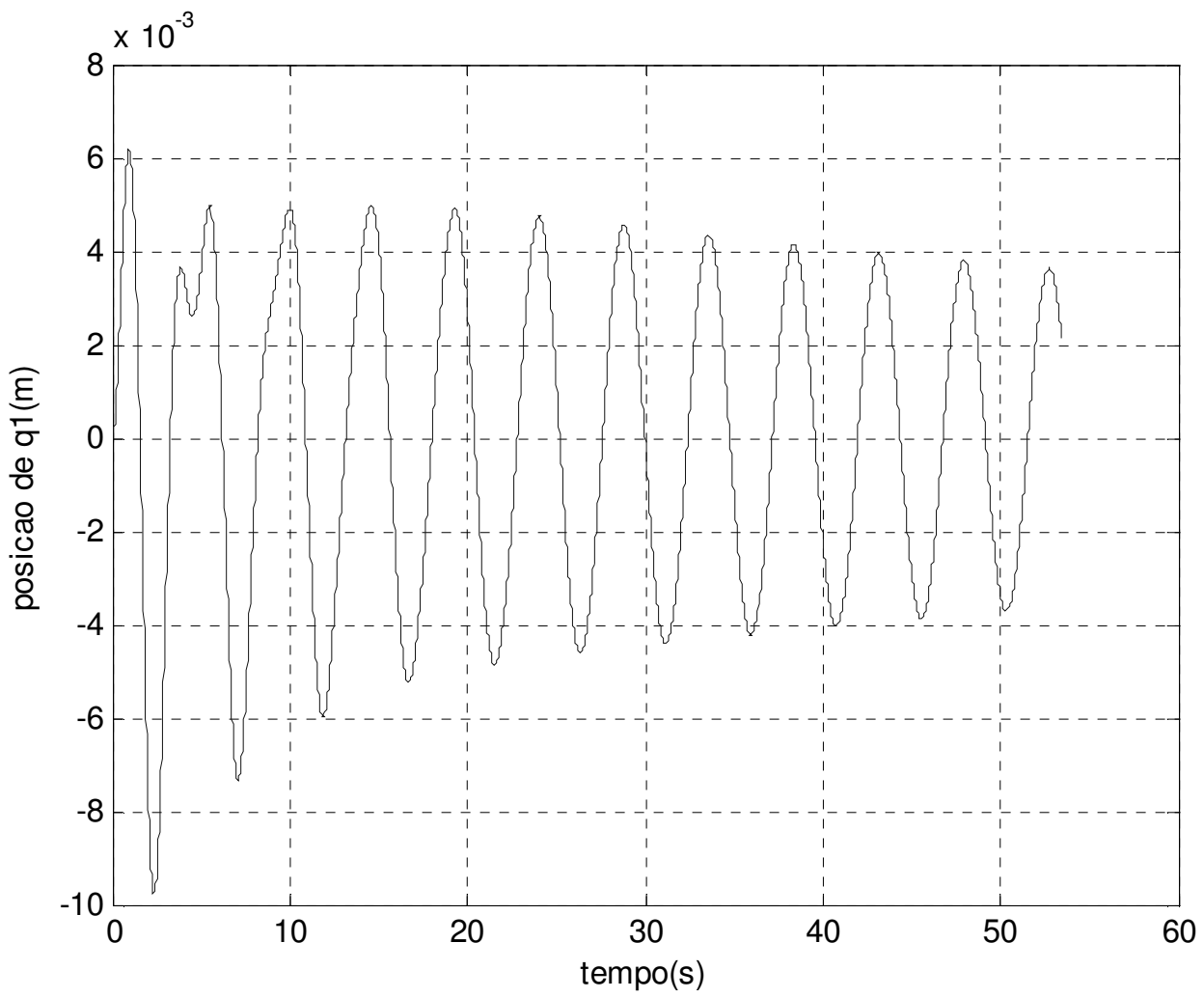

Gráfico 7 - Posição de $q_{1}$ em função do tempo - sistema com 2 graus de liberdade 


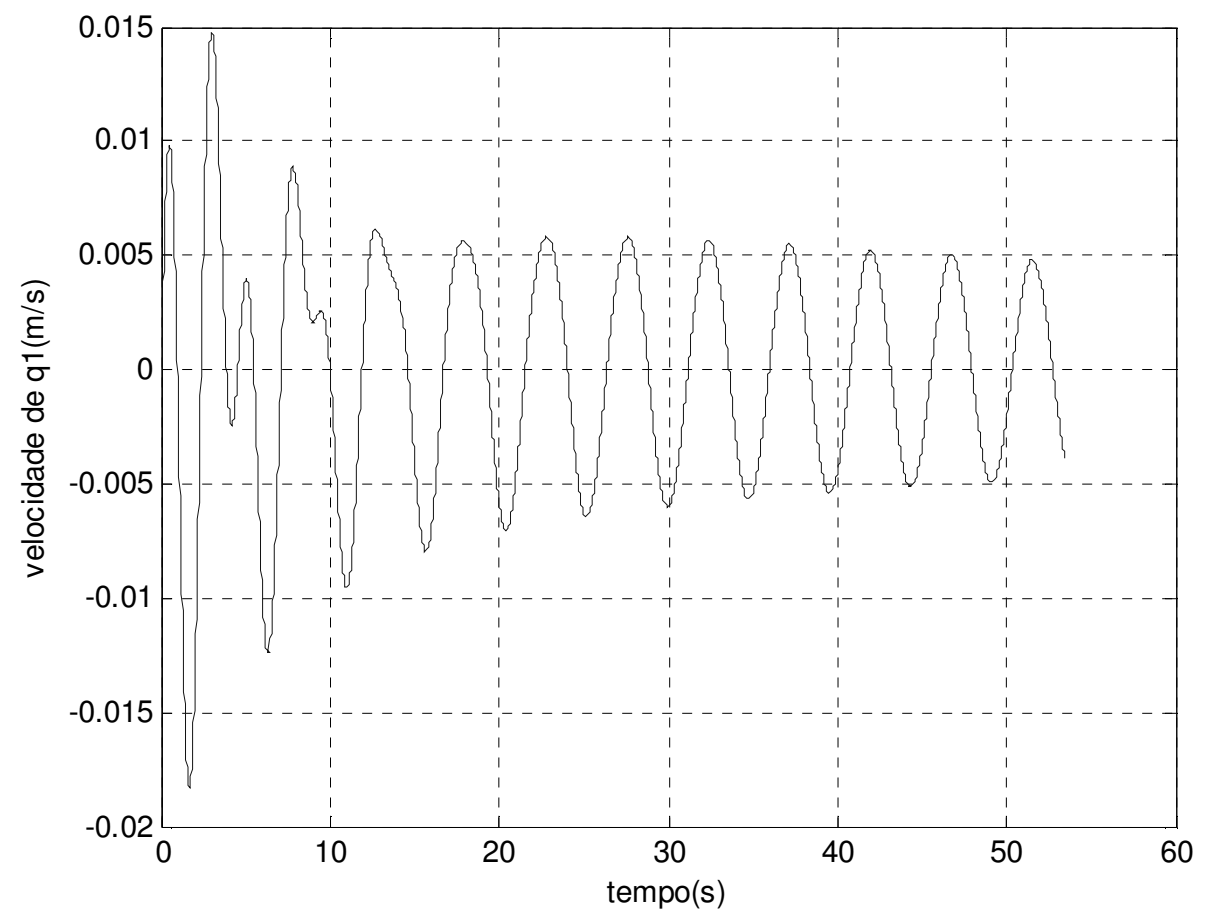

Gráfico 8 - Velocidade de $q_{1}$ em função do tempo - sistema com 2 graus de liberdade

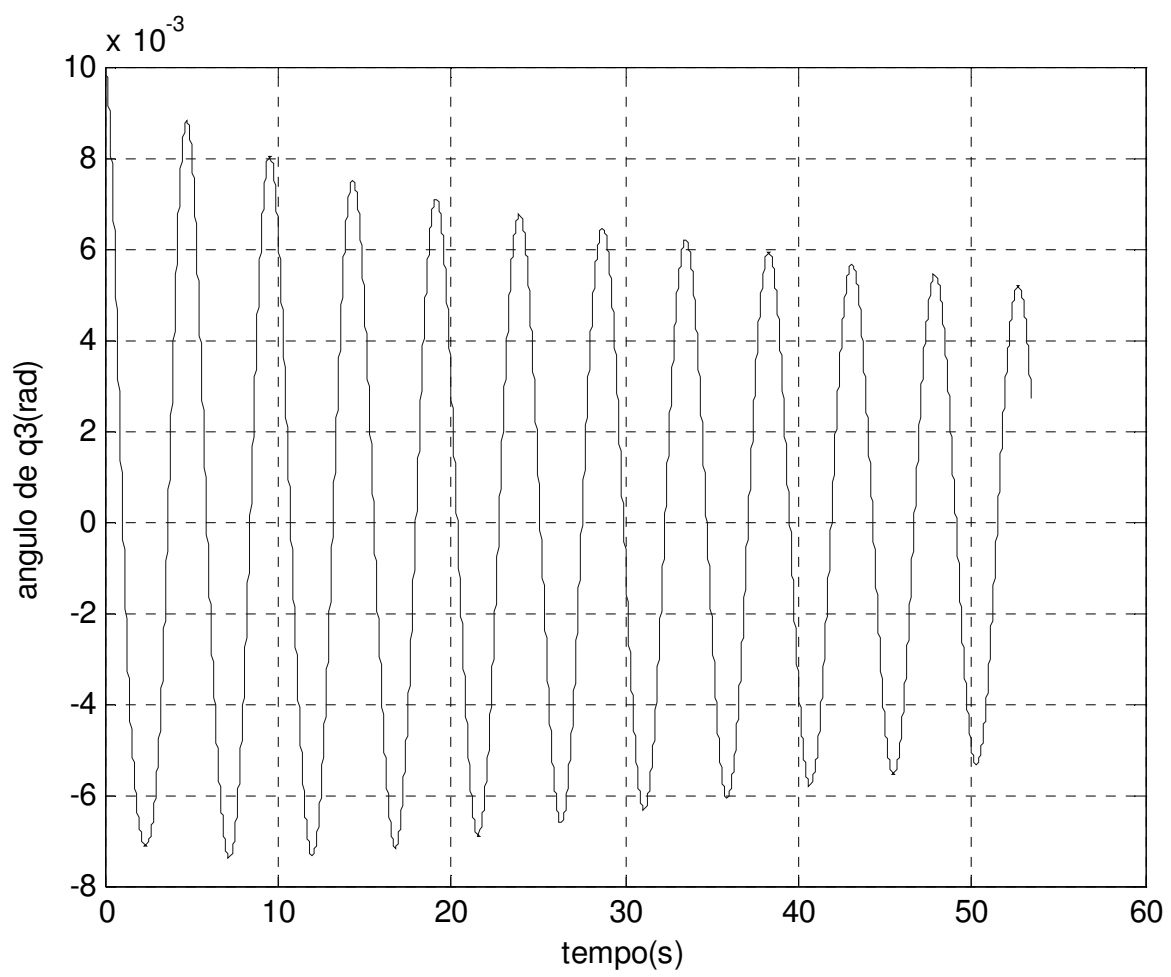

Gráfico 9 - Ângulo de $q_{3}$ em função do tempo - sistema com 2 graus de liberdade 


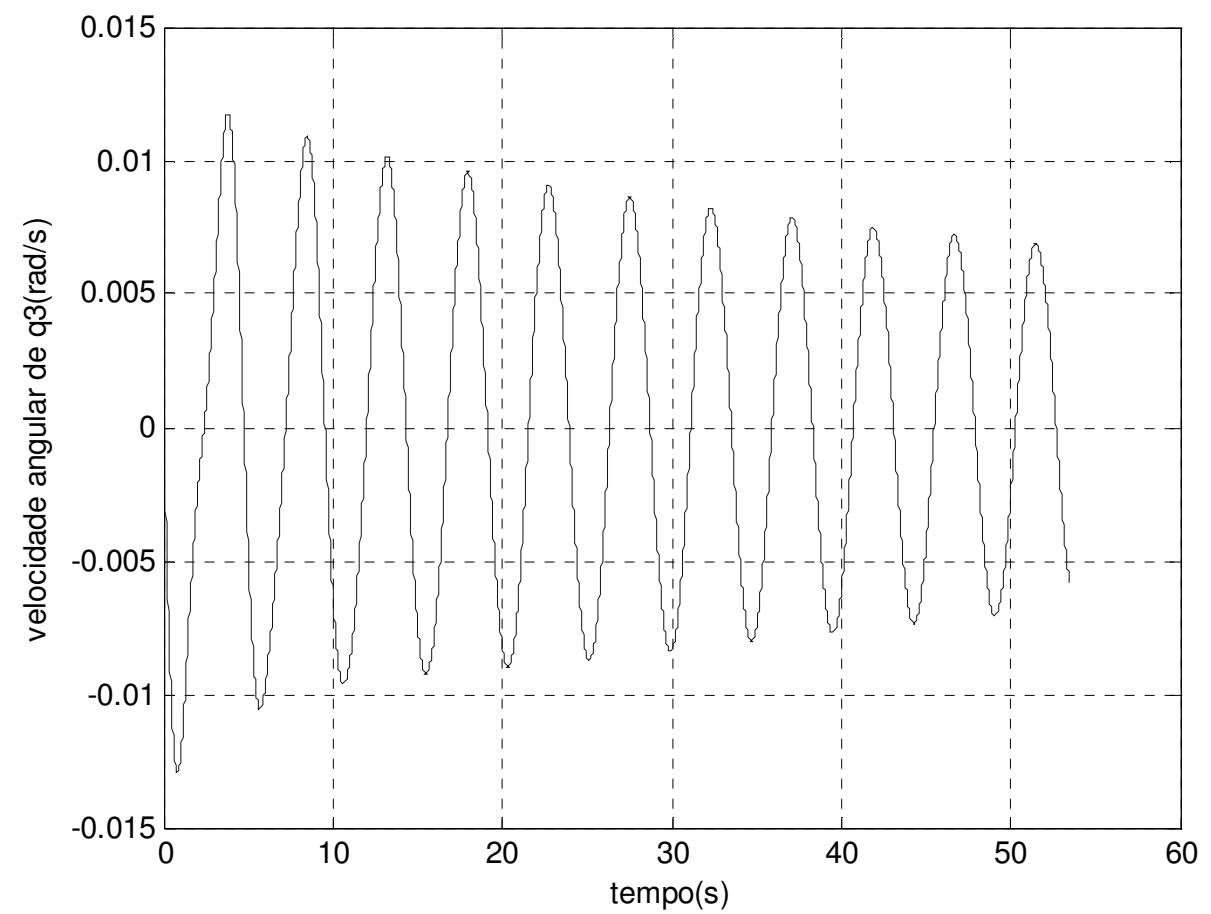

Gráfico 10 - Velocidade angular de $q_{3}$ em função do tempo - sistema com 2 graus de liberdade

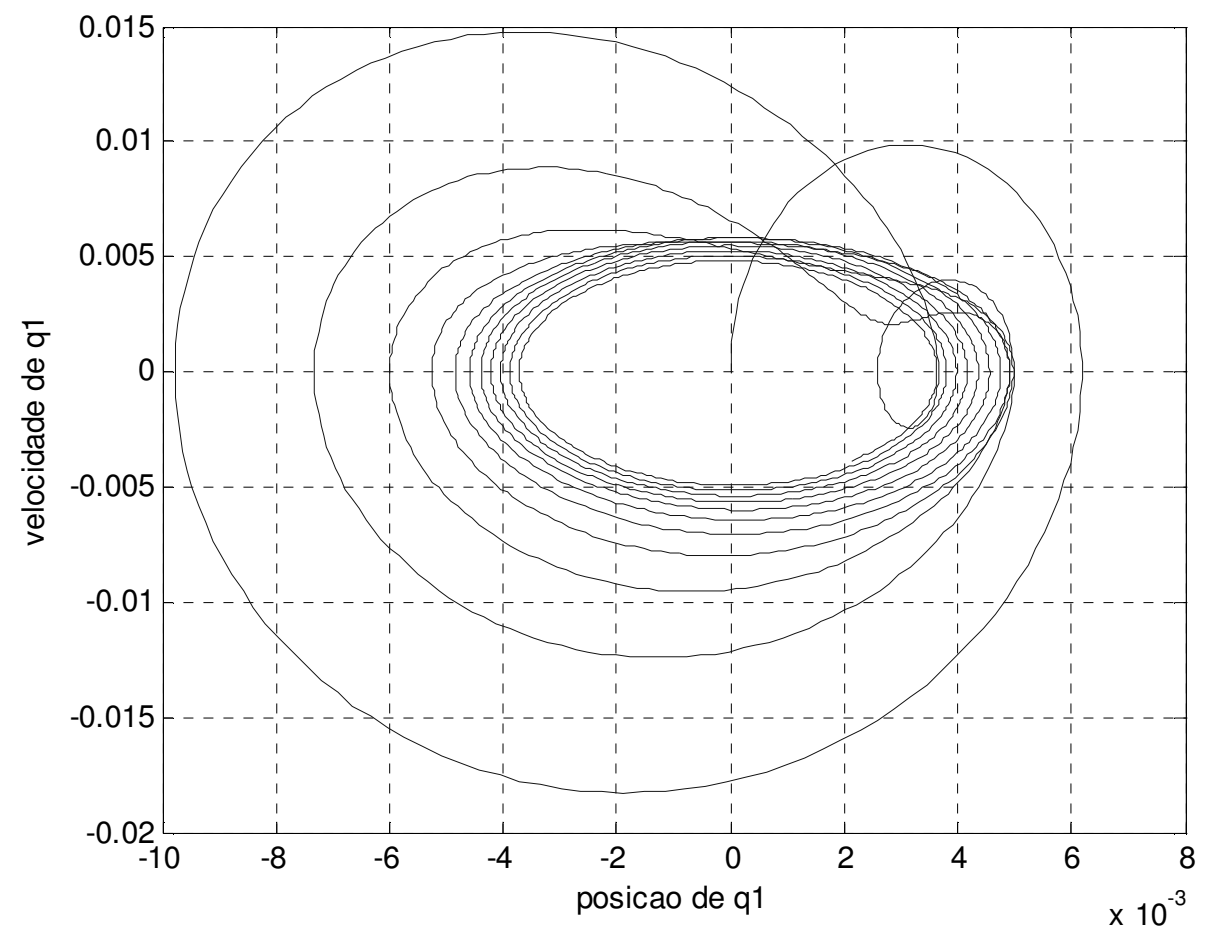

Gráfico 11 - Velocidade de q1 em função da posição de $q_{1}$ - sistema com 2 graus de liberdade 


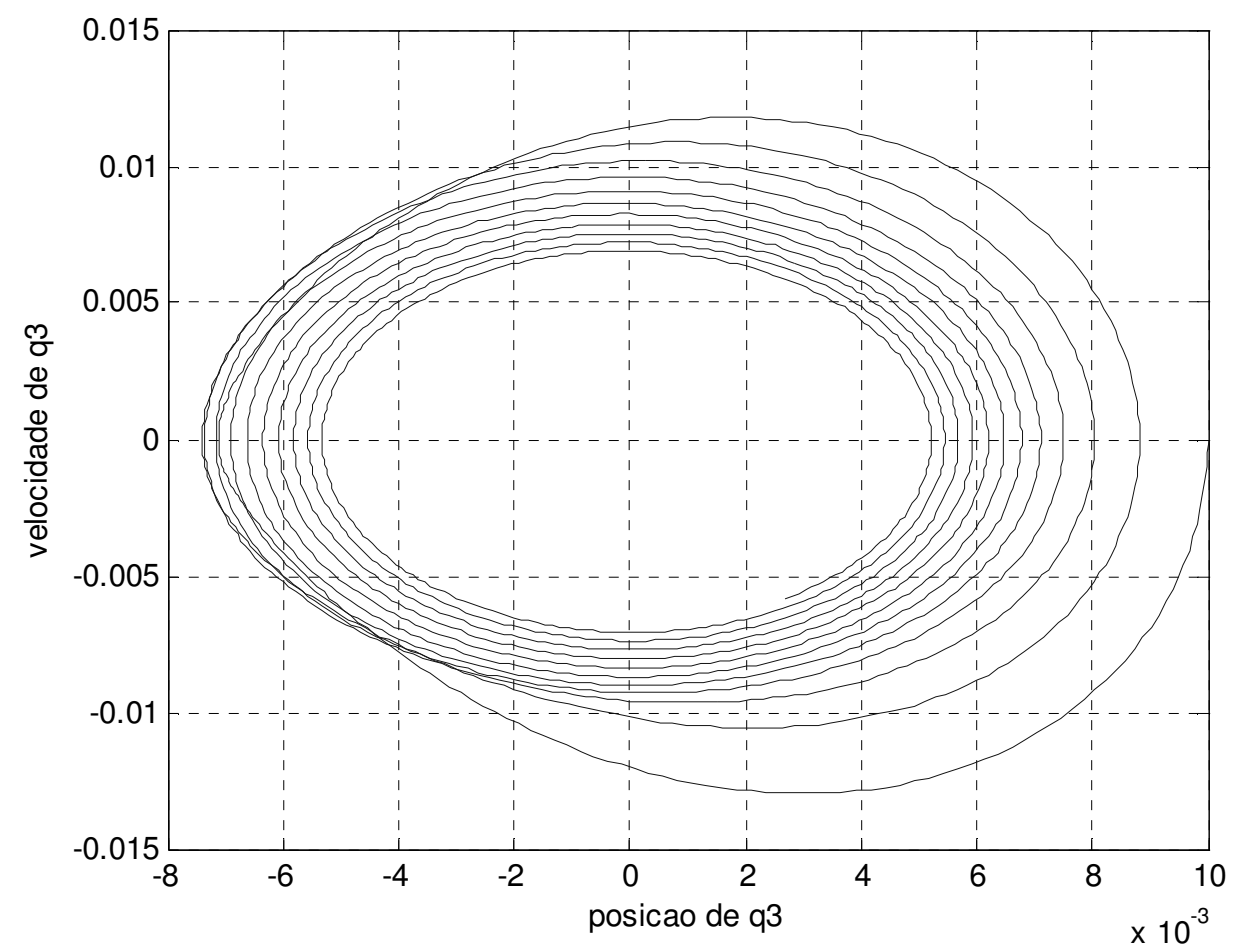

Gráfico 12 - velocidade de $q_{3}$ em função da sua posição- sistema com 2 graus de liberdade

De acordo com os planos de fase dos gráficos 11 e 12 notamos que as coordenadas generalizadas $q_{1}, q_{1}^{\prime}, q_{2}$ e $q_{2}^{\prime}$ retornam a posição de equilíbrio nula, após o decurso de um longo tempo. 


\subsection{Sistema com 3 graus de liberdade}

Neste sistema utilizam-se as mesmas condições iniciais dos modelos anteriores. Alem disso, foi adicionado um deslocamento inicial não nulo em q2.

Como nos casos anteriores verifica-se que as coordenadas tendem a posição de equilíbrio nula assintoticamente.

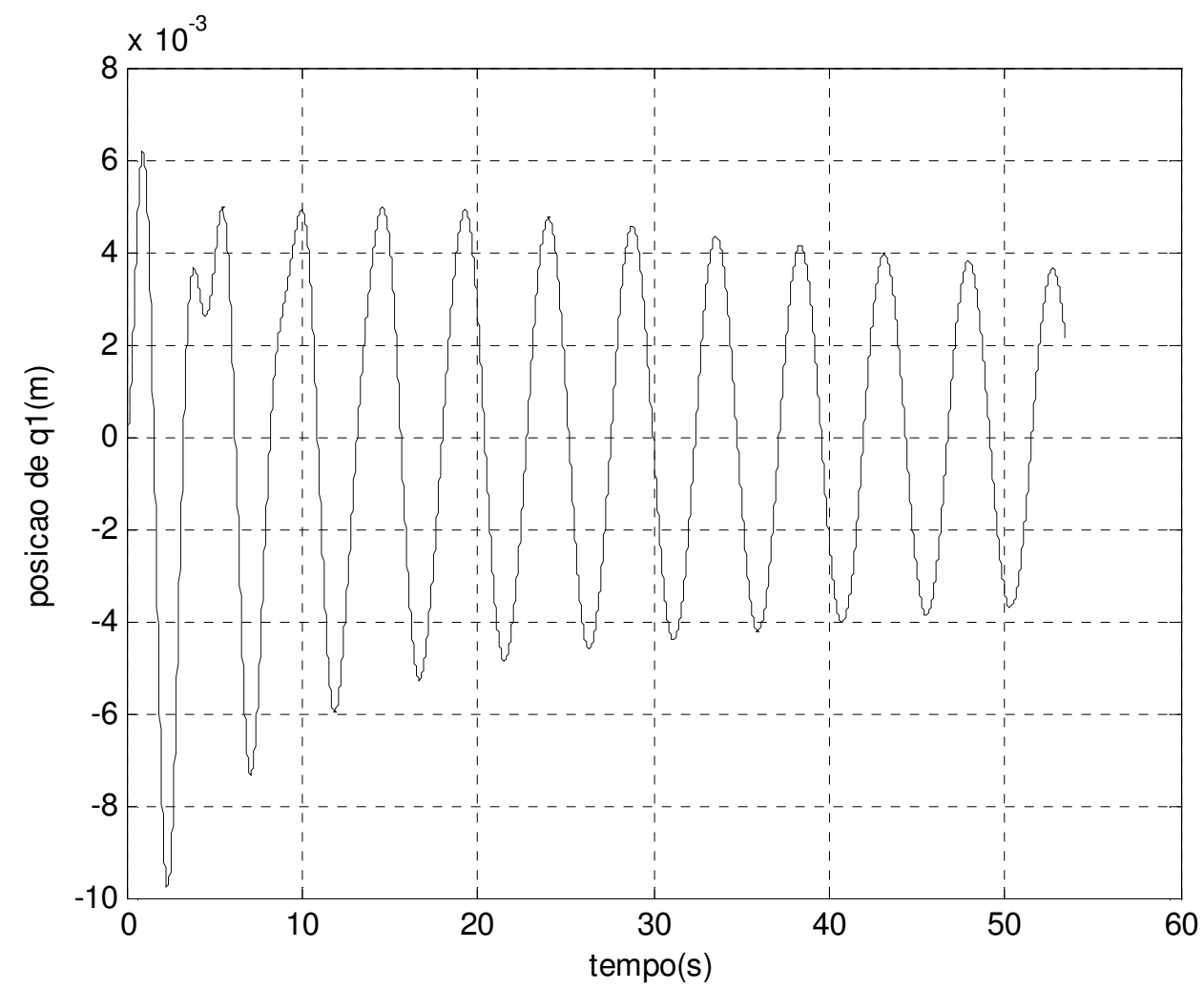

Gráfico 13 - Posição de $q_{1}$ em função do tempo - sistema com 3 graus de liberdade 


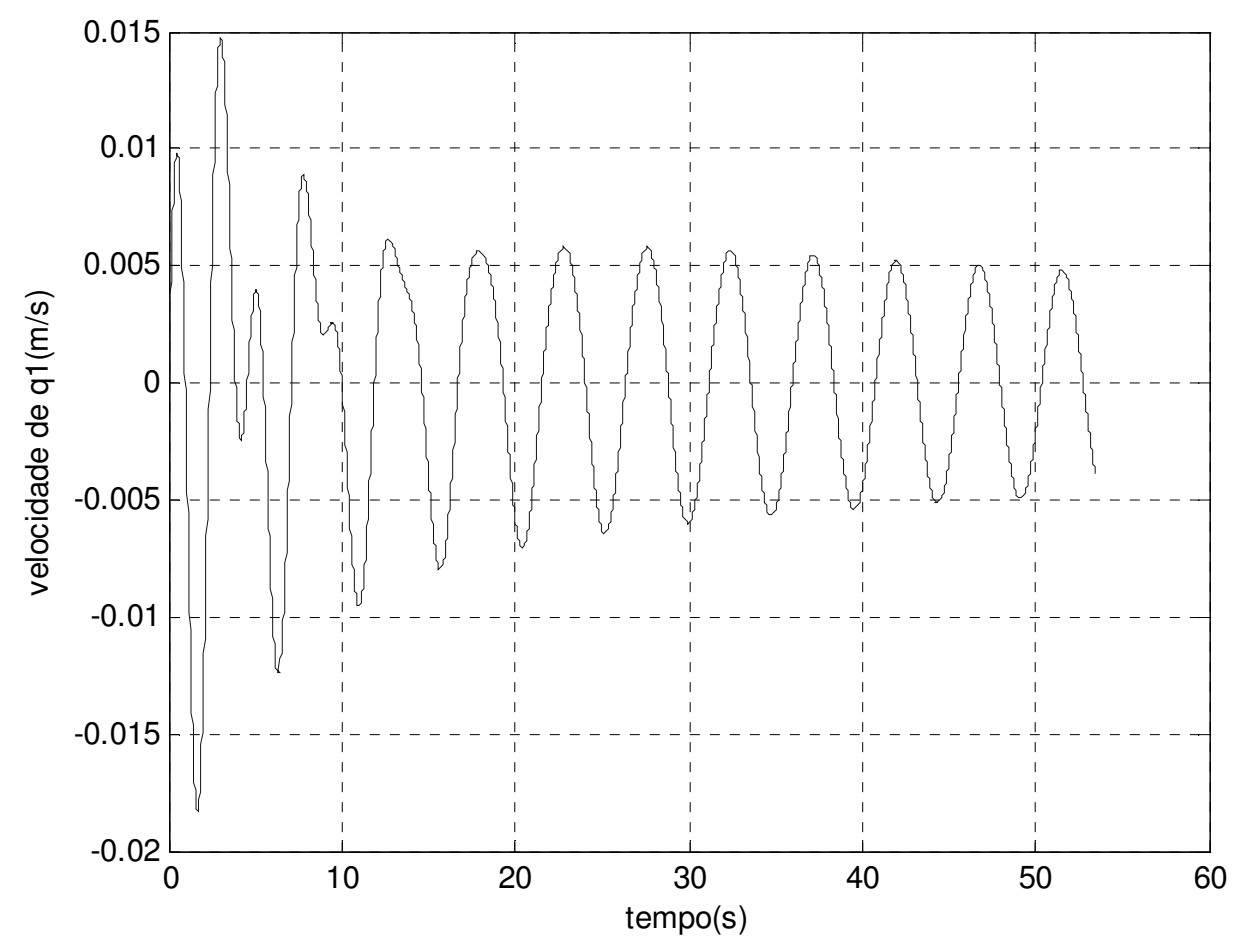

Gráfico 14 - velocidade de $q_{1}$ em função do tempo - sistema com 3 graus de liberdade

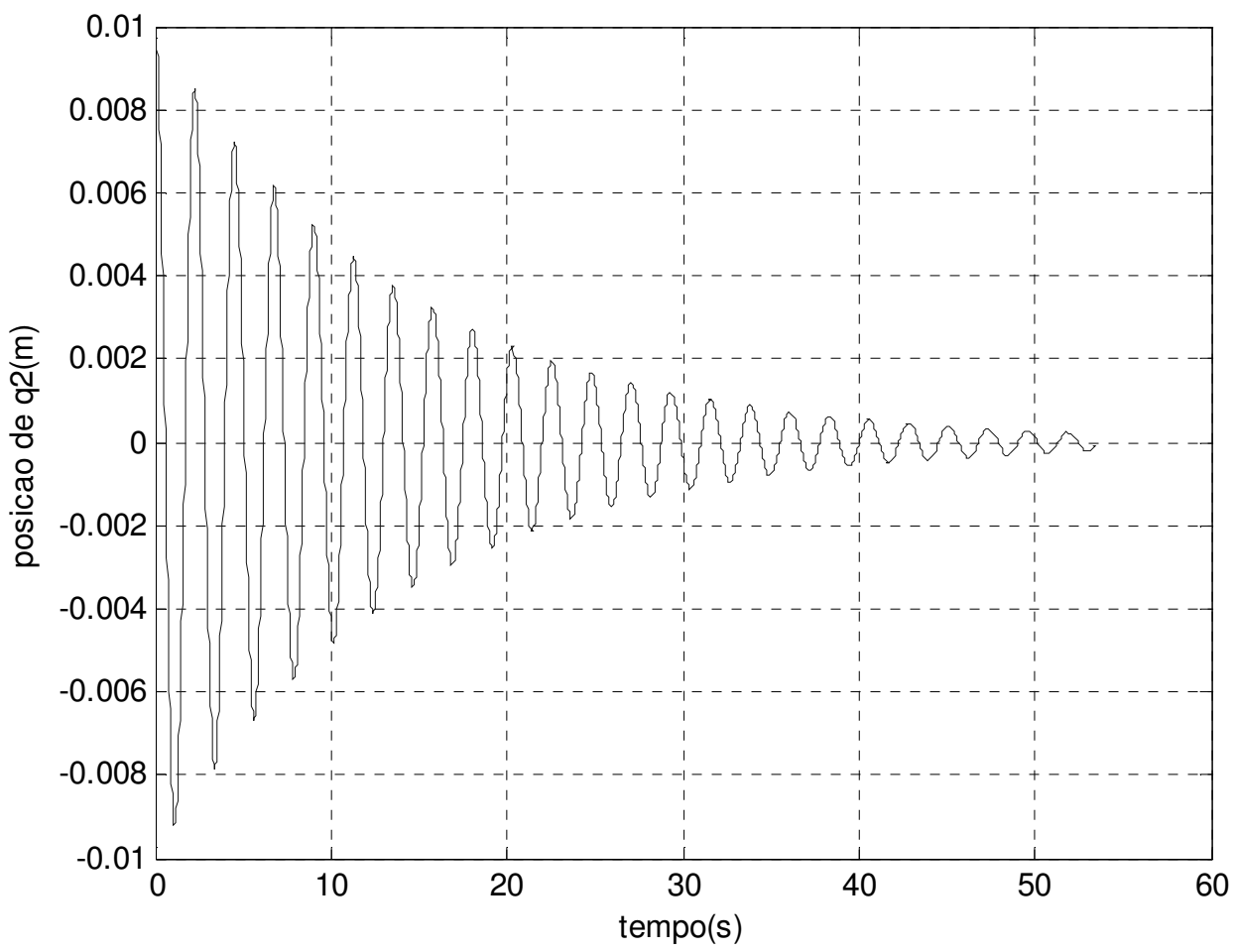

Gráfico 15 - posição de $q_{2}$ em função do tempo - sistema com 3 graus de liberdade 


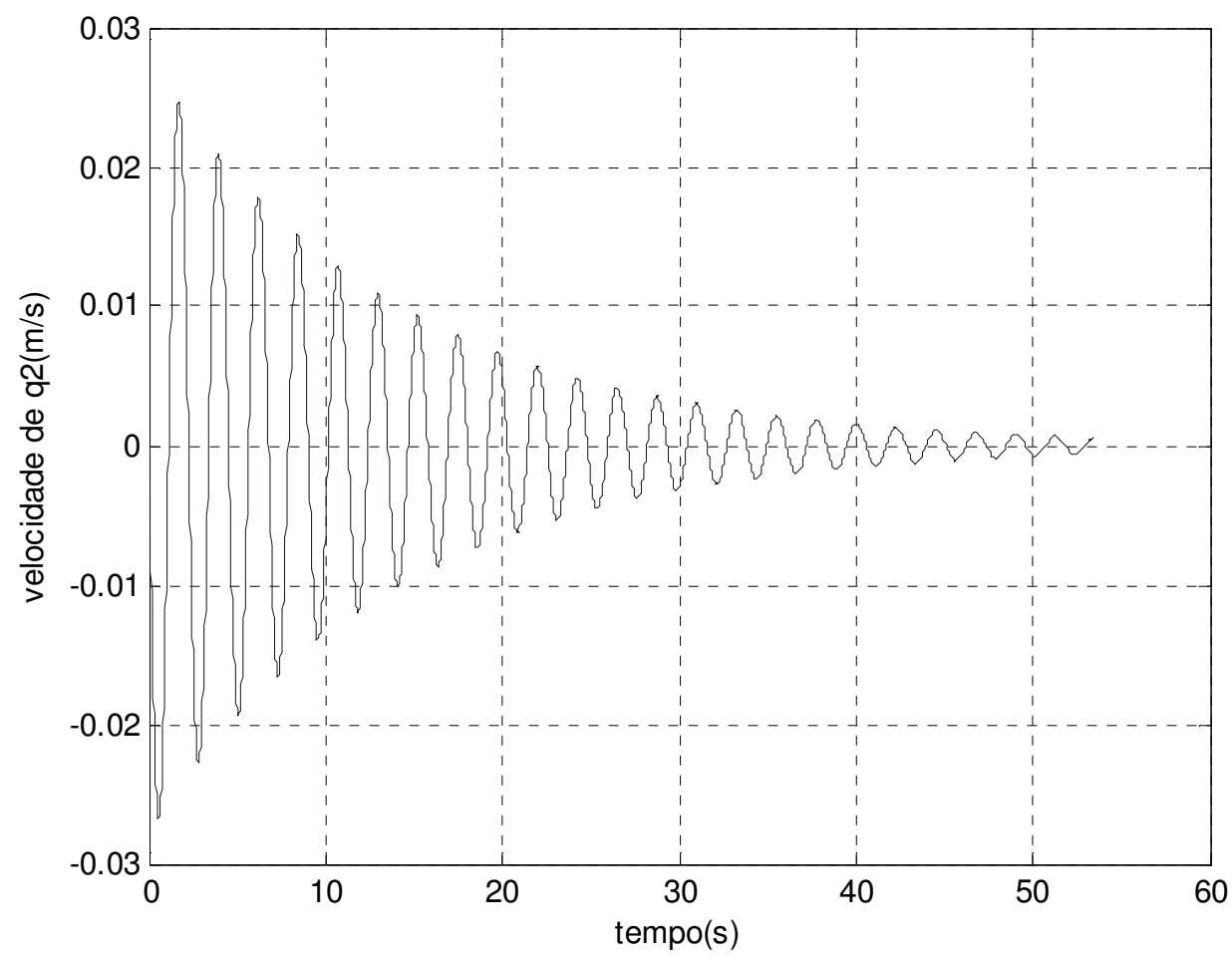

Gráfico 16 - velocidade de $q_{2}$ em função do tempo - sistema com 3 graus de liberdade

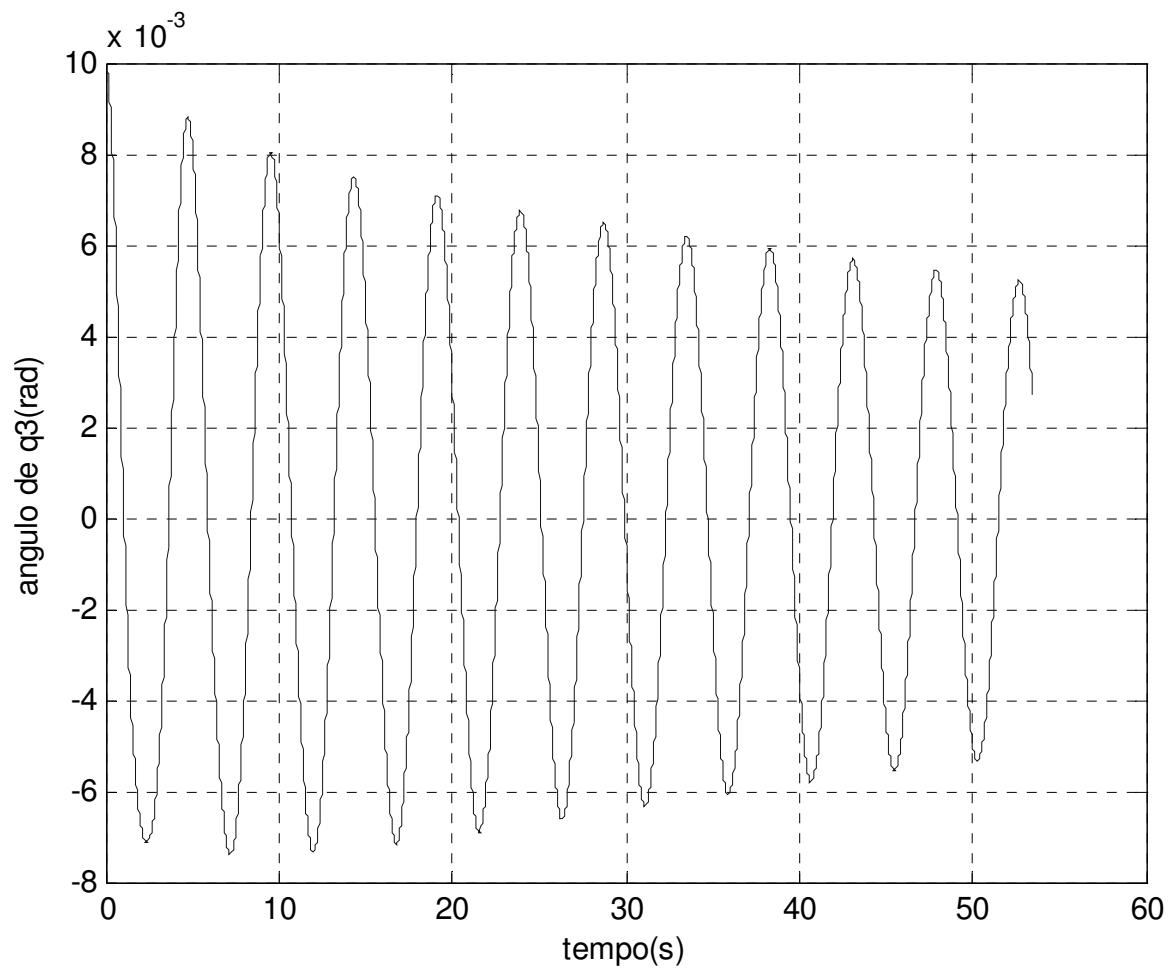

Gráfico 17 - ângulo de $q_{3}$ em função do tempo - sistema com 3 graus de liberdade 


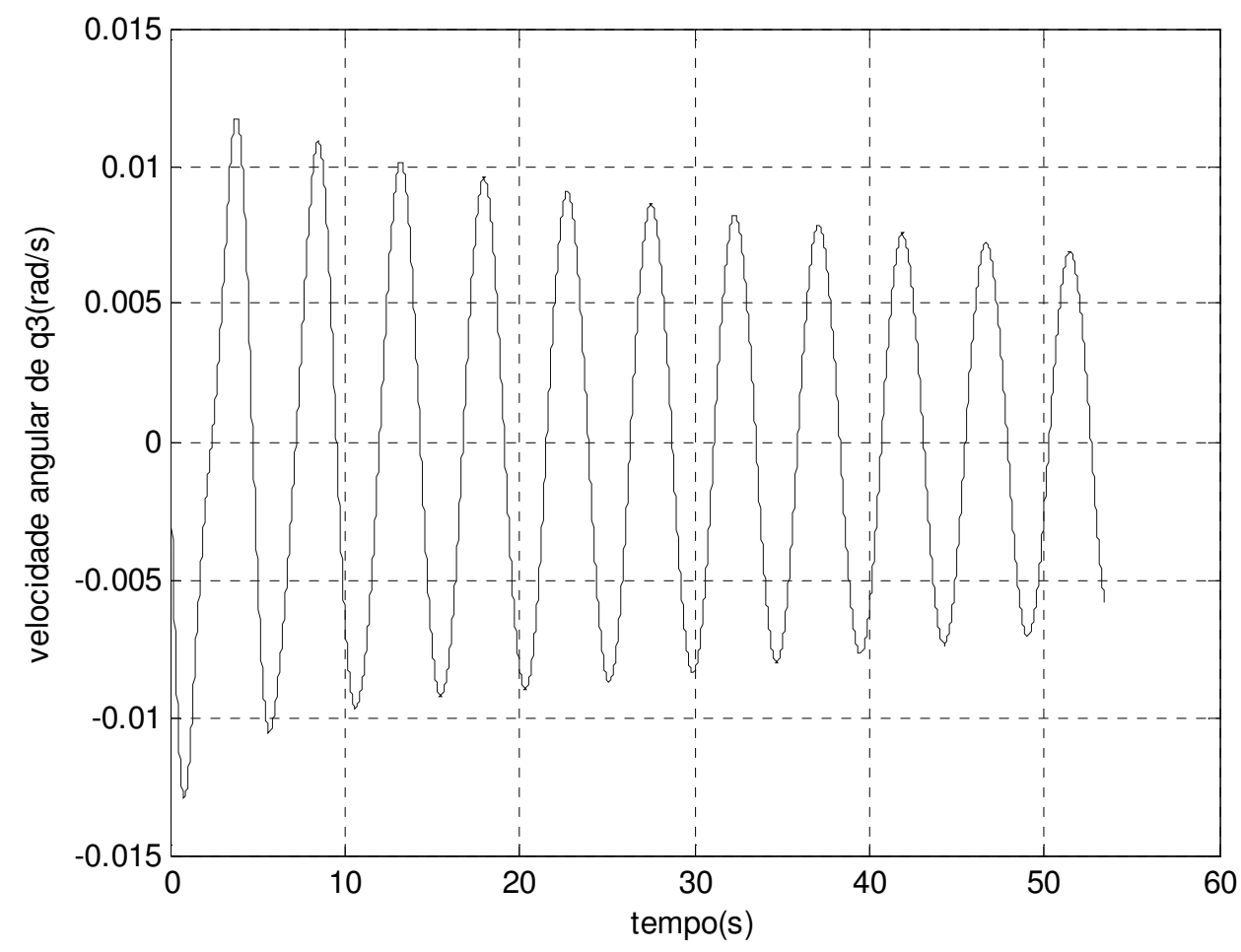

Gráfico 18 - velocidade de $q_{3}$ em função do tempo - sistema com 3 graus de liberdade

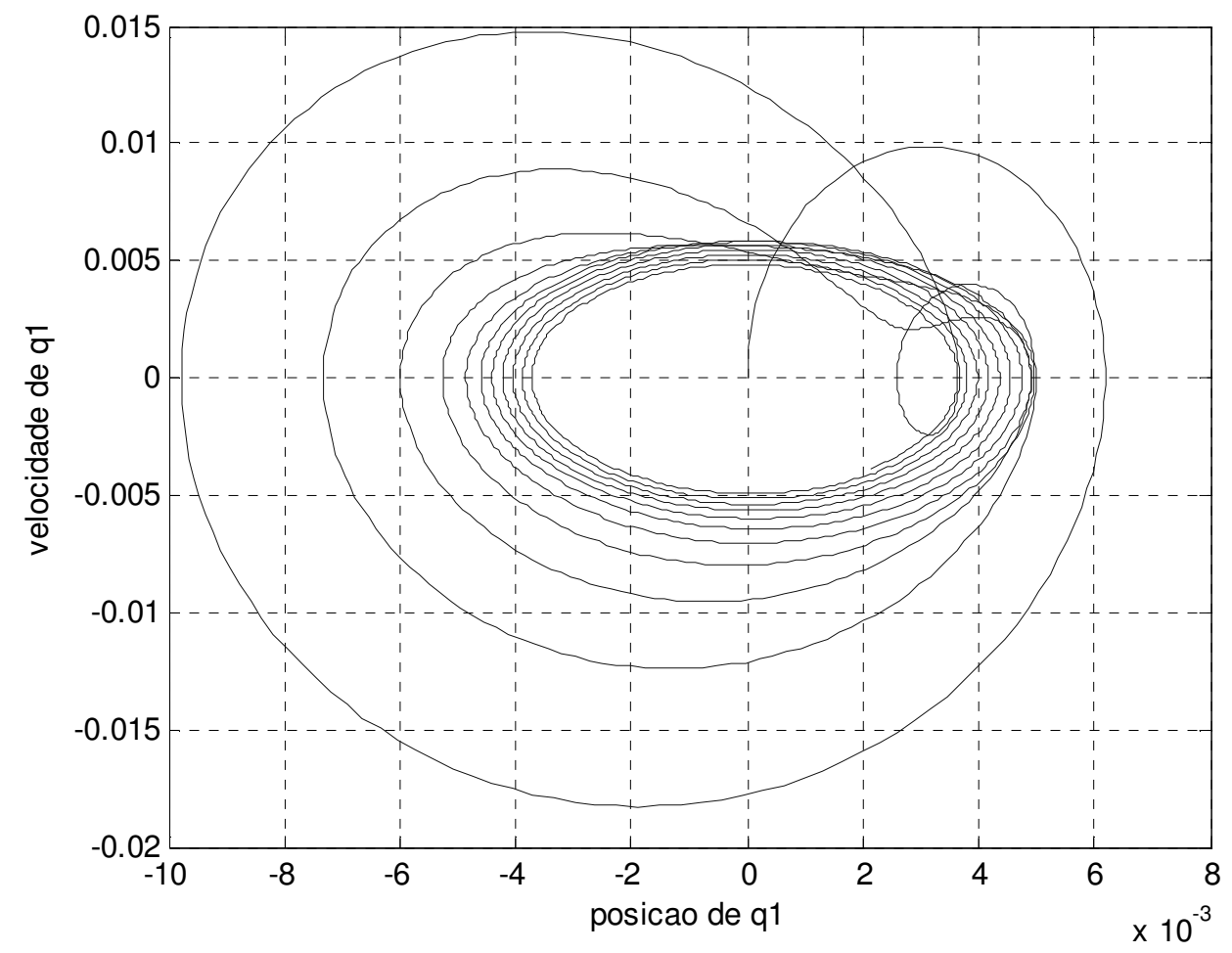

Gráfico 19 - velocidade de $q_{1}$ em função de sua posição - sistema com 3 graus de liberdade 


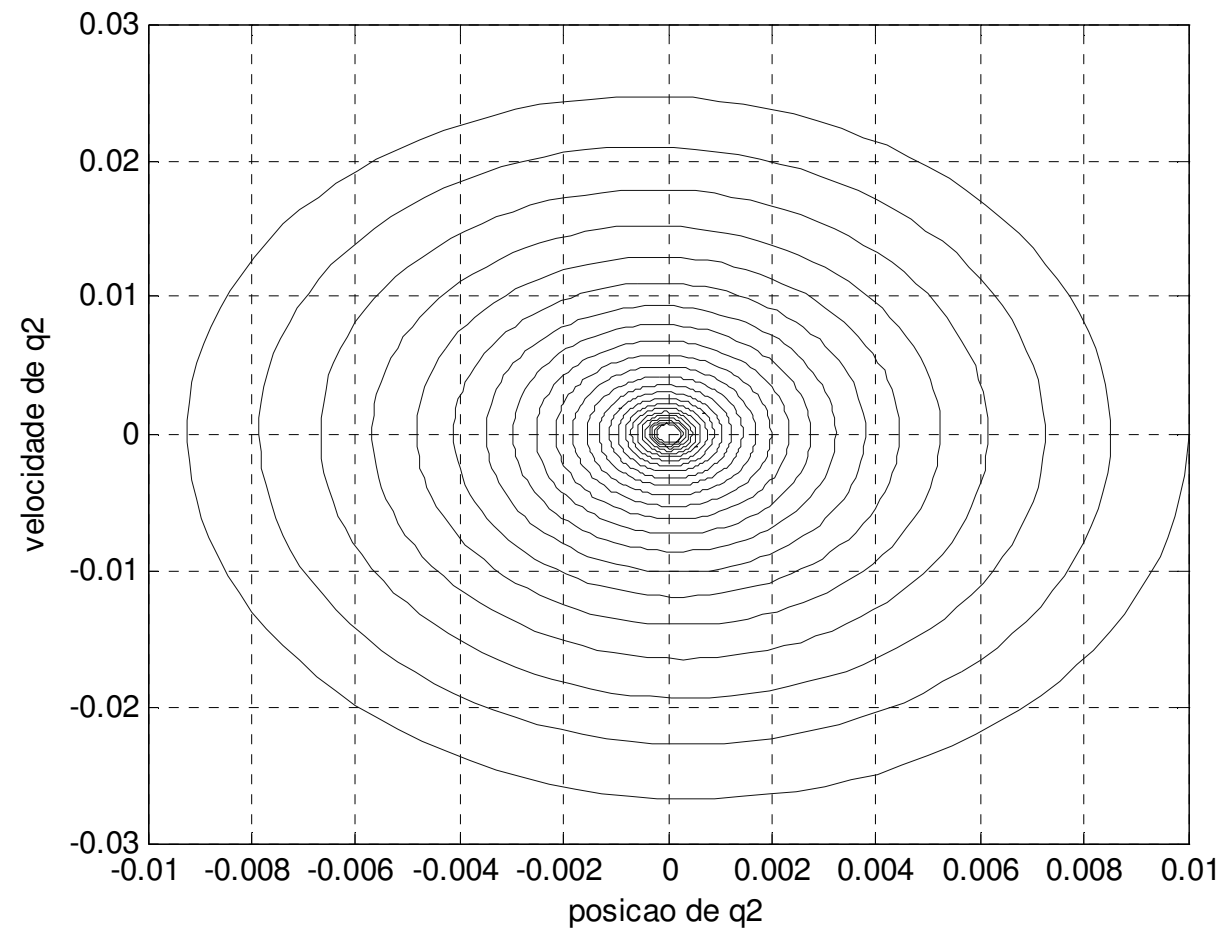

Gráfico 20 - plano de fase de $q_{2}$ - sistema com 3 graus de liberdade

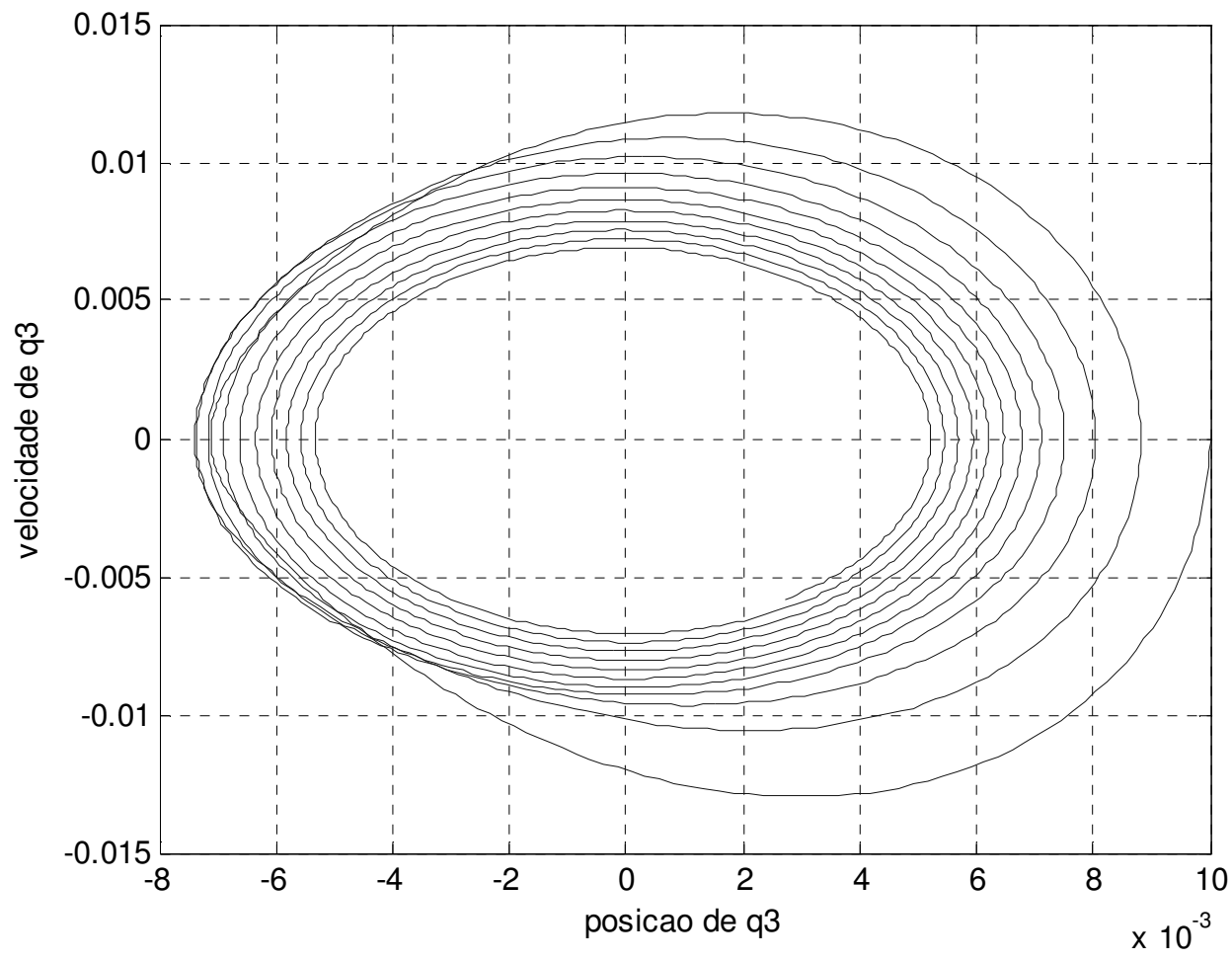

Gráfico 21 - plano de fase de $q_{3}$ - sistema com 3 graus de liberdade 


\subsection{Comparativo entre os modelos}

Neste tópico compara-se a evolução das coordenadas generalizadas em função do tempo, para vibrações livres dos diversos modelos.

\subsubsection{Coordenada $q_{3}$}

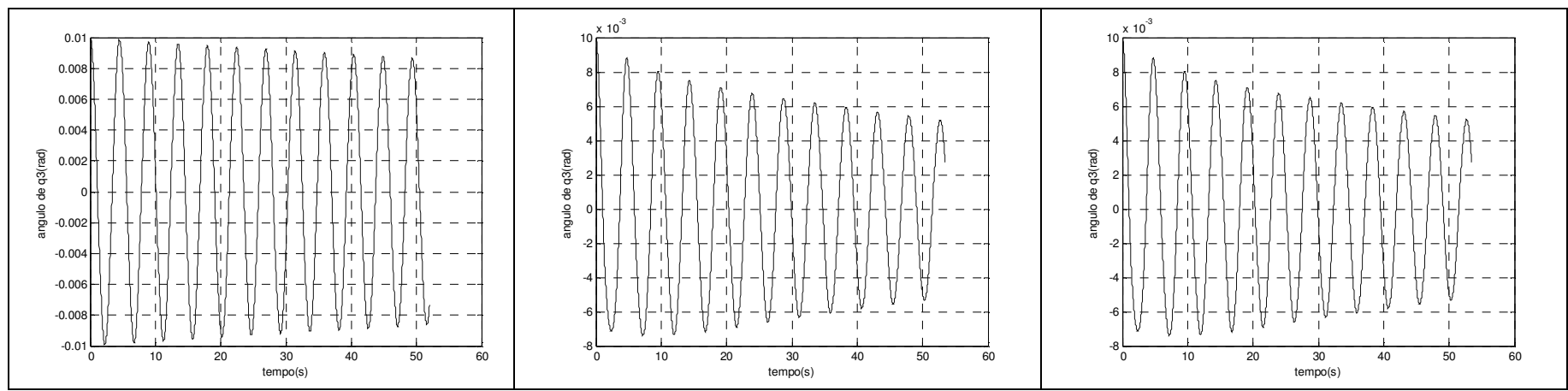

Gráfico 22 - comparativo de $q_{3}$ para 1, 2 e 3 graus de liberdade

Com relação à oscilação do pêndulo nota-se que os deslocamentos no modelo de 2 e 3 graus de liberdade são idênticos e tendem a posição de equilíbrio nula.

\subsubsection{Coordenada $q_{1}$}

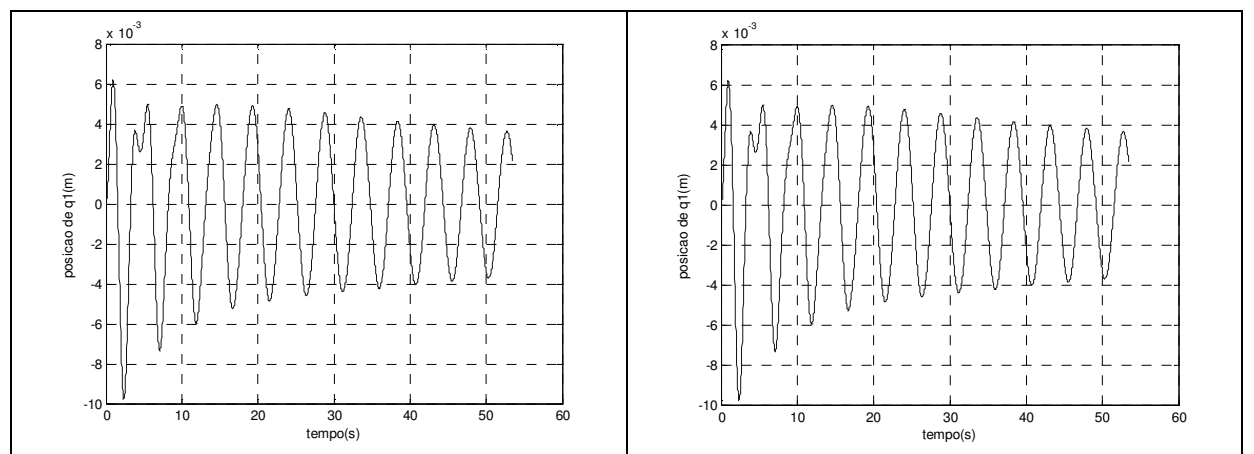

Gráfico 23 - comparativo de $q_{1}$ para 2 e 3 graus de liberdade - entradas iniciais

O deslocamento do sistema na direção horizontal $x$ é idêntico para os dois últimos sistemas. 


\subsection{3 plano de fase q3}

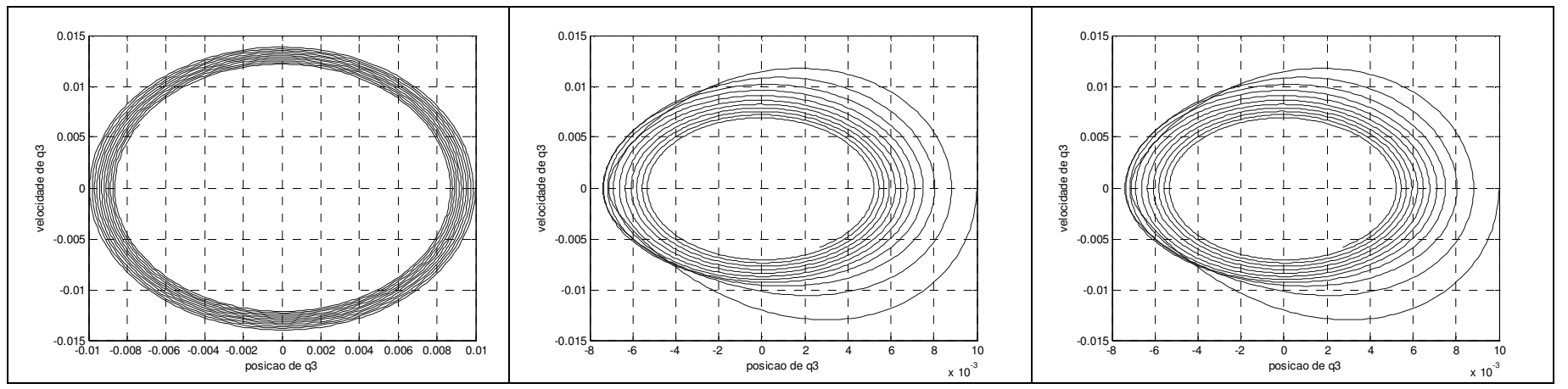

Gráfico 24 - comparativo do plano de fase de $q_{3}$ para 1, 2 e 3 graus de liberdade - entradas iniciais

\subsection{4 plano de fase q1}

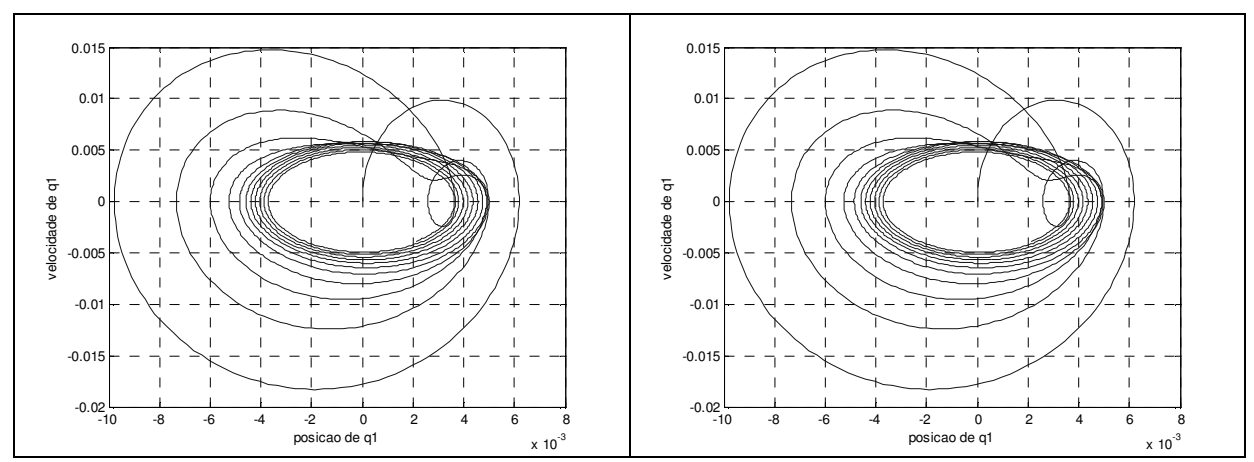

Gráfico 25 - comparativo do plano de fase de $q_{1}$ para 2 e 3 graus de liberdade - entradas iniciais

A partir de condições iniciais não nulas pode-se verificar o comportamento da estrutura em vibrações livres. Verifica-se que todas as simulações tendem a posição de equilíbrio nula, e que o comportamento dos dois últimos sistemas é idêntico para as coordenadas $q_{1}$ e $q_{3}$. Nota-se também que o sistema com 1 grau de liberdade possui os maiores deslocamentos angulares. 


\section{RESPOSTAS DOS SISTEMAS A UM TERREMOTO REAL}

Neste tópico submetem-se os sistemas à entrada um sismo real já registrado (El centro), conforme tópico 2.2.

\subsection{Sistema com 1 grau de liberdade}

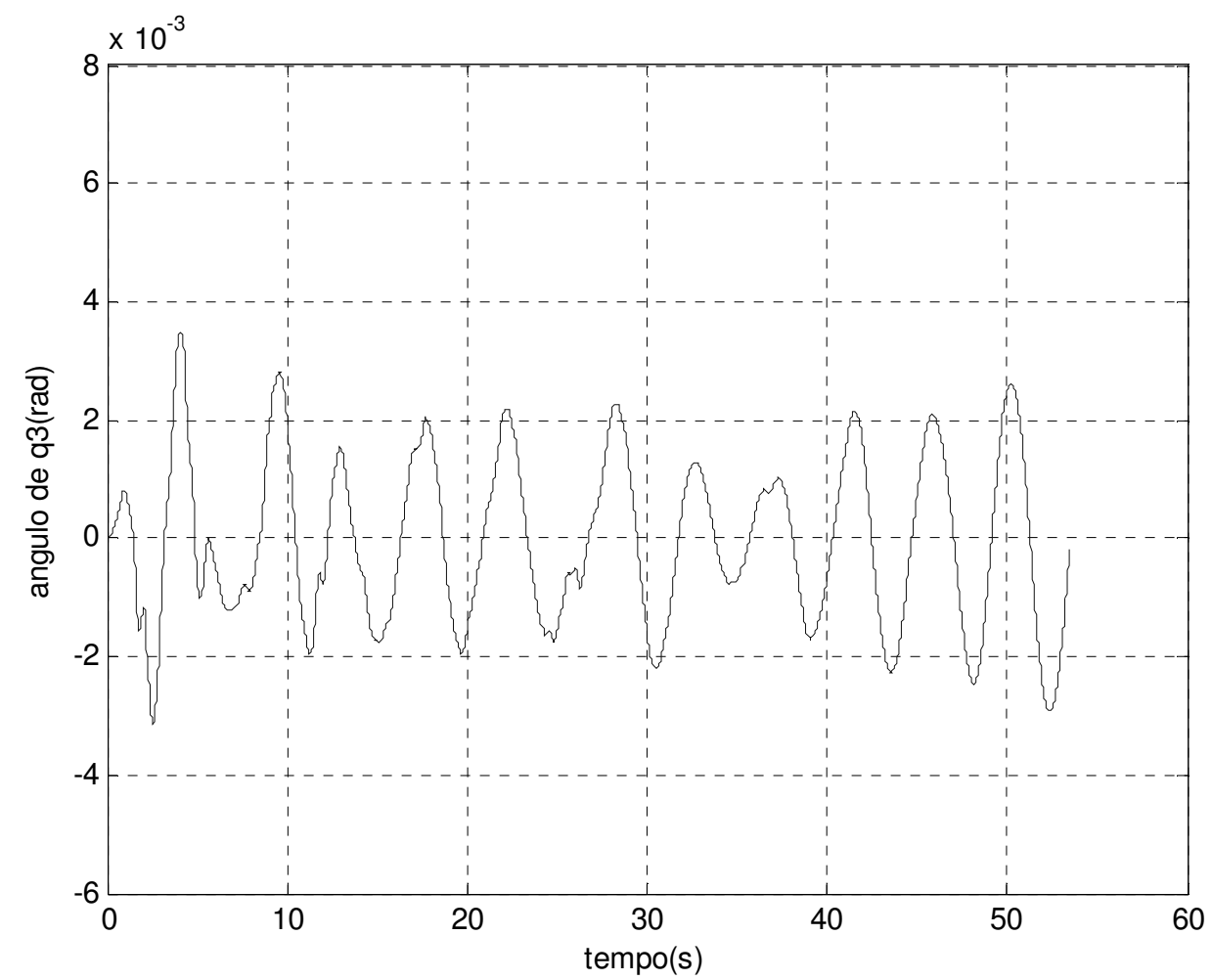

Gráfico 26 - ângulo de $q_{3}$ em função do tempo - sistema com 1 grau de liberdade - entrada sísmica

O pêndulo oscila com amplitudes baixas quando excitado pelo sismo. 


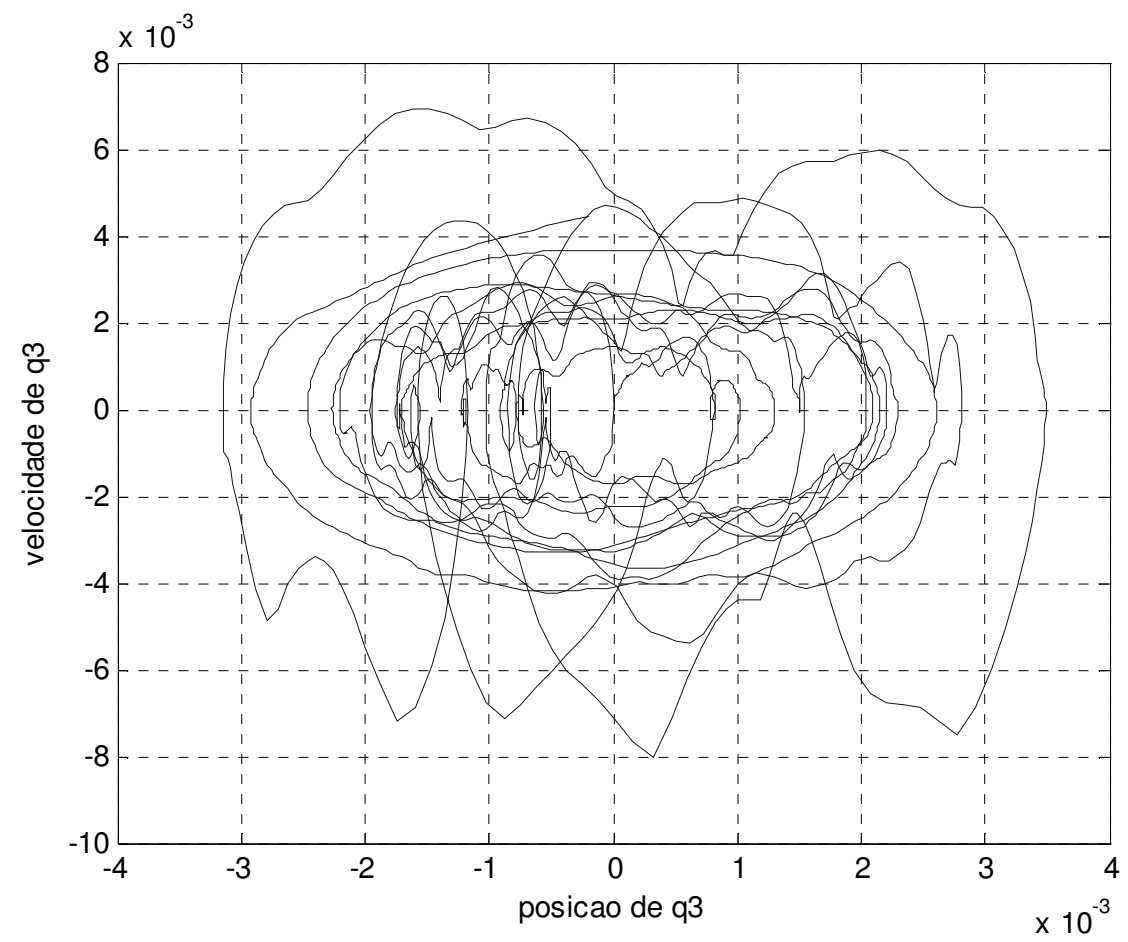

Gráfico 27 - plano de fase de $q_{3}$ - sistema com 1 grau de liberdade - entrada sismica

\subsection{Sistema com 2 graus de liberdade}

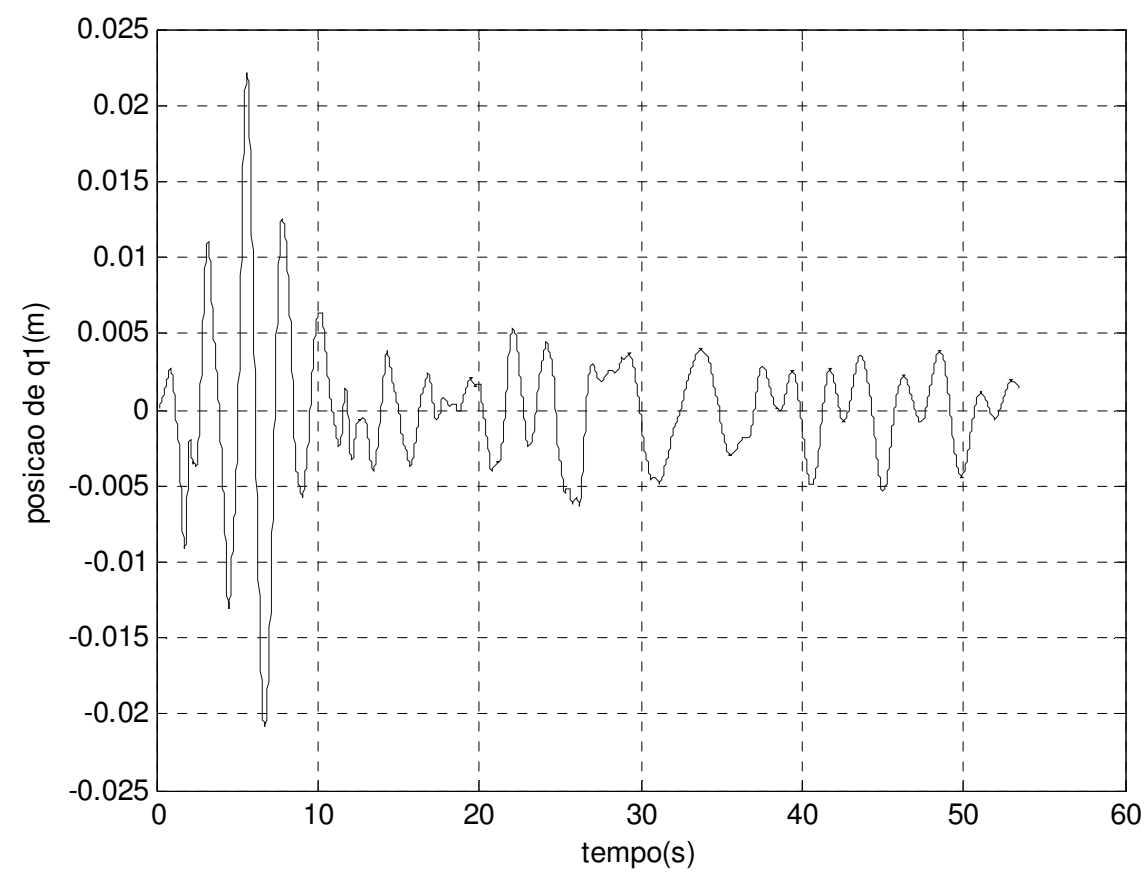

Gráfico 28 - posição de $q_{1}$ em função do tempo - sistema com 2 graus de liberdade - entrada sísmica 


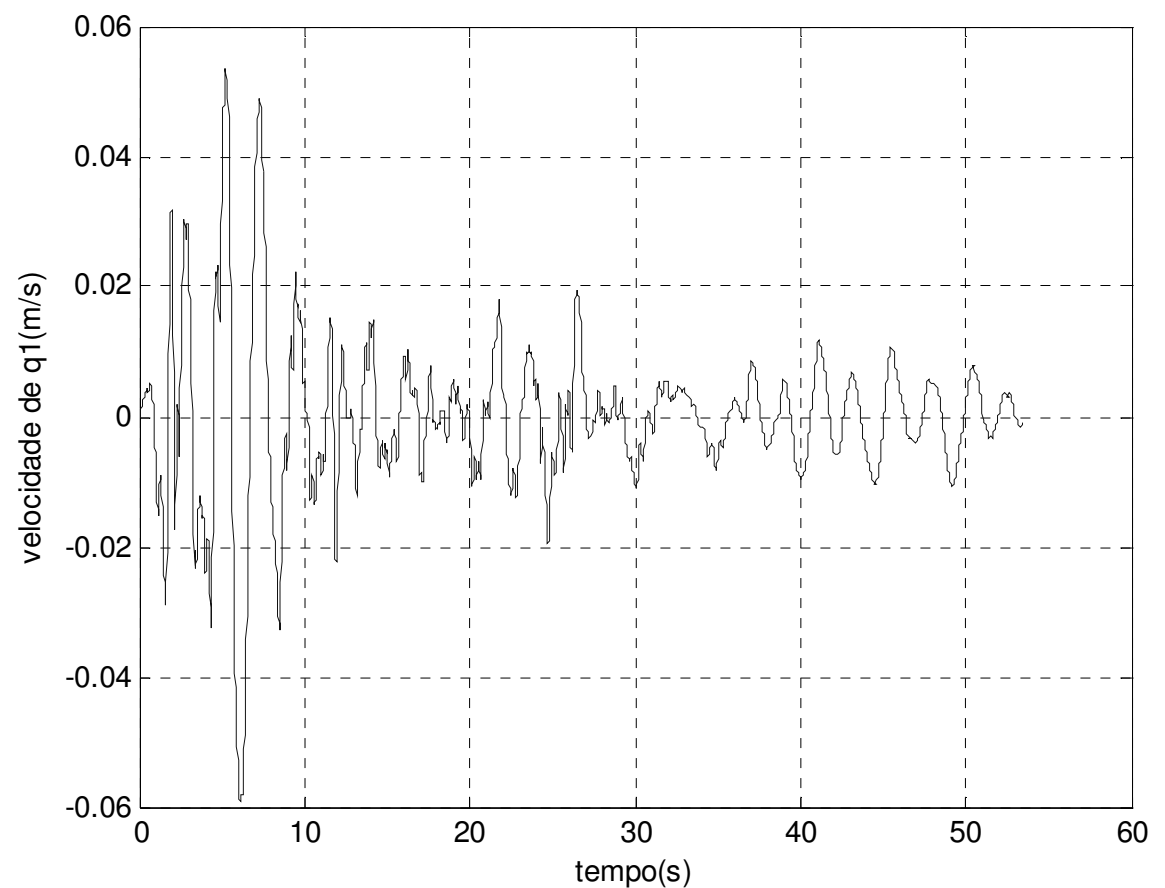

Gráfico 29 - velocidade de $q_{1}$ em função do tempo - sistema com 1 grau de liberdade - entrada sísmica

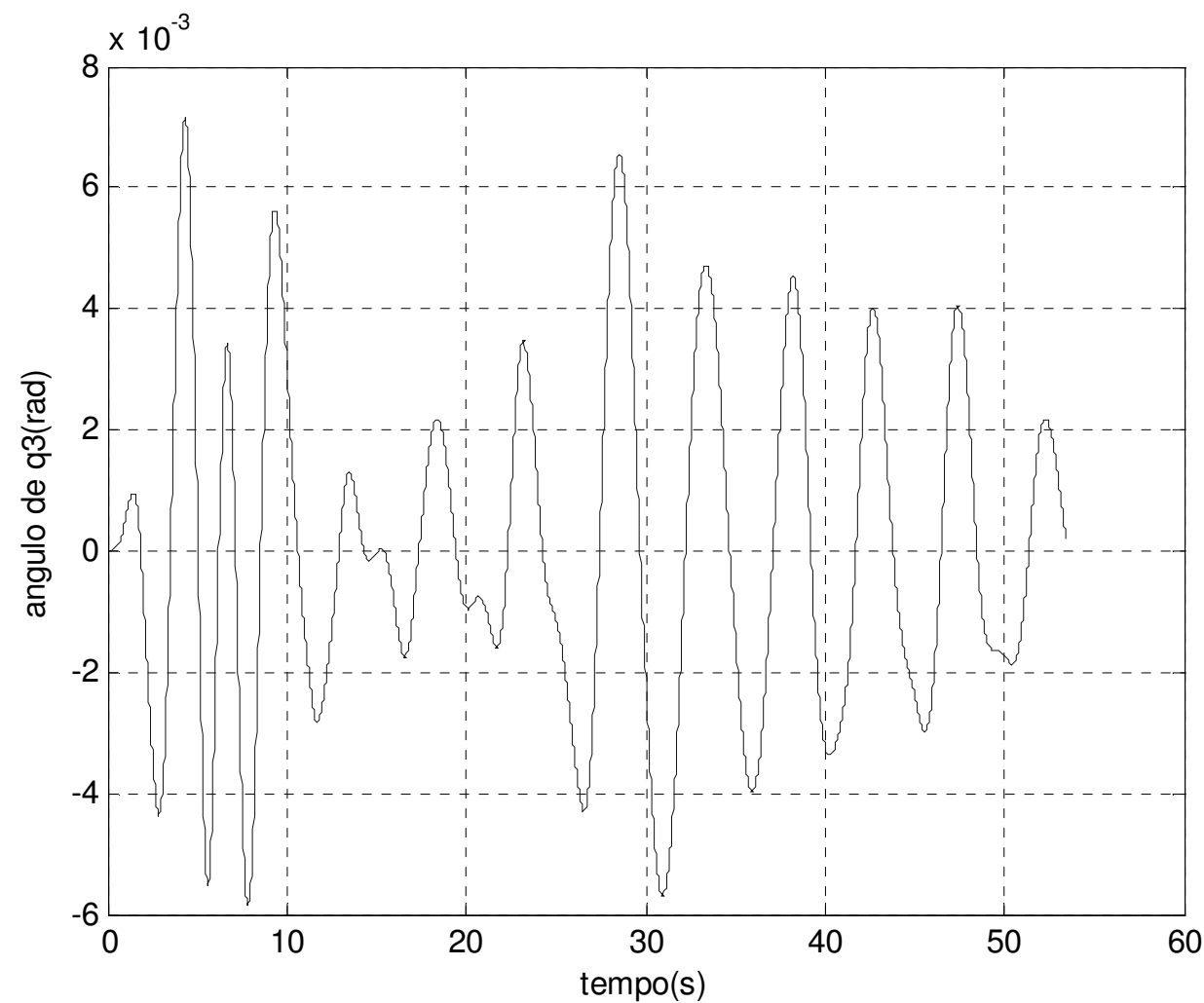

Gráfico 30 - ângulo de $q_{3}$ em função do tempo - sistema com 2 graus de liberdade - entrada sísmica 
Nota-se um aumento significativo na amplitude do pendulo quando consideramos no sistema a coordenada $q_{1}$. Os valores de amplitude quase chegaram a dobrar.

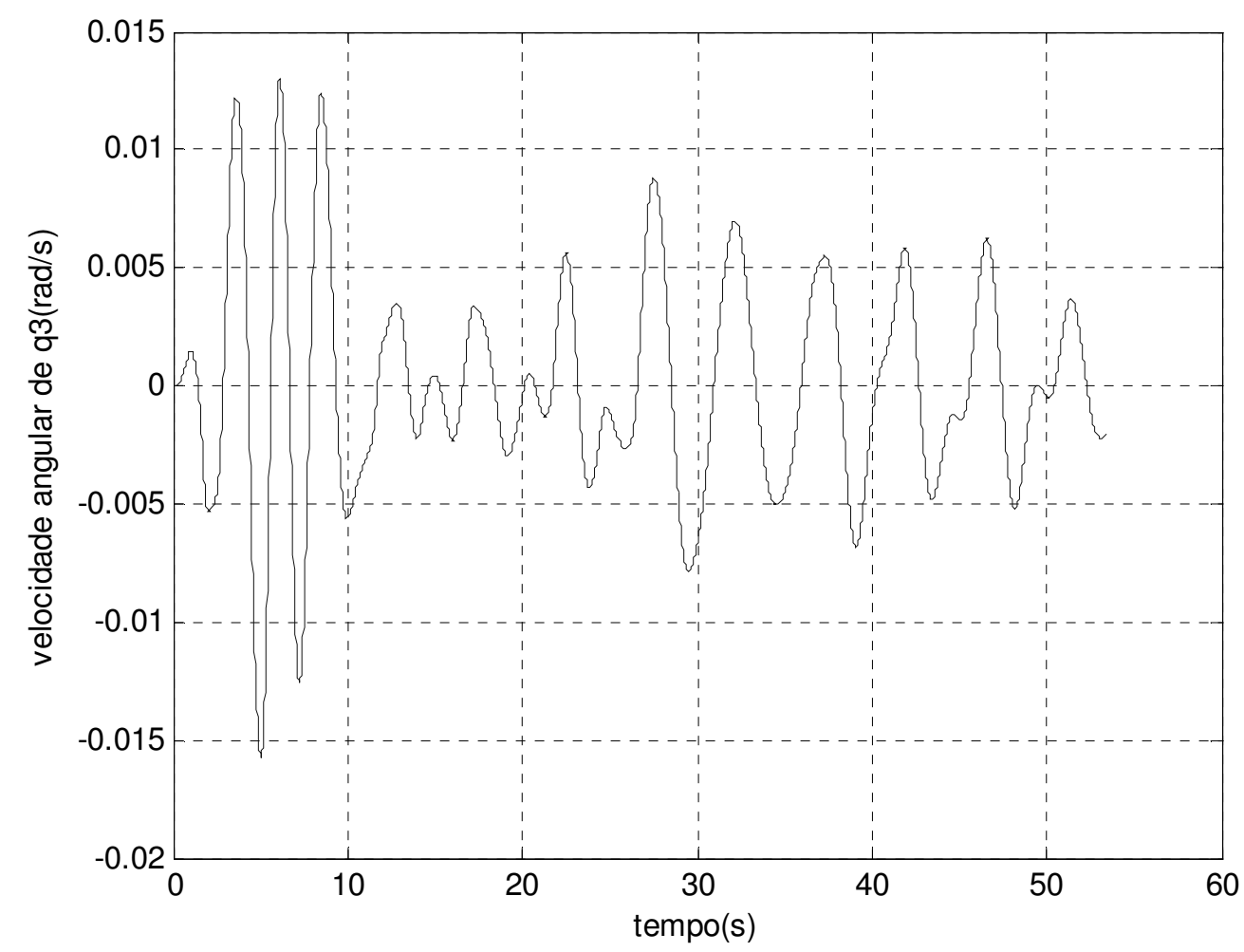

Gráfico 31 - velocidade angular de $q_{3}$ em função do tempo - sistema com 2 graus de liberdade entrada sísmica 


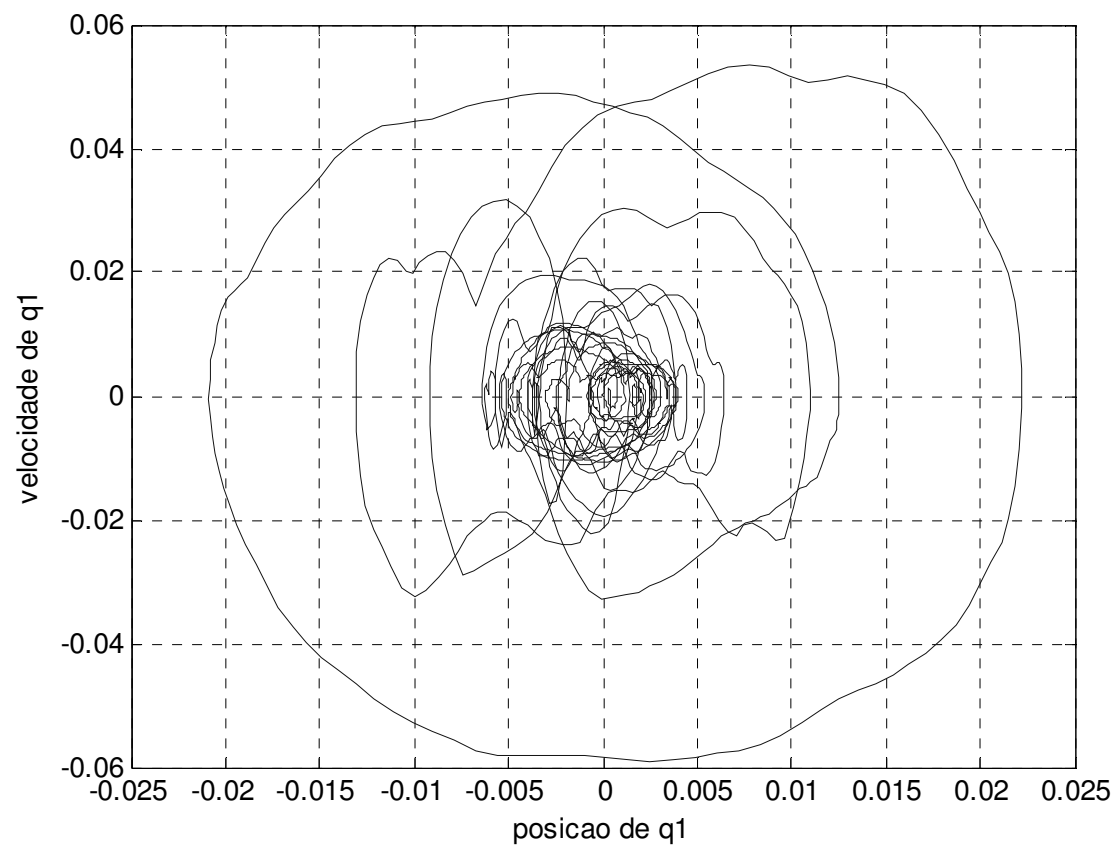

Gráfico 32 - plano de fase de $q_{1}$ - sistema com 2 graus de liberdade - entrada sísmica

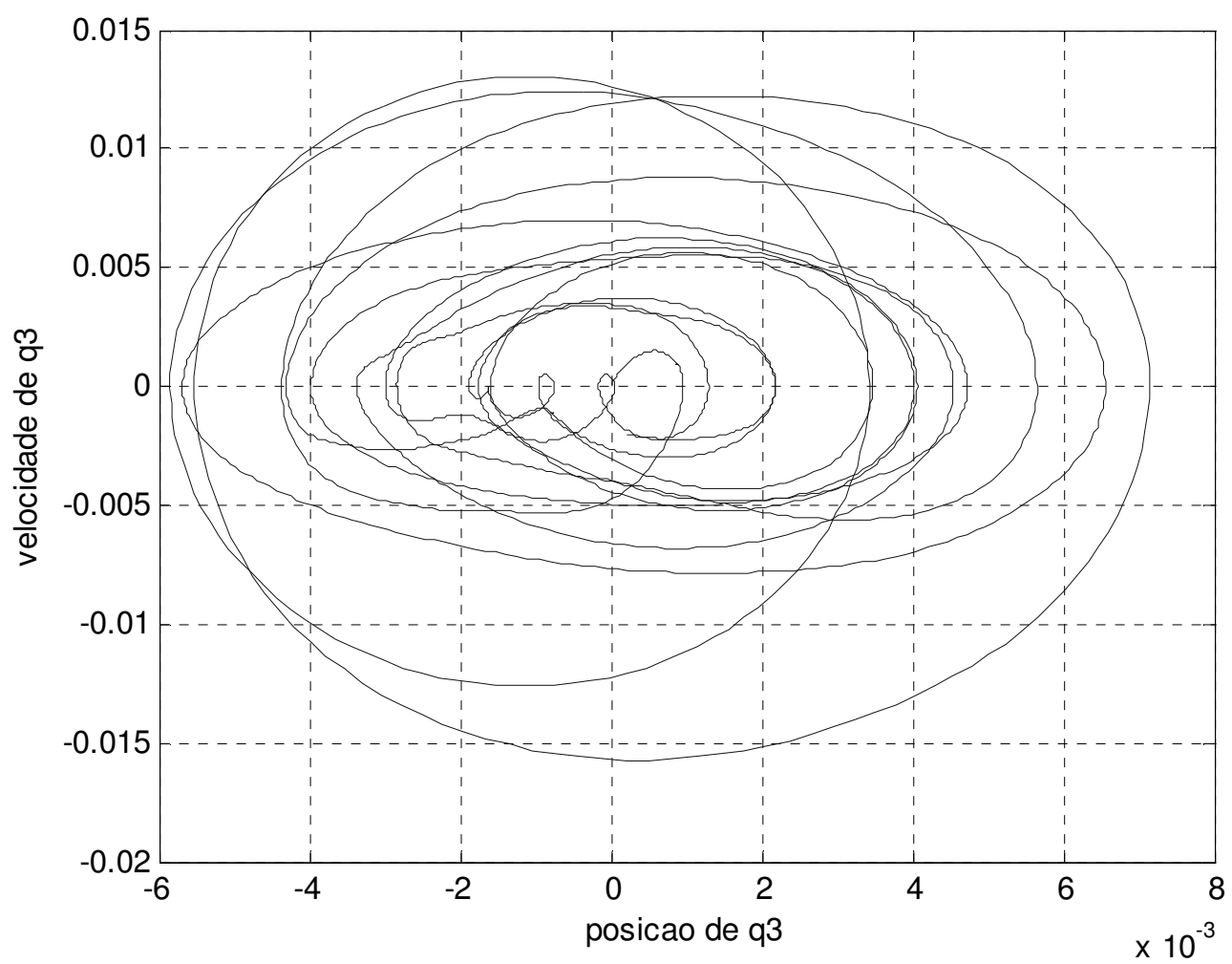

Gráfico 33 - plano de fase de $q_{3}$ - sistema com 2 graus de liberdade - entrada sísmica 


\subsection{Sistema com 3 graus de liberdade}

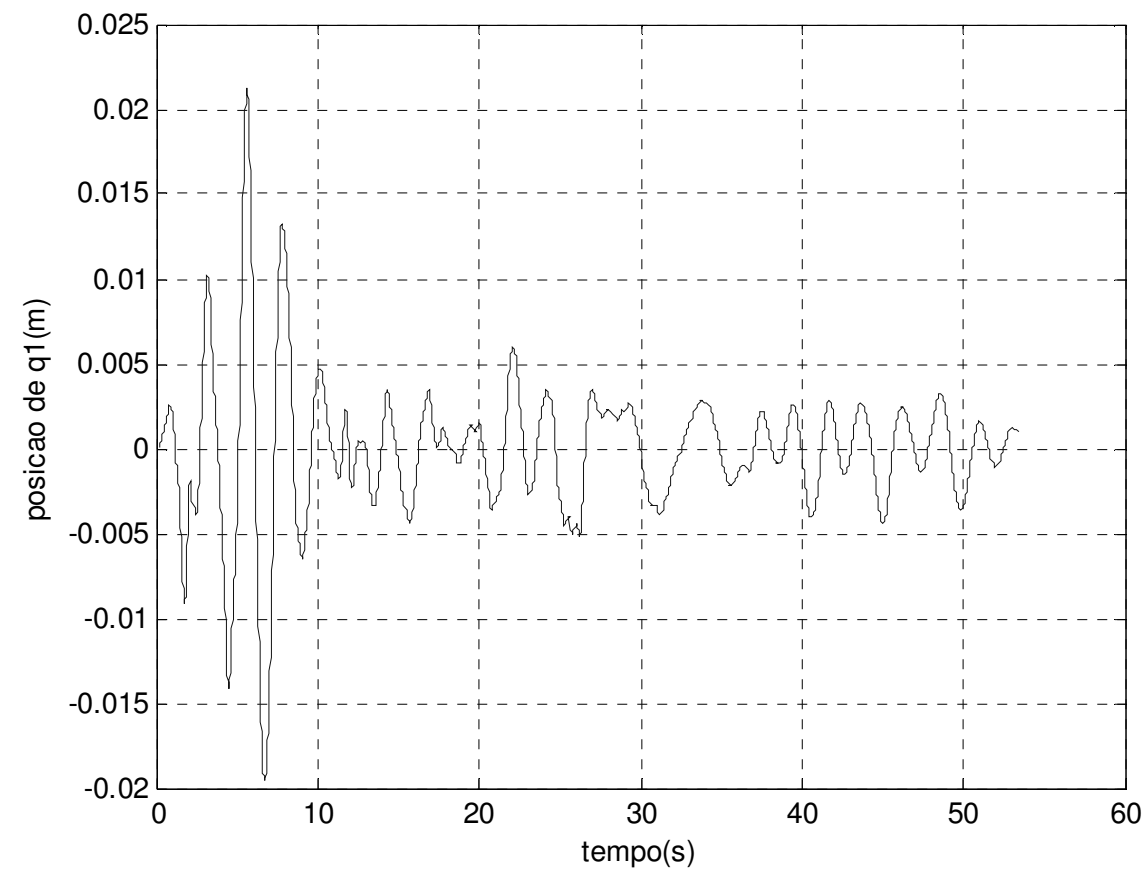

Gráfico 34 - posição de $q_{1}$ em função do tempo - sistema com 3 graus de liberdade - entrada sísmica

O deslocamento horizontal maximo encontrado foi de $0,021 \mathrm{~m}$.

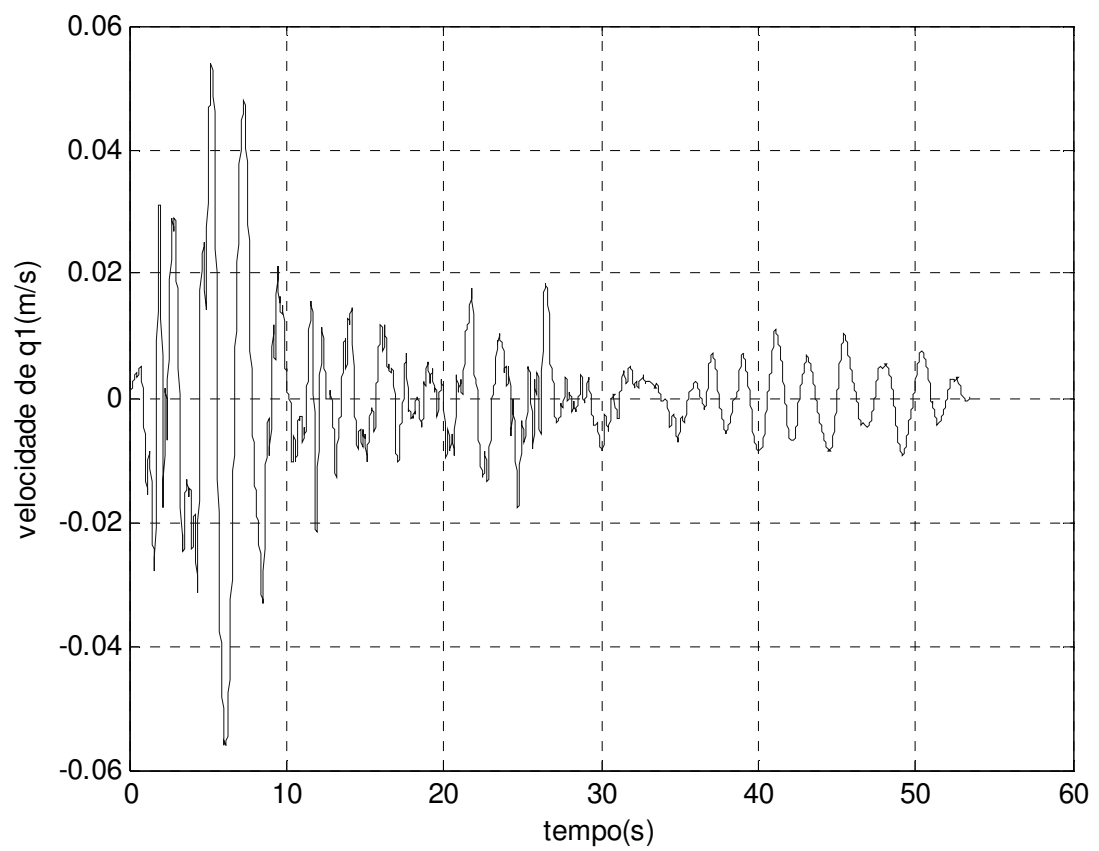

Gráfico 35 - velocidade de $q_{1}$ em função do tempo - sistema com 3 graus de liberdade - entrada sismica 


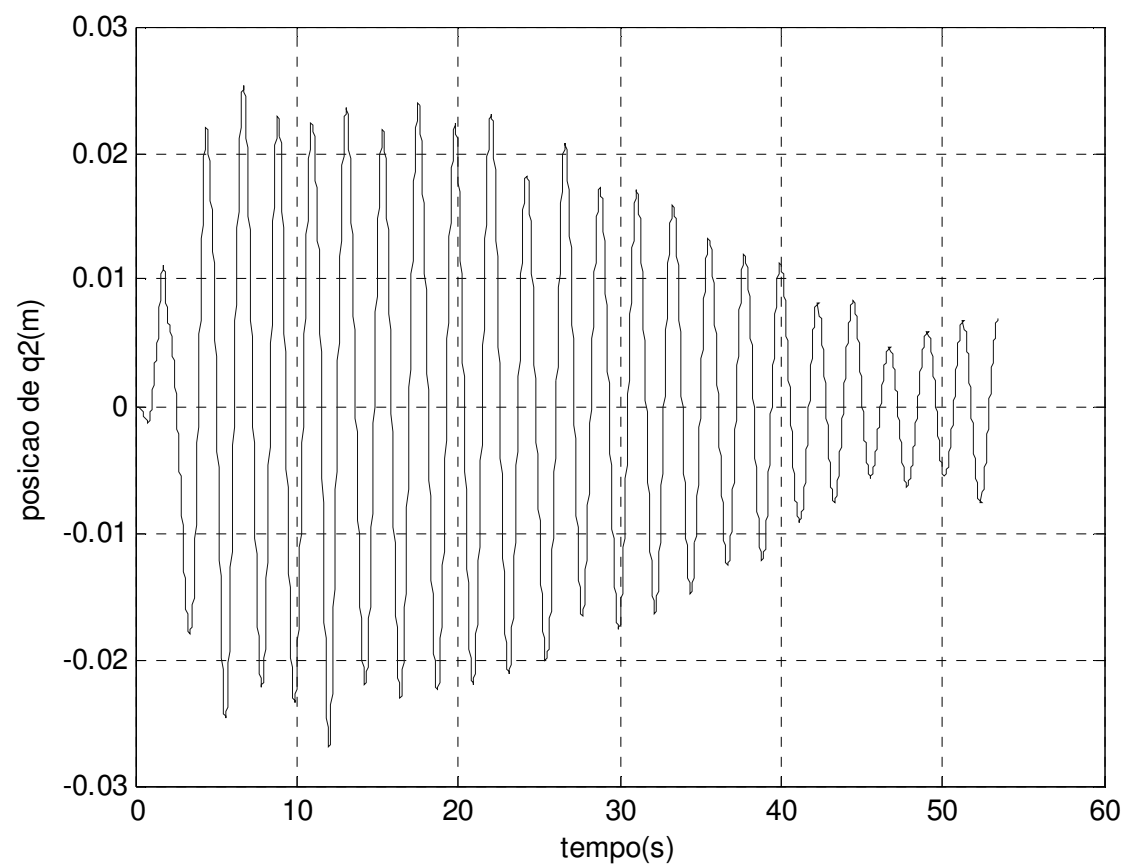

Gráfico 36 - posição de $q_{2}$ em função do tempo - sistema com 3 graus de liberdade - entrada sísmica

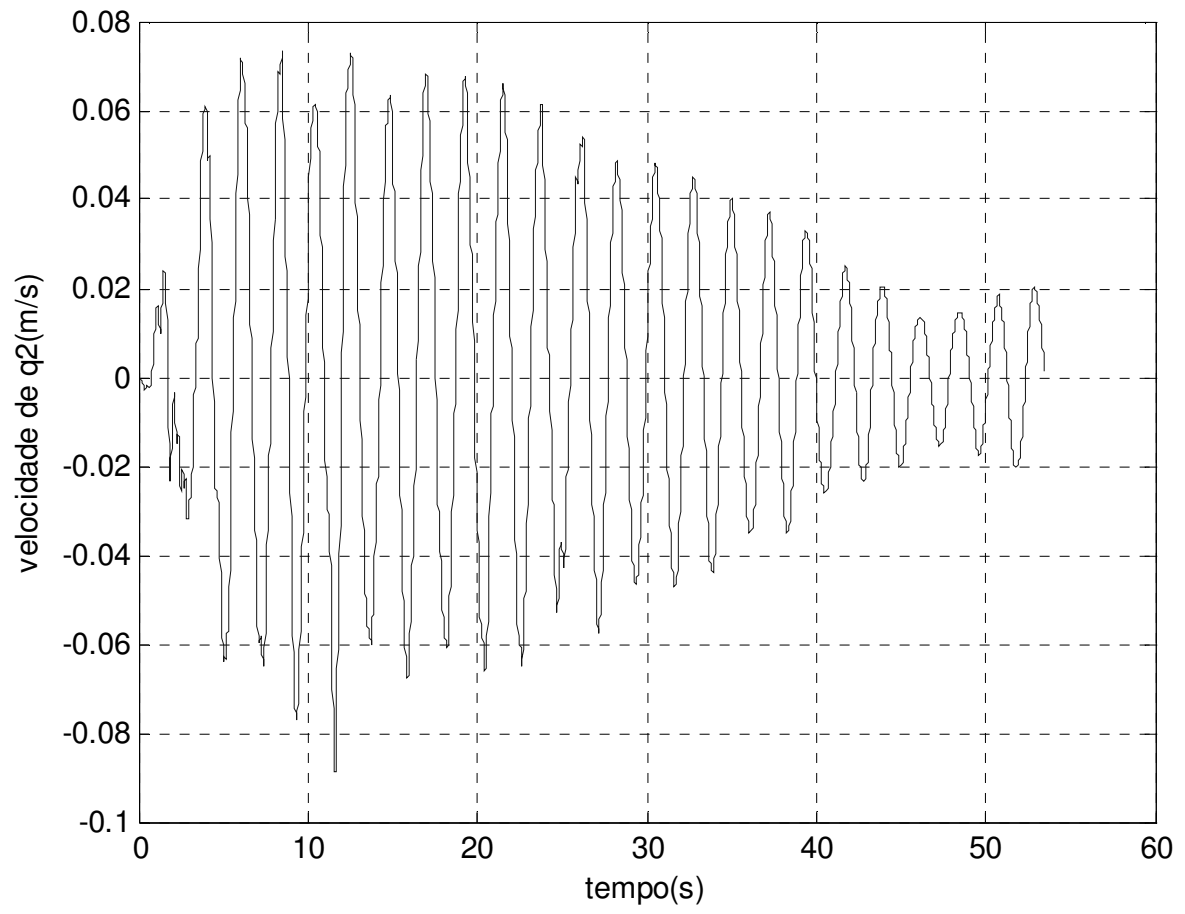

Gráfico 37 - velocidade de $q_{2}$ em função do tempo - sistema com 3 graus de liberdade - entrada sísmica 


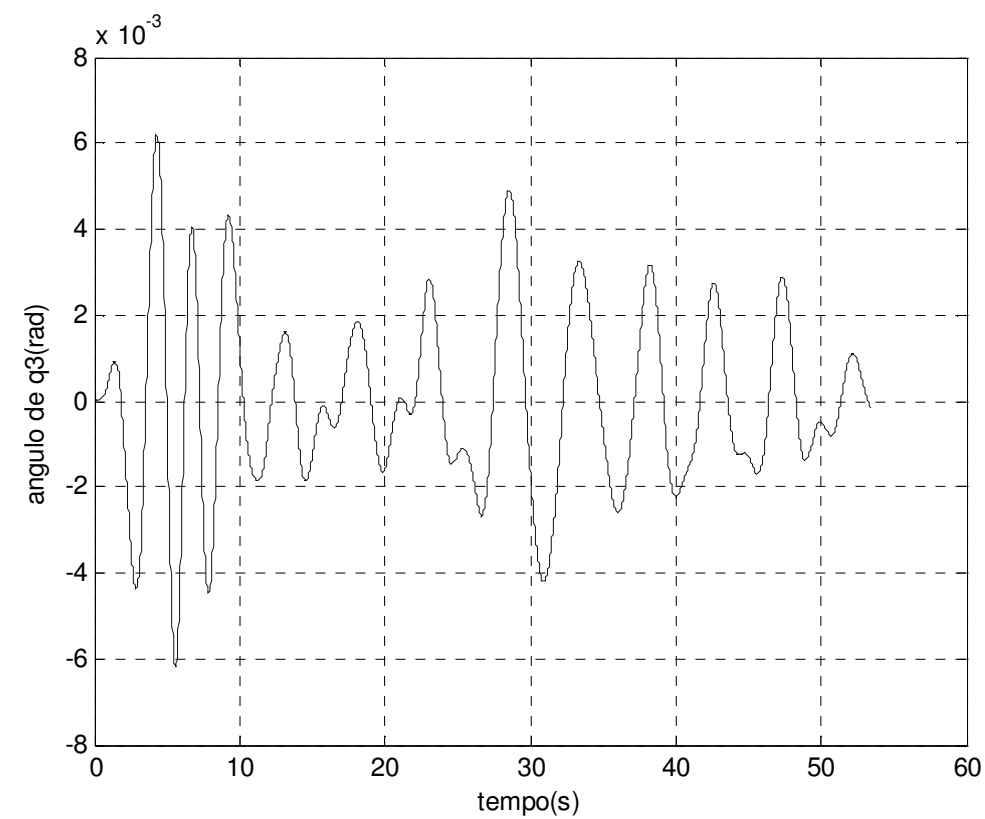

Gráfico 38 - ângulo de $q_{3}$ em função do tempo - sistema com 3 graus de liberdade - entrada sísmica

Em q3, deslocamentos pequenos com valor máximo de 0,008rad.

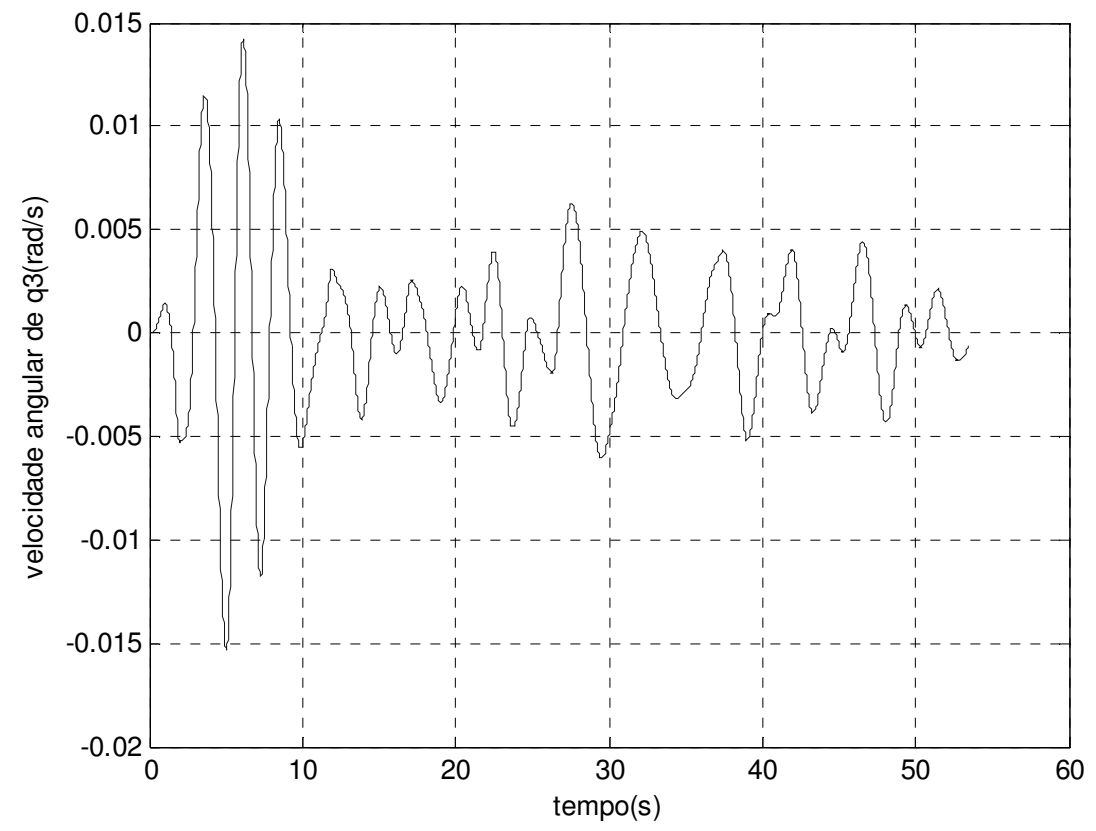

Gráfico 39 - velocidade angular de $q_{3}$ em função do tempo - sistema com 3 graus de liberdade entrada sísmica 


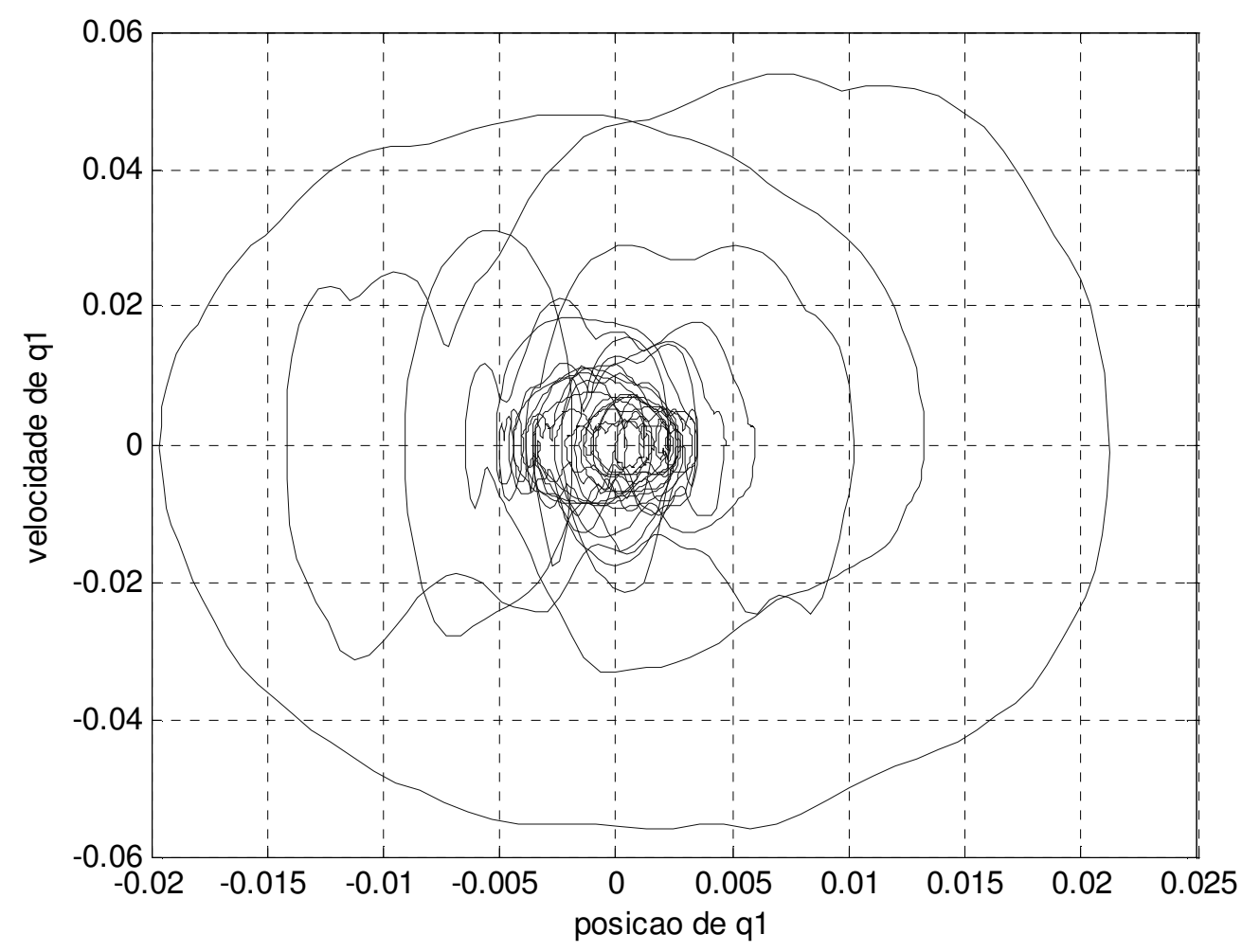

Gráfico 40 - plano de fase de $q_{1}$ - sistema com 3 graus de liberdade - entrada sísmica

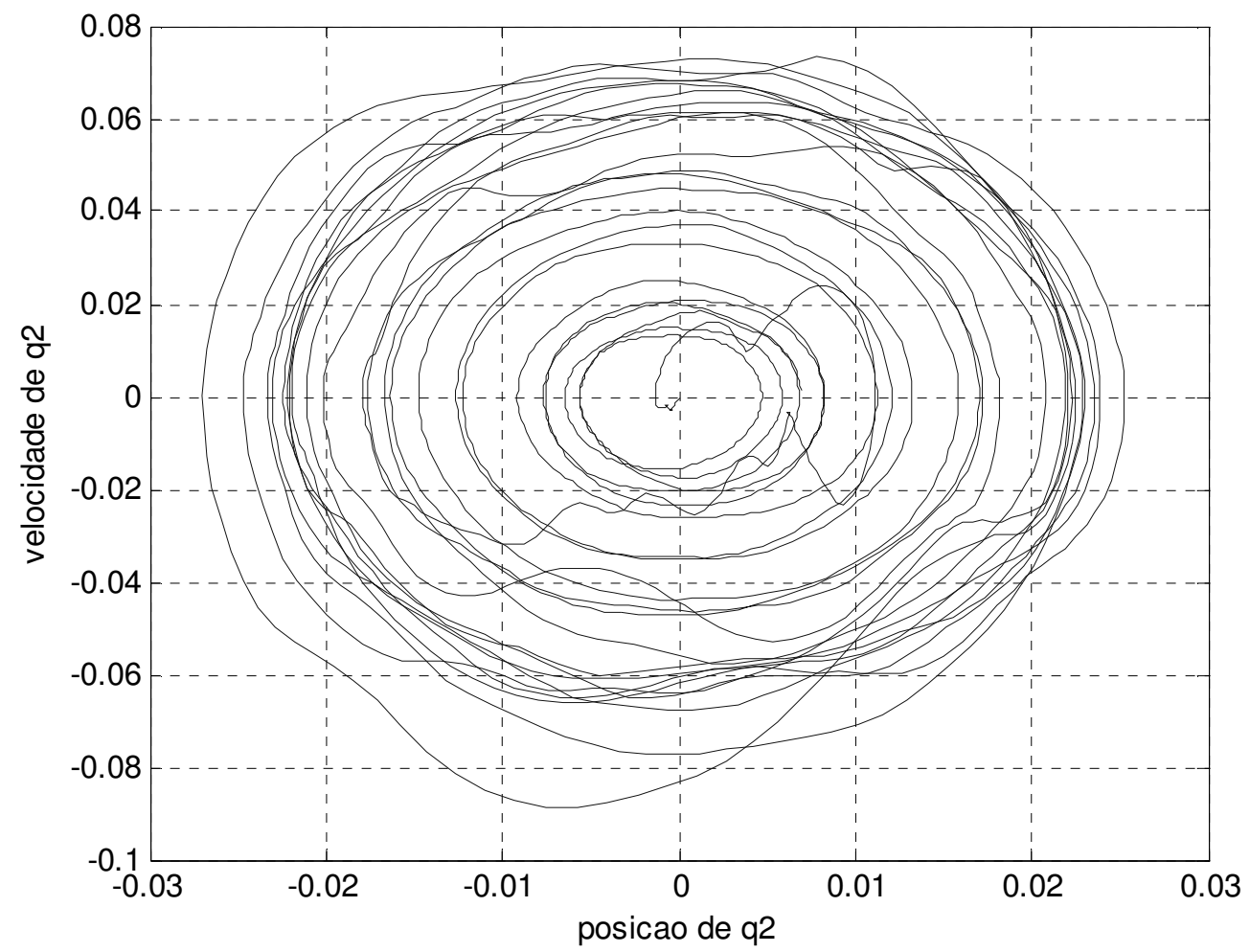

Gráfico 41 - plano de fase de $q_{2}$ - sistema com 3 graus de liberdade - entrada sísmica 


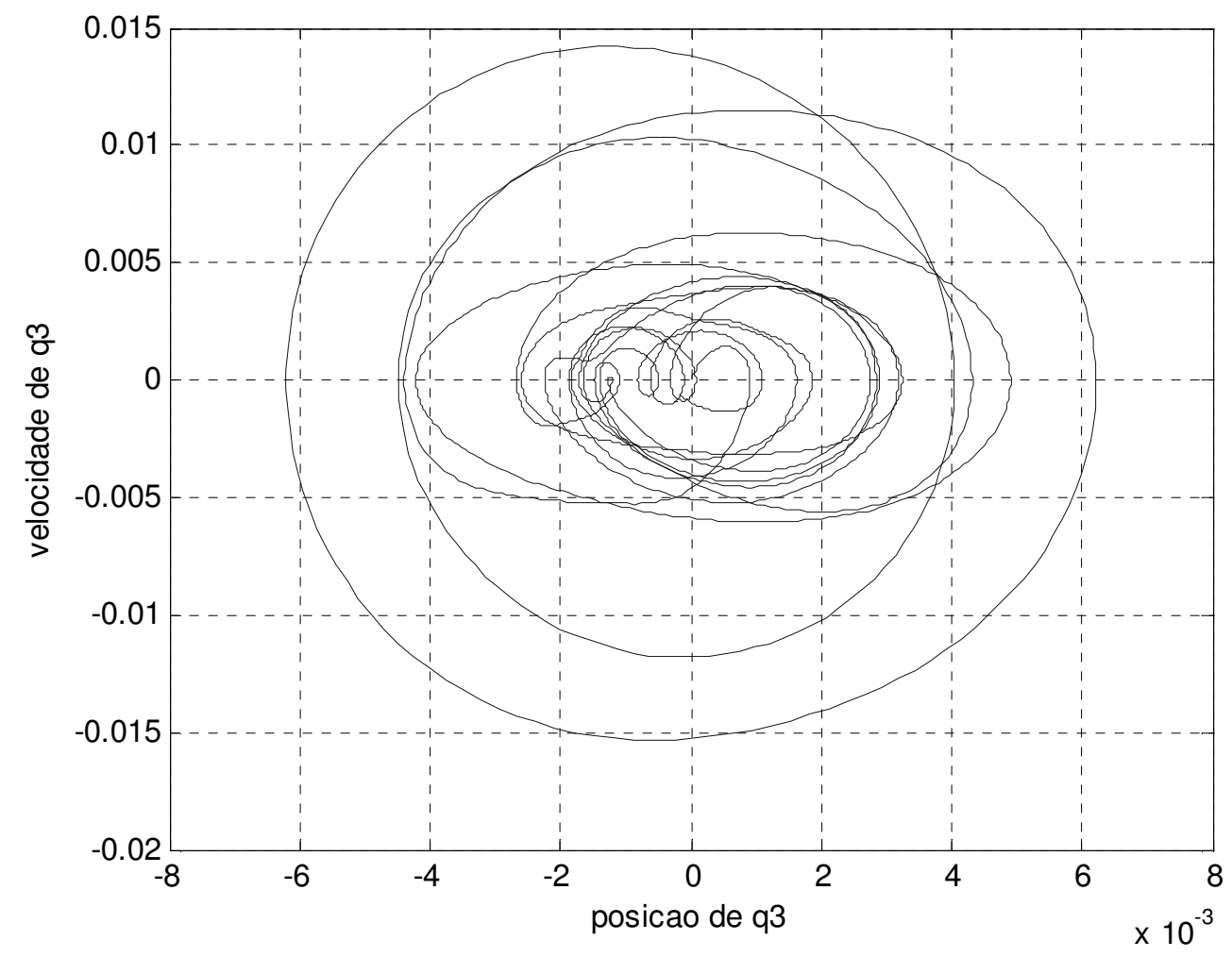

Gráfico 42 - plano de fase de $q_{3}$ - sistema com 3 graus de liberdade - entrada sísmica

\subsection{Comparativo entre os modelos}

Verifica-se que, quando submetidos a um sismo real, conforme adicionamos graus de liberdade ao modelo inicial, as respostas se modificam.

\subsubsection{Coordenada $q_{3}$}

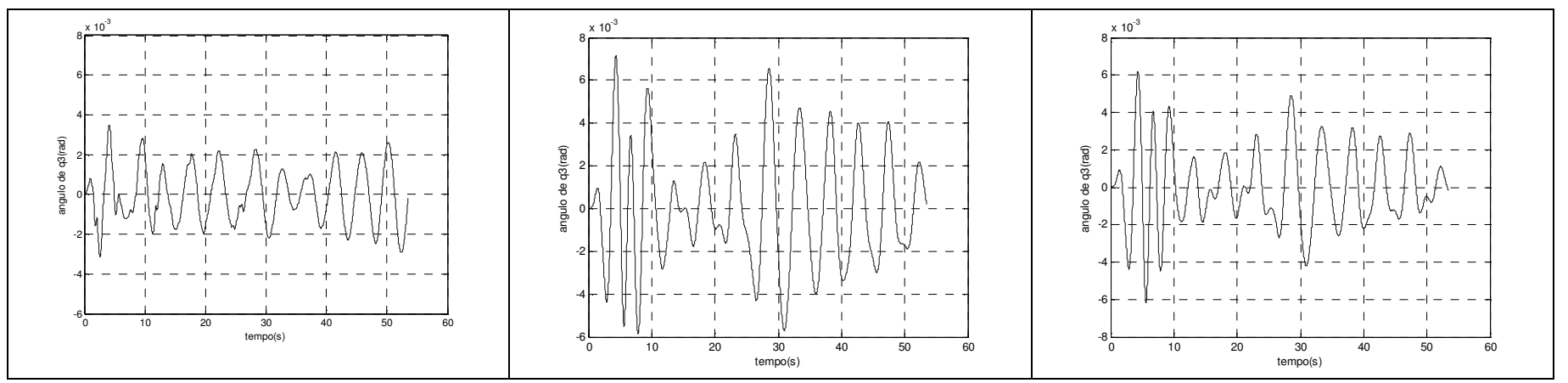

Gráfico 43 - comparativo de $q_{3}$ sistemas com 1, 2 e 3 graus de liberdade - entrada sísmica 
Os deslocamentos para os sistemas de ordem superior são maiores do que os de ordem inferior, notando que com 2 graus de liberdade encontra-se a maior amplitude dos três casos.

\subsubsection{Coordenada $q_{1}$}

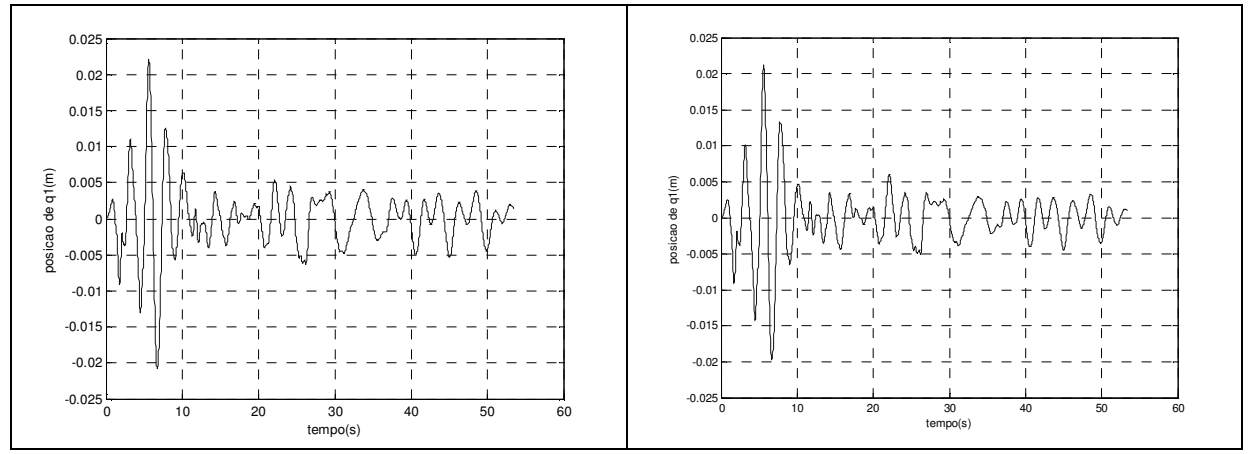

Gráfico 44 - comparativo de q1 - sistemas com 2 e 3 graus de liberdade - entrada sísmica

O sistema de ordem superior apresenta deslocamentos menores do que o de ordem inferior.

\subsection{3 plano de fase $q_{3}$}

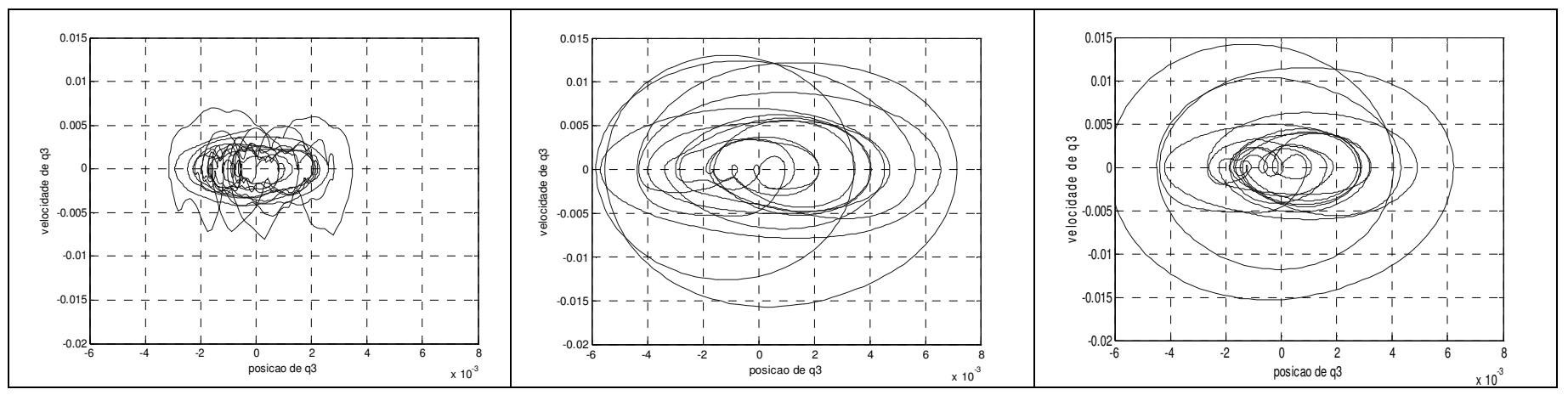

Gráfico 45 - comparativo do plano de fase de $q_{3}$ - sistemas com 1, 2 e 3 graus de liberdade entrada sismica 


\subsection{4 plano de fase $q_{1}$}

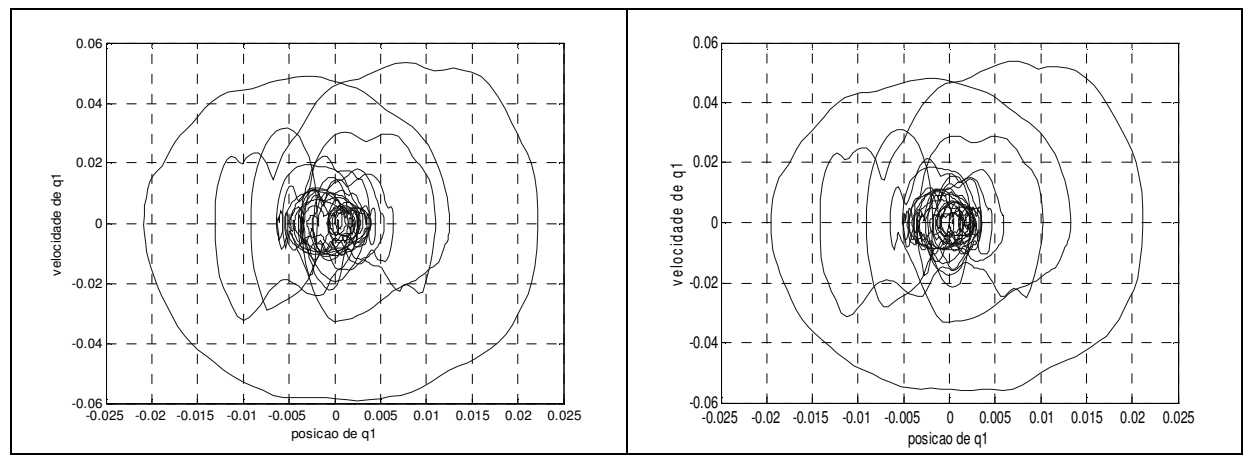

Gráfico 46- comparativo do plano de fase de $q_{1}$ - sistemas com 2 e 3 graus de liberdade entrada sismica

Percebe-se que a resposta dos modelos quando excitados por um sismo padrão são pequenos, e que as não linearidades não devem acrescentar particularidades na análise. Devido a esse motivo, será comparado no próximo capitulo os resultados encontrados do modelo com três graus de liberdade com o mesmo modelo linearizado, fazendo a função seno igual ao seu próprio argumento, em radianos, o que é válido para pequenos deslocamentos. 


\section{COMPARATIVO DOS SISTEMAS DE TRÊS GRAUS DE LIBERDADE NÃO LINEAR COM O LINEARIZADO}

Devido aos resultados encontrados, será apresentado um comparativo entre o modelo de 3 graus de liberdade não linear com 0 linearizado, fazendo $\operatorname{sen}\left(q_{3}\right)=q_{3}$.

\subsection{Coordenada $q_{1}$}

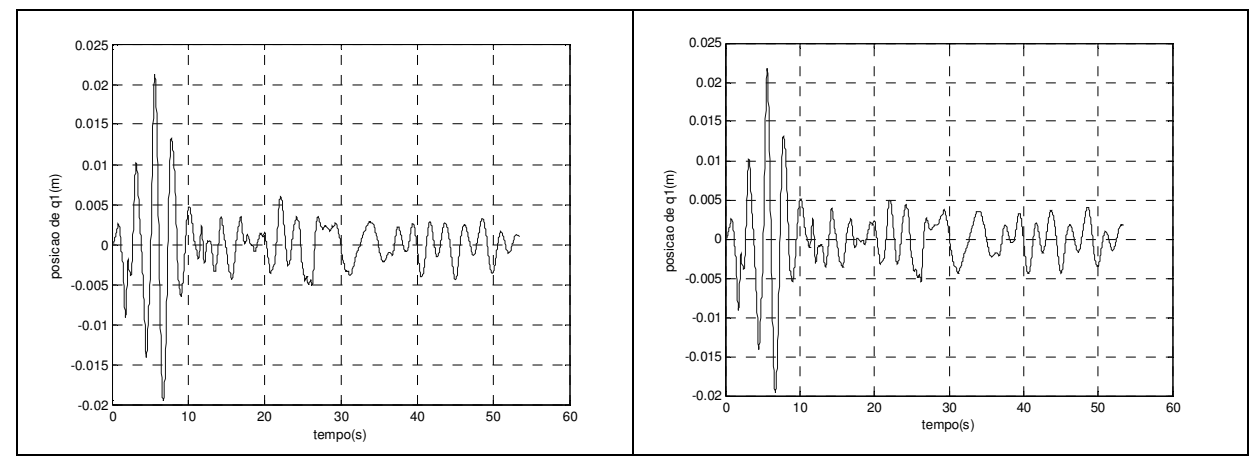

Gráfico 47 - comparativo de $q_{1}$ - modelo com 3 graus de liberdade - não linear e linear

\subsection{Coordenada $q_{2}$}

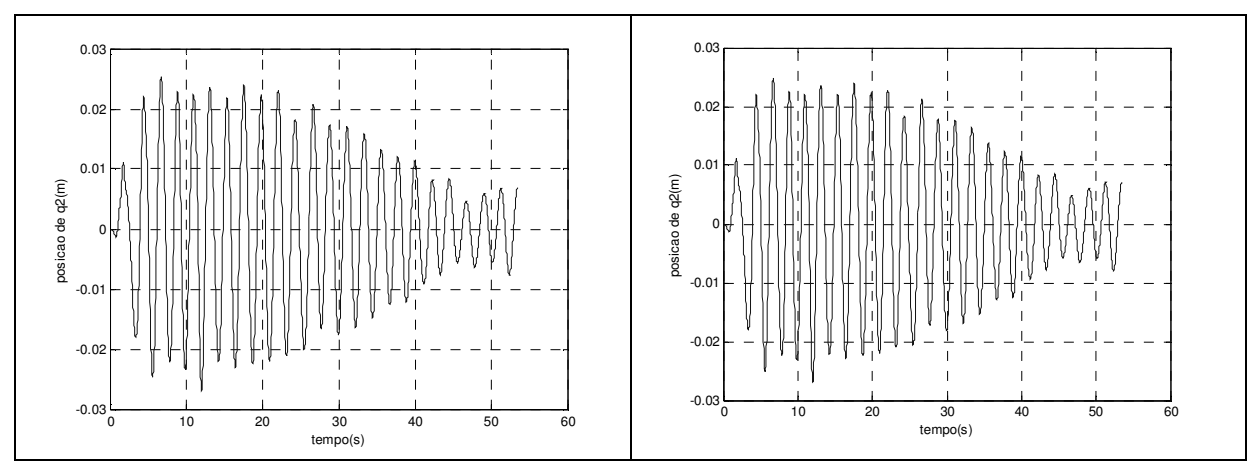

Gráfico 48- comparativo de $q_{2}$ - modelo com 3 graus de liberdade - não linear e linear 


\subsection{Coordenada $q_{3}$}

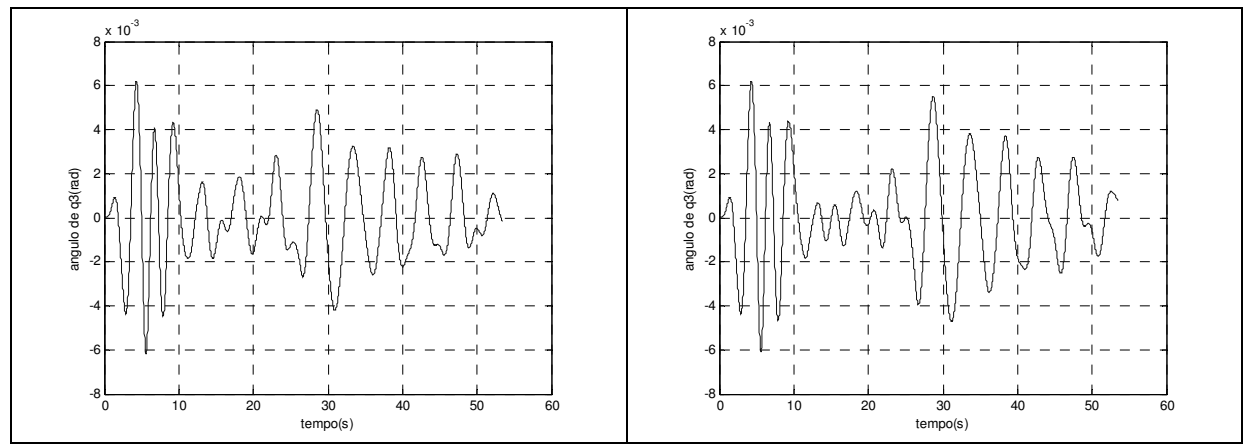

Gráfico 49- comparativo de $q_{3}$ - modelos com 3 graus de liberdade - não linear e linear

\section{4 plano de fase $q_{3}$}

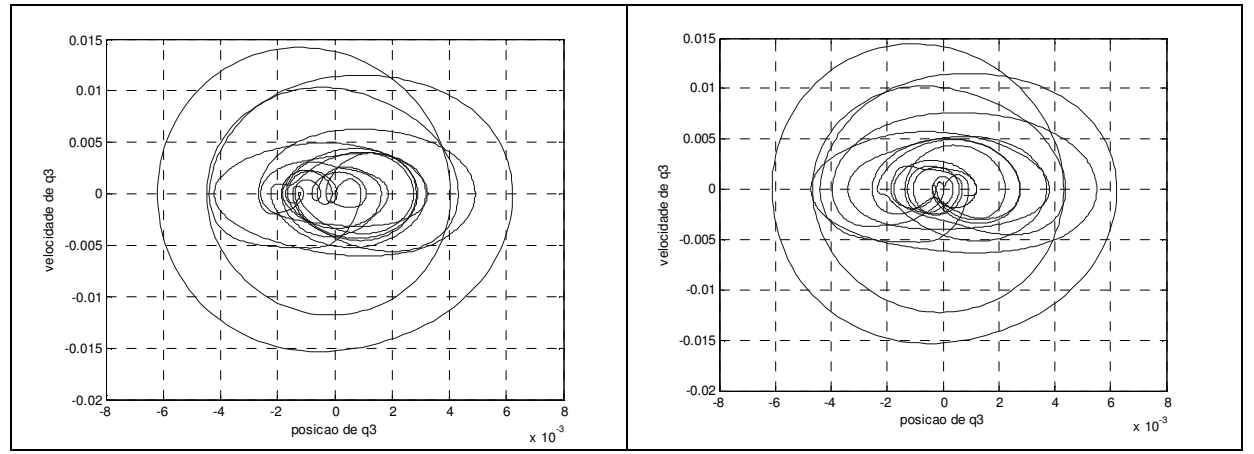

Gráfico 50- comparativo do plano de fase de $q_{3}$ - modelos com 3 graus de liberdade - não linear e linear 


\section{5 plano de fase $q_{1}$}

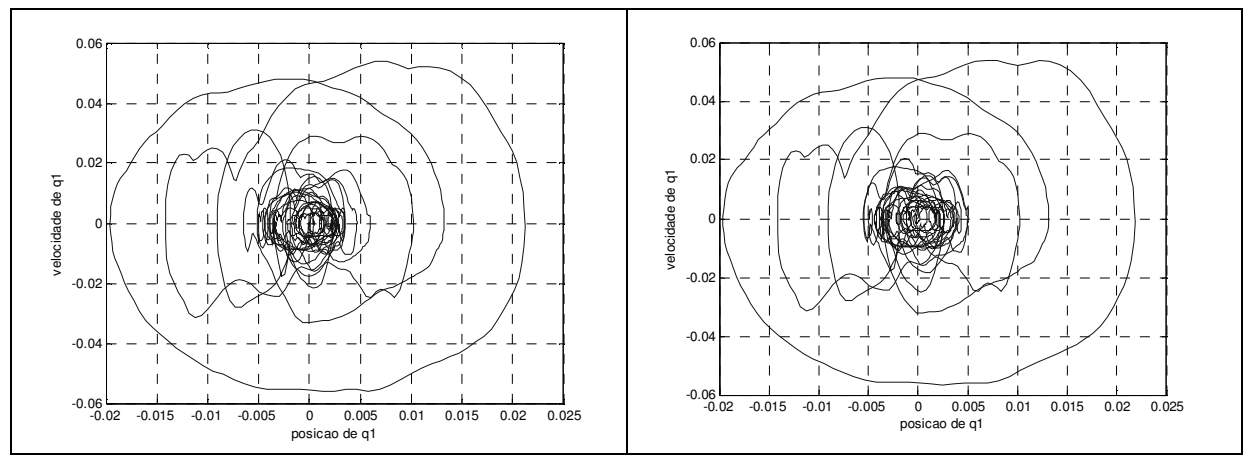

Gráfico 51- comparativo do plano de fase de $q_{1}$ - modelos com 3 graus de liberdade - não linear e linear

É possível notar nos gráficos de 47 a 51 que o comportamento do sistema, apesar de pequenas diferenças é equivalente para os dois casos. 


\section{VERIFICAÇÃO DO ESTADO LIMITE DE SERVIÇO DO PRECIPITADOR}

Como discutido anteriormente, o deslocamento do sistema de emissão, representado nos equacionamentos pelo pêndulo, possui limites de deslocamentos para que o equipamento possa ser mantido em serviço. $O$ deslocamento máximo permitido para que não haja interrupção do processo produtivo é de $50 \mathrm{~mm}$ na direção horizontal.

Foi encontrado um ângulo máximo de $0.008 \mathrm{rad}$ para $q_{3}$, como no modelo analisado o sistema de emissão possui 10 metros de altura temos um deslocamento de $80 \mathrm{~mm}$. Ou seja, para o sismo analisado o modelo estudado não cumpre com o limite de serviço, sendo necessários estudos posteriores para que essa verificação seja cumprida. Também podem ser estudadas soluções simples como a adoção de batentes limitadores. 


\section{CONCLUSÃo}

Foi feito um estudo sobre o comportamento sísmico das partes internas de um equipamento de controle ambiental, com modelos de várias ordens, lineares e não lineares, derivados pelo método de Lagrange.

A partir da comparação do comportamento dos modelos verifica-se que os sistemas de ordem superior possuem maiores amplitudes de resposta, e que a adição da coordenada generalizada $\mathrm{q}_{2}$ ortogonal ao plano principal $x z$ tem pouco impacto na resposta do sistema.

Verifica-se, também, que o sistema respondeu bem a um sismo real já registrado, apresentando pequenos deslocamentos nas placas. Como o amortecimento do pendulo acabou se mostrando alto, isso o levou a apresentar movimentos rapidamente amortecidos. Por esses motivos, após comparativo com seu modelo linearizado, podemos dizer que esse sistema em particular pode ser representado por um modelo linear de 2 graus de liberdade sem perdas importantes na resposta. No entanto, como o limite de serviço não foi atendido, se fazem necessários estudos posteriores, modificando parâmetros de projeto para que essa condição seja cumprida.

Como dificilmente são encontrados acelerogramas de projeto, indicamos como um próximo passo a ser seguido nas pesquisas do autor, um estudo da obtenção de acelerogramas a partir de espectros de resposta, que são encontrados em normas de sismos. Pretende-se, também, fazer um estudo paramétrico no sistema não linear a fim de poder validar o modelo linear para outros grupos de equipamentos. Alem disso, medições em campo e determinações experimentais dos fatores de rigidez e amortecimento são desejáveis. 


\section{REFERÊNCIAS BIBLIOGRÁFICAS}

[1] ARZE, L. DARRIGRANDE, IVAN. et al., "Diseño sísmico de estructuras e instalaciones industriales”, ASIMET, 2003.

[2] BELTRAMI, EDWARD., "Mathematics for dynamic modeling", Academic Press, 1987.

[3] BRASIL, R. M. L. R. F., ORBOLATO, L., and EGUTI, R.T., "On the seismic loading of large environmental control equipment". In: Cobem 19th International Congress of Mechanical Engineering, Brasília: UnB, 2007.

[4] CHOPRA, A.K., "Dynamics of Structures", Earthquake engineering research institute, Berkley, 1980.

[5] CLOUGH, R.W. and PENZIEN J., "Dynamics of Structures", McGraw Hill, New York, 1993.

[6] COOPER, C. DAVID., “Air pollution Control”, Waveland Press, 2002.

[7] DATTA, T. K., "Seismic Analysis of Structures", Wiley, 2010.

[8] FERREIRA, M. C., "Análise de um sistema dinâmico não ideal com excitação vertical e horizontal". Dissertação de mestrado. Instituto de Biociências, Letras e Ciência Exatas - UNESP, São José do Rio Preto, 2007.

[9] HYNDMAN, DAVID., "Natural Hazards and Disasters", Cengace Learning, 2009.

[10] OGATA, K., “Discrete time control systems”, Prentice Hall, 1987.

[11] MAZILLI, C.E.N and NETO, O.G.P.B., "Evaluation of non-linear normal modes for finite -element models", Computers \& Structures, Pergamon, 2002.

[12] MONTEIRO, L.H.A., "Sistemas Dinâmicos", Livraria da Física, 2002.

[13] MORCELLI, R.S., "Análise Sismica de estruturas $p$ ara máquinas de papel”, Dissertação de mestrado. Escola Politécnica. Departamento de Engenharia Civil, 2010.

[14] NAYFEH, A.H. and MOOK, D.T., "Nonlinear Oscillations", John Wiley, New York, 1979. 
[15] ORBOLATO, L. and Okabayashi, M "Control of non linear vibrations excited by non ideal energy sources ", CONEM, 2008.

[16] PERKO, L. "Differential Equations and Dynamical Systems", Springer, 2000.

[17] PORLE, KJELL. FRANCIS, STEVE L. BRADBURN, KEITH M., "Electrostatic Precipitators for industrial applications". Forssan Kirjaipino, Finland, 2007.

[18] SAVI, M. AMORIM., "Dinâmica Não-Linear e Caos", E-Papers Serviços Editoriais, 2006.

[19] STROGATZ, STEVEN., "Non linear dynamics and chaos", Westview, 2000.

[20] THOMAS, M. PETERS. JOHN VOLCKENS and SUSANNE V.HERING., "Impactors, Cyclones, and Other Particle Collectors", Cincinnati, 2009. 